$$
D \circ E / I D / 13233-T 5-P t, 3
$$

\title{
AN EVALUATION OF DIRECT PRESSURE SENSORS \\ FOR MONITORING \\ THE ALUMINUM DIE CASTING PROCESS
}

\author{
A Thesis \\ Presented in Partial Fulfillment of the Requirements for \\ the Degree Master of Science in the \\ Graduate School of The Ohio State University
}

By

Xueheng Zhang, M.S.E.

$* * * * *$

The Ohio State University

1997

Master's Examination Committee:

Approved by

Professor Carroll E. Mobley, Adviser

Professor Jerald R. Brevick

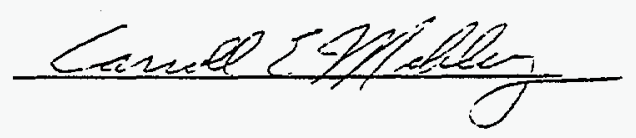

Adviser

Department of Materials Science \& Engineering df 


\section{DISCLAIMER}

Portions of this document may be illegible in electronic image products. Images are produced from the best available original document. 


\begin{abstract}
This study was conducted as part of the U.S. Department of Energy (DoE) sponsored project "Die Cavity Instrumentation". One objective of that project was to evaluate thermal, pressure, and gas flow process monitoring sensors in or near the die cavity as a means of securing improved process monitoring and control and better resultant part quality. The objectives of this thesis are to (1) evaluate a direct cavity pressure sensor in a controlled production campaign at the GM Casting Advanced Development Center (CADC) at Bedford, Indiana; and (2) develop correiativins between sensor responses and product quality in terms of the casting weight, volume, and density.
\end{abstract}

A direct quartz-based pressure sensor developed and marketed by Kistler Instrument Corp. was acquired for evaluation as an in-cavity liquid metal pressure sensor. This pressure sensor is designed for use up to $700^{\circ} \mathrm{C}$ and 2000 bars $(29,000 \mathrm{psi})$. It has a pressure overload capacity up to 2500 bars $(36,250 \mathrm{psi})$. 
Based on the data acquired from a OSU die casting campaign and GM production die casting campaign, the Kistler direct pressure sensor was judged reliable and durable. Pressure records from the Kistler direct pressure sensor provide insight into the die casting process and serve as necessary complementary data to the hydraulic pressure record. The Kistler sensor pressure records allow definition of the impact pressure on cavity fill, the start of intensification, the cavity pressure rise time, the gate freezing time, and the onset of flashing. The Kistler pressure sensor operated without any sign of degradation over the one hundred and fifty-six shot campaign at GM. It is found that the casting volume, density, and weight correlate best a mean pressure between the average hydraulic pressure and the average pressure derived from the Kistler direct pressure sensor.

\section{DISCLAIMER}

This report was prepared as an account of work sponsored by an agency of the United States Government. Neither the United States Government nor any agency thereof, nor any of their empleyees, makes any warranty, express or implied, or assumes any legal liability or responsibility for the accuracy, completeness, or usefulness of any information, apparatus, product, or process disclosed, or represents that its use would not infringe privately owned rights. Reference herein to any specific commercial product, process, or service by trade name, trademark, manufacturer, or otherwise does not necessarily constitute or imply its endorsement, recommendation, or favoring by the United States Government or any agency thereof. The views and opinions of authors expressed herein do not necessarily state or reflect those of the United States Government or any agency thereof. 
Dedicated to my parents 


\section{ACKNOWLEDGMENTS}

I wish to thank my adviser, Professor Carroll Mobley, for intellectual and financial support, encouragement, and enthusiasm which made this thesis possible, and for his patience in correcting both my stylistic and scientific errors.

I am grateful to Professor Jerald Brevick for his constructive role in my studies and thesis writing. I wish to thank those who helped me in my two-year studies here, especially Xiaopo Ma, Jian Zhang, Qi Shi, Angela Wollenburg, Lloyd Barnhart and Gary Dodge. I wish to thank Douglas Todora and Derek Peelle for the Archimedes' density measurements and providing me with all the casting volume, density, and weight data. I also would thank the staff at theGM CADC for their kind support.

This research was sponsored by the U.S. Department of Energy (DoE) and was monitored by The North American Die Casting Association (NADCA). 
VITA

September 7, 1965

Born - Shanghai, China

1985

Graduation Diploma

Shanghai Jiao Tong University

$1985-1988$

Technician

Shanghai Research Institute of

Tool \& Die Technology

1991

M.S.E., Graduation Diploma

Shanghai Jiao Tong University

$1990-1993$

Computer Software Programmer

Shanghai DaiKei Data Processing Co., Ltd.

1995 - present.

Graduate Teaching and Research Assistant

The Ohio State University

\section{FIELDS OF STUDY}

Major Field: Materials Science and Engineering

Metal Forming

Mold and Die Design and Manufacturing 


\section{TABLE OF CONTENTS}

$\underline{\text { Page }}$

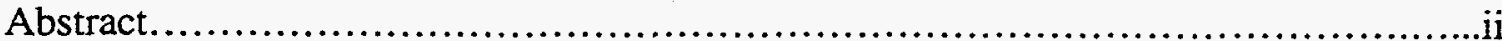

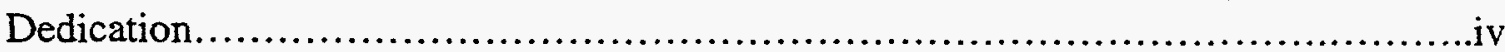

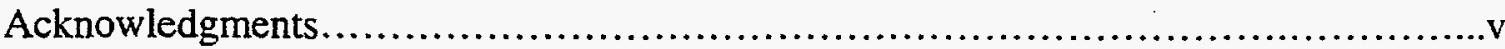

Vita............................................................................ vi

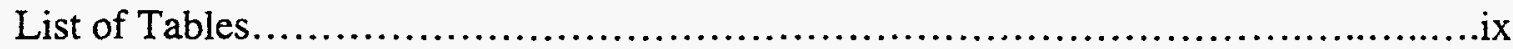

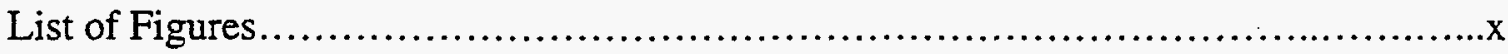

\section{Chapters:}

1. Introduction........................................................................

1.1 Process description..................................................

1.2 Technical background of the project and problem statement.................4

1.3 Research objectives........................................................

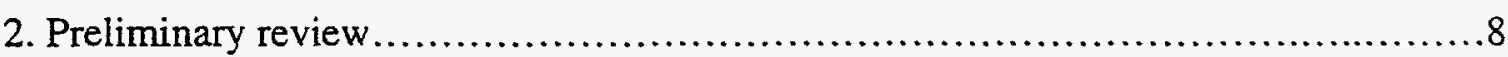

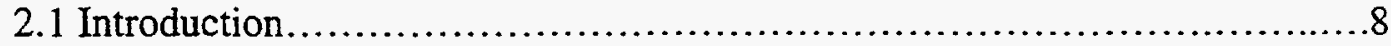

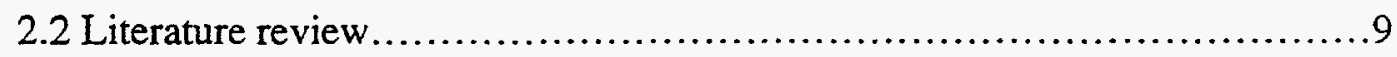

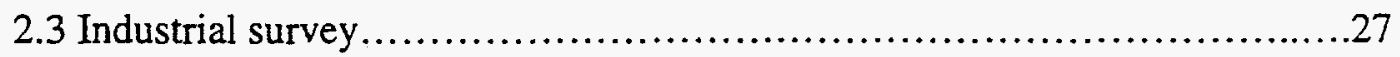

3. Evaluation of Kistler direct pressure sensors in die casting campaigns...............28

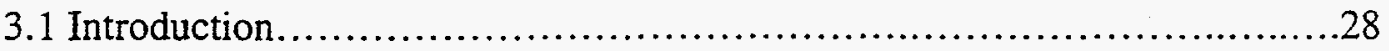

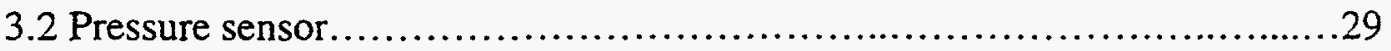

3.3 Experiment set-up for OSU die casting campaign.........................35 
3.4 Results from OSU ERC/NSM campaign and discussion. 39

4. Examining the correlations between the Kistler direct pressure sensor outputs and casting weight, volume and density

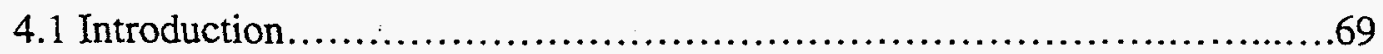

4.2 Archimedes' density measurement....................................70

4.3 The effects of applied pressure on the casting volume.....................75

4.4 The effects of applied pressure on the casting density.......................8

4.5 The effects of applied pressure on the casting weight........................83

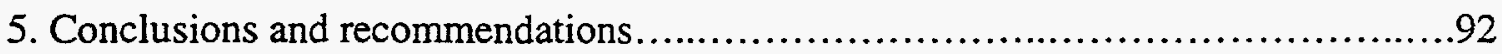

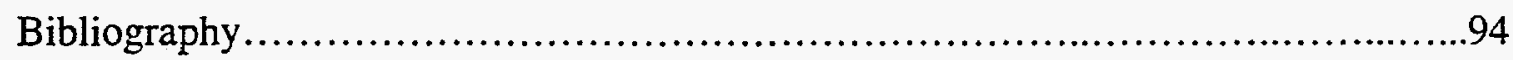

Appendices

A. NADCA survey of die casting cavity instrumentation.............................96

B. Technical Specifications of Buhler H-250SC...................................98

C. Machine set-up analysis for OSU die casting campaign..........................99

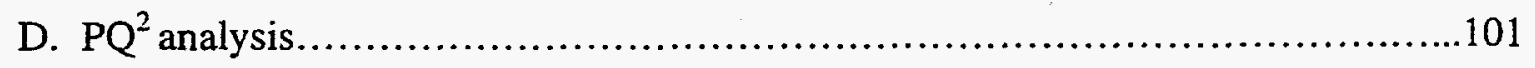

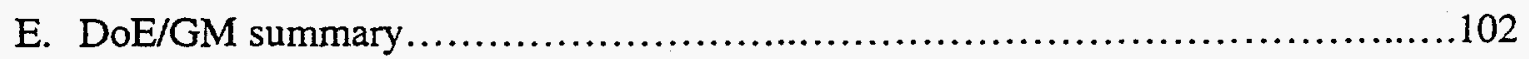




\section{LIST OF TABLES}

Table

1.1 Process Variables for Cold Chamber Die Casting.................................5

2.1 Die casting system characterization..............................................

2.2 Tensile strength test piece characterization.................................... 15

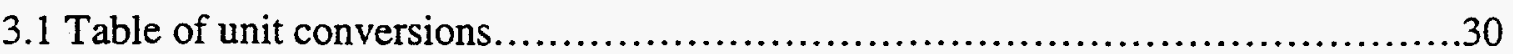

3.2 Average and standard deviation of some process variables of earlier stages before intensification starts.

3.3 The average and standard deviation values of pressure parameters, intensification stroke, pressure difference and pressure rise time of sets II, III, IV, and V.

4.1 Nominal composition range for Aluminum alloy 380 (weight percent) .70

4.2 Casting weight plus overflows, and trimmed casting weight, volume, and density of the selected shots

4.3 Various pressure parameters of the selected shots

4.4 Actual casting weight, calculated casting weight, and average relative error. .84

4.5 Weight, volume, and density of overflow and runner and biscuit of shots $20,50,60,90,91$, and 120 . 


\section{LIST OF FIGURES}

$\underline{\text { Figure }}$

1.1 Operating sequence of the cold chamber die casting process.......................

2.1 Thermocouple traces from various depths in a die casting die ......................9

2.2 Temperature distribution, measured temperature and calculated surface temperature and heat flux vs. time

2.3 Structure of Mochiku et al. temperature sensor.................................11

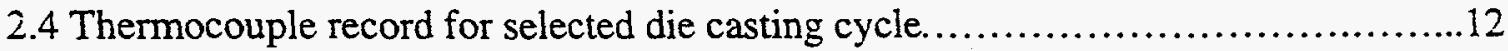

2.5 Sectioned Papai and Mobley thermocouple probe tip............................ 13

2.6 Relative porosity as a function of pressure applied during solidification..............14

2.7 Effects of metal pressure on tensile strength and specific gravity of test piece. 16

2.8 Structure of pressure sensor...................................................

2.9 Schematic drawing of sample castings specimen and transferred pressure gauges.

2.10 Transferred pressure curves by various measuring methods.

2.11 Change in solidification time for different sections of castings.

2.12 Transferred pressure curves for various gate thickness with and without insulating film. 
2.13 Relation between gate thickness solidification time of gate and duration of the maximum transferred pressure

2.14 Transferred pressure curves for diecasting 22

2.15 Relation between surface roughness, maximum transferred pressure and molten metal velocity.

2.16 Relation between internal defects, maximum transferred pressure and molten metal velocity

2.17 System for measuring gas pressure in die cavity. .25

$2.18 \mathrm{Gas}$ pressure curve of thin wall box castings cast in 1200-ton machine.

3.1 Kistler direct pressure sensor and specifications.

3.2 Kistler pressure sensor 1 calibration curve. .33

3.3 Kistler pressure sensor 2 calibration curve. .33

3.4 Calibration loading beyond configured operating limits .34

3.5 Dynamic calibration curve of Kistler pressure sensors .34

3.6 Wall die casting for OSU die casting campaign................................37

3.7 Locations of pressure sensors and thermocouple probes...........................38

3.8 Metal pressures from hydraulic pressure and Kistler pressure sensors...............42

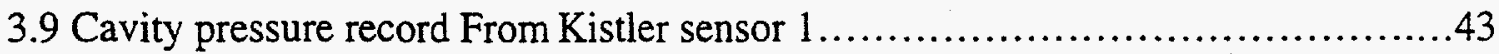

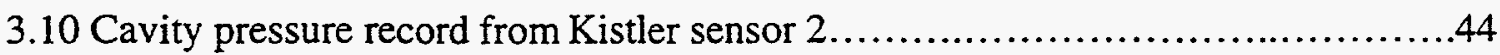

3.11 Plunger Pressure-Time Curve ...............................................

3.12 Temperatures at the time the die closed at different locations in the die for each shot

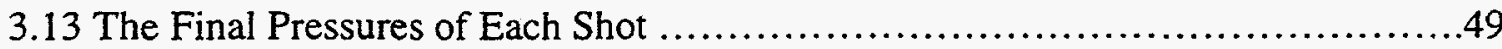

3.14 Basic Types of Pressure Difference Curves..................................52 


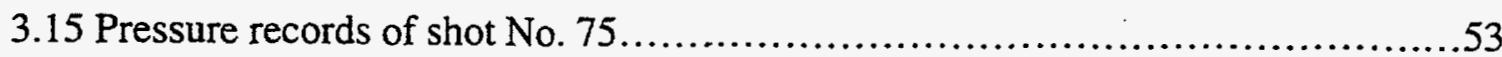

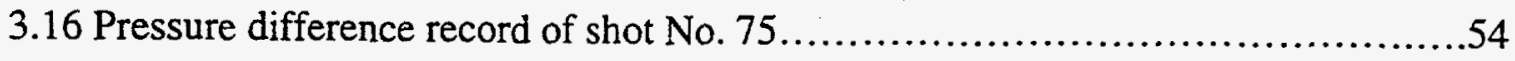

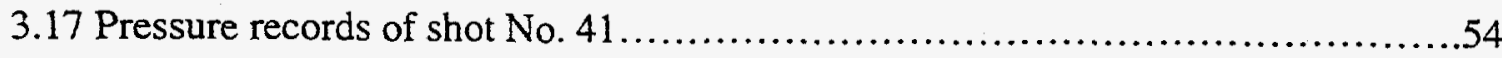

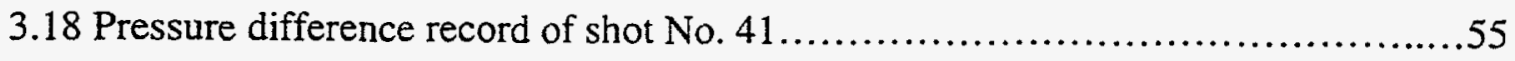

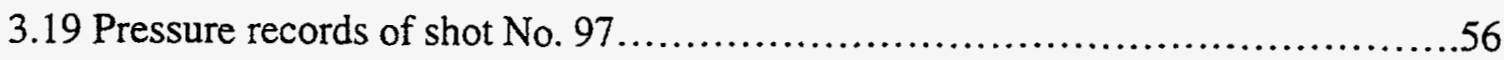

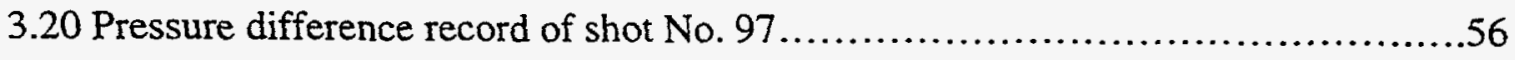

3.21 The maximum metal pressure pressures from the hydraulic pressure of selected shots.......................................59

3.22 The final pressures of selected shots............................................59

3.23 The intensification stroke length of selected shots............................60

3.24 The maximum Kistler pressure of selected shots..............................61

3.25 Pressure rise time of selected hydraulic pressure records.......................62

3.26 Pressure rise time of selected Kistler pressure records............................63

3.27 Pressure difference $100 \mathrm{~ms}$ after minimum pressure difference...................64

3.28 Pressure difference $1900 \mathrm{~ms}$ after minimum pressure difference....................65

3.29 Impact pressure of selected shots ............................................6

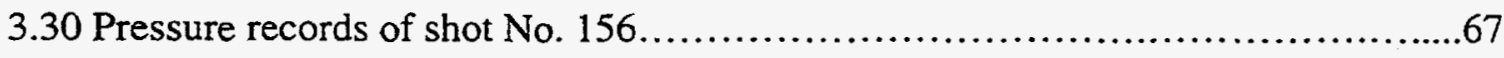

3.31 Pressure difference records for shot No. $156 \ldots \ldots \ldots \ldots \ldots \ldots \ldots \ldots \ldots \ldots \ldots \ldots \ldots$

4.1 Schematic of Archimedes' measurement system.................................73

4.2 The effect of final pressure on the casting volume................................76

4.3 The effect of the max metal pressure from

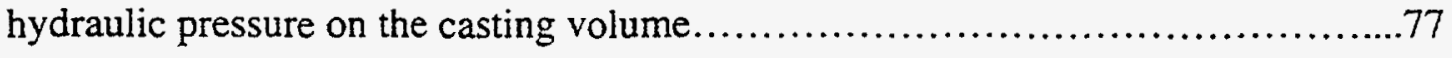

4.4 The effect of average Kistler pressure on the casting volume.......................77 
4.5 The effect of the maximum Kistler pressure on the casting volume

4.6 The effect of mean pressure on the casting volume............................... 78

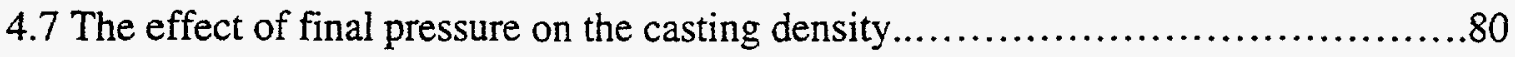

4.8 The effect of maximum metal pressure from hydraulic pressure on the casting density

4.9 The effect of average Kistler pressure on the casting density $\ldots \ldots \ldots \ldots \ldots \ldots \ldots \ldots \ldots . . .81$

4.10 The effect of maximum Kistler pressure on the casting density $\ldots \ldots \ldots \ldots \ldots \ldots \ldots \ldots . . . .82$

4.11 The effect of mean pressure on the casting density ............................ 82

4.12 The effect of final pressure on casting weight..................................85

4.13 The effect of maximum metal pressure from

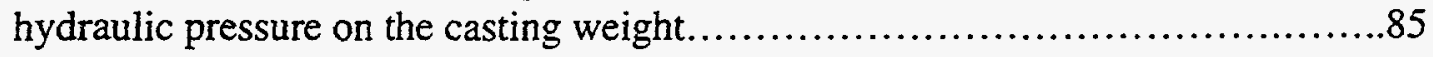

4.14 The effect of average Kistler pressure on the casting weight.....................86

4.15 The effect of maximum Kistler pressure on the casting weight....................86

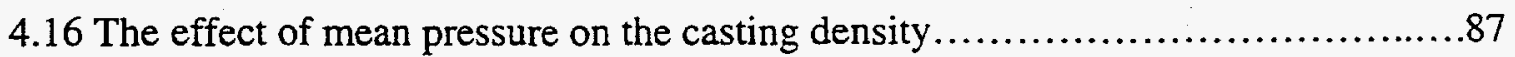

4.17 Density of runner and biscuit, casting, and overflows vs. reciprocal of final pressure.

4.18 Density of runner and biscuit, casting versus reciprocal of final pressure for runner and biscuit and reciprocal of mean pressure. 
CHAPTER 1

INTRODUCTION

\subsection{PROCESS DESCRIPTION}

Die casting is a cost effective near net shape manufacturing process for mass production of thin walled and complex shape products with excellent surface finish and close dimensional tolerance. In this process molten metal, primarily aluminum, zinc, and magnesium alloy, is injected at high velocities into reusable metallic molds and solidified under pressure. Die casting allows production of a wide variety of castings. The weights of castings can vary from a few grams to 20 kilograms. Complex products such as transmission cases and engine blocks can be made using this process.

The three primary variations of the die casting processes are the hot chamber

process, the cold chamber process, and direct injection [1]. The difference between the hot chamber process and cold chamber process is that in hot chamber die casting the 
actuator is placed in intimate contact with the molten metal while in cold chamber die casting the actuator is separated from the molten metal reservoir. Direct injection is similar to the injection molding of polymers [1]. Aluminum alloy die castings are traditionally made using the cold chamber die casting process. A cold chamber die casting machine usually consists of a melting furnace or holding furnace, ladling system, molten metal injection system, die holding system, and spraying system. A schematic diagram of the primary steps of a cold chamber die casting process is shown in Figure 1.1.

The cold chamber die casting process consists of the following basics steps [2]:

1. die closure, where the cover and ejector dies are closed and locked with the required force,

2. ladling, where the molten metal is ladled into the shot sleeve from the furnace,

3. cavity filling, where the plunger pushes the molten metal into the die cavity,

4. solidification, where the metal is held under pressure until it solidifies,

5. die opening, where the cover die moves backward, the plunger advances to insure the diecasting stays in the ejector die. Cores, if any, retract. Then, the diecasting is ejected.

6. die spray and lubrication, where the die is sprayed with coolant and lubricant. (This step is not shown in Figure 1.1) 

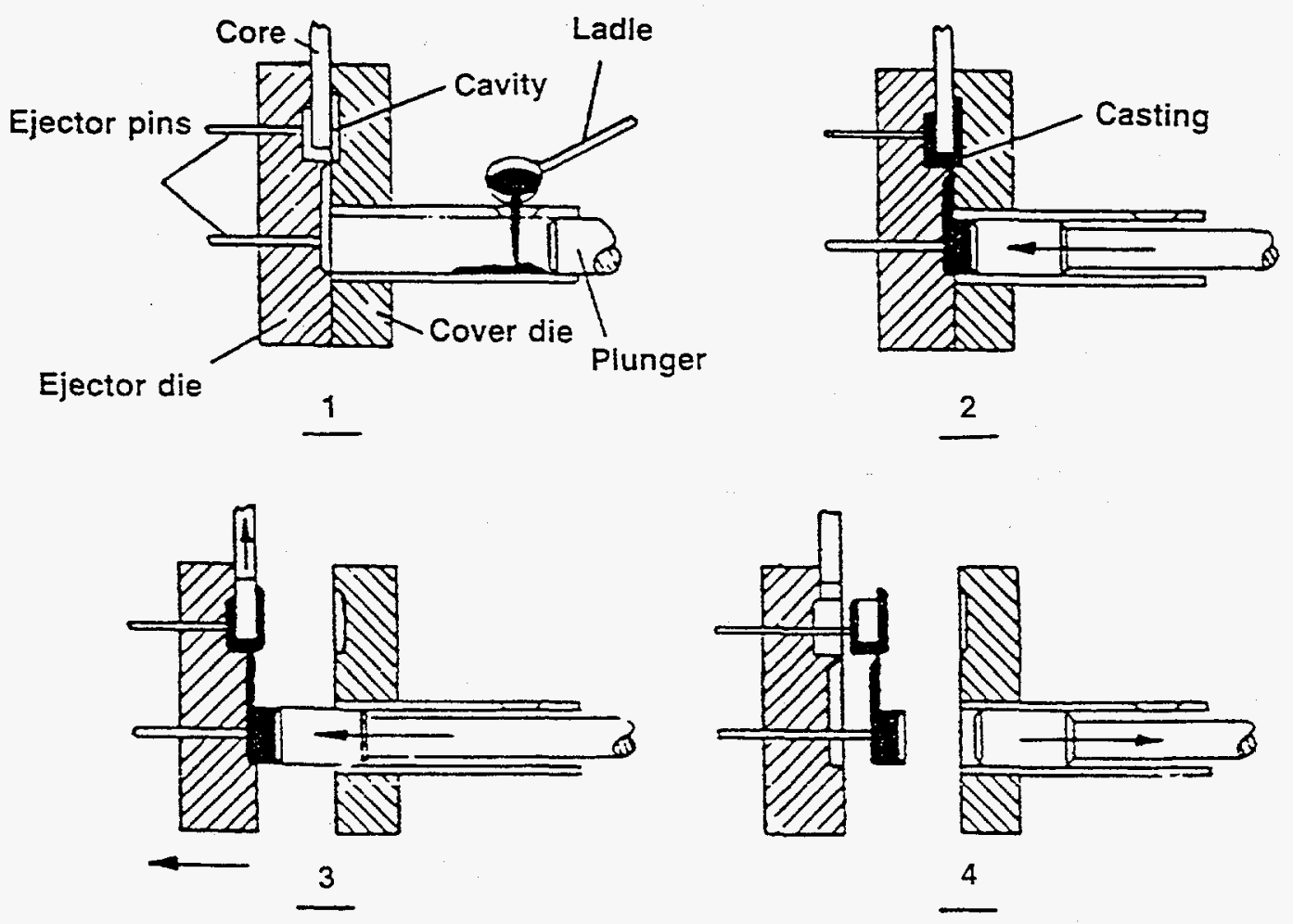

Figure 1.1 Operating sequence of the cold chamber die casting process [2] 


\subsection{TECHNICAL BACKGROUND OF THE PROJECT \& PROBLEM STATEMENT}

To reproducibly make die castings of acceptable quality, die design and process control are two key factors. Assuming that one begins with a properly designed die, the process variables which must be controlled are listed in Table 1.1.

Research studies by Sully [1], and Kaye and Street [3] have shown that successfu] die casting is contingent upon the maintenance of several variables. However, the interdependence among these variables complicates the problem. For the present, efficiency and quality can be achieved empirically by monitoring the process variables, studying the effects of variation of each on a given part and controlling the variables for each individual job. In a first stage application of process controi, the following steps are necessary in the absence of a complete scientific model [4]:

1. Monitor the process

2. Derive empirical model

3. Establish setpoints for independent variables currently controlled automatically 4. Maintain dependent variables by periodic adjustments 


\begin{tabular}{|c|c|}
\hline \multirow{3}{*}{ Melting Furnace } & Alloy Composition \\
\hline & Melt Temperature \\
\hline & Melt Treatment \\
\hline Ladling System & Ladling Time \\
\hline \multirow{5}{*}{ Metal Injection System } & Shot Sleeve Dimensions \\
\hline & Shot Delay Time \\
\hline & Shot Profile \\
\hline & Cavity Fill Time \\
\hline & Intensification Pressure \\
\hline \multirow[t]{2}{*}{ Dies } & Tie Bar Load \\
\hline & Die Temperature \\
\hline \multirow[t]{2}{*}{ Ejection System } & Die Open Time \\
\hline & Ejection Timing \\
\hline \multirow[t]{4}{*}{ Spraying } & Spray Type \\
\hline & Spray Timing \\
\hline & Spraying Duration \\
\hline & Spray Amount \\
\hline
\end{tabular}

Table 1.1 Process variables for cold chamber die casting [5] 
In a second stage, the following steps would be taken after the critical variables are identified in Stage I:

1. Feedback control all critical variables,

2. Maintain constant optimum values,

3. Provide alarms to indicate inability to maintain process with limits.

To reach such a goal in a single step is impractical at present. According to Mochiku et al. [6], the poor understanding of the die casting process results from the following:

1. The physical phenomena which occur during the casting process have not been sufficiently investigated,

2. The sensors which are needed to analyze the detailed behavior of the process do not currently exist,

3. A die casting system which incorporates detailed process knowledge and related sensors has not yet been developed.

To obtain accurate data, characterizing the die casting process is critical to the development of effective control algorithms. The most practical way is to obtain the data which are used in process control directly from the die casting as it is being cast in the die cavity. Measurement of the pressure on molten metal, the temperature of the die surface contacting with molten metal, and gas vent condition is expected to provide the most sensitive records of the conditions under which the part is made. 


\section{-1.3 RESEARCH OBIECTIVES [5]}

This study is part of the U.S. Department of Energy (DoE) sponsored project "Die Cavity Instrumentation", which aims to evaluate process monitoring sensors that record the thermal, pressure, and gas flow condition in or near die cavity as a means of securing improved process sensors whose outputs better correlate with resultant part quality.

The objectives of this thesis are to:

1. Evaluate a commercially available pressure sensor in a OSU die casting campaign and a controlled production campaign at GM Casting Advanced Development Center at Bedford, Indiana.

2. Characterize the porosity of die castings produced during the beta site campaign and develop correlations between product quality, in terms of the density, and sensor responses. 


\section{CHAPTER 2}

\section{PRELIMINARY REVIEW}

\subsection{INTRODUCTION}

A literature review on how to measure and control process variables and to identify and correlate casting defects to these variable was undertaken as a part of the DoE project. Additionally, a industrial survey to obtain an assessment of the current industrial usage of sensors to measure the thermal and pressure fields and gas flow rates from the die cavity of US die casting companies was conducted. 


\subsection{LITERATURE REVIEW}

Many die casting process parameters have been defined; however some have proven to be more crucial to the process and product than others.

Die temperature is one of the most important factors influencing the quality of die castings, their production rate, and die life. The surface temperature and the near surface thermal gradient in the die are majoring characterizing parameters [7]. Figure 2.1 shows the temperature gradient present in a die. In this case a heavy section aluminum casting was being produced with a 60 second cycle. Other detailed information was not provided. Obviously no evidence of die spray can found from these traces.

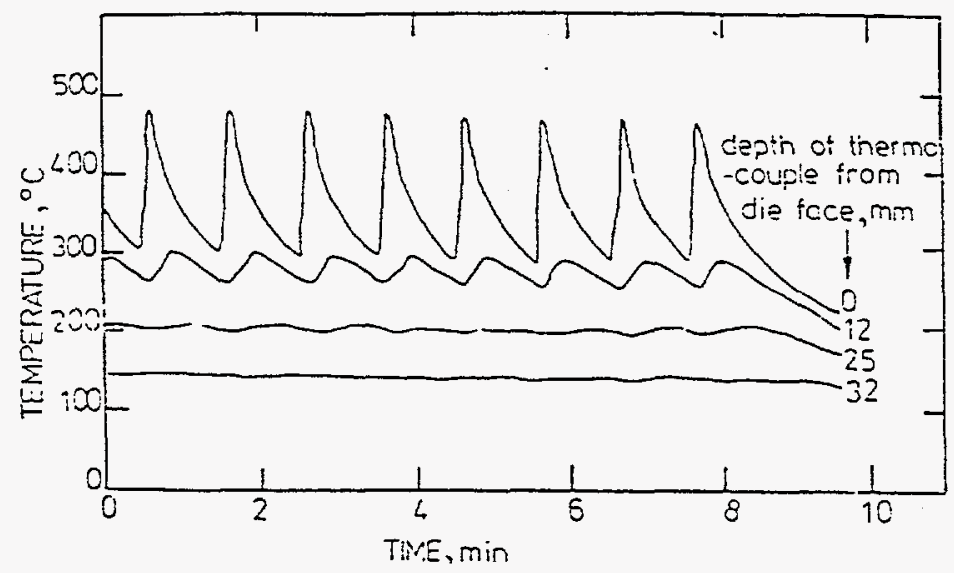

Figure 2.1 Thermocouple traces from various depths in a die casting die [8]. 
According to Booth et al [8] the temperature gradient in the die may be divided into two zones, (a) where the cyclic fluctuation are present; and (b) where these variations are lessened and a steady gradient exists. The temperature fluctuations are almost zero at $32 \mathrm{~mm}$ from the cavity surface.

Mochiku et al. [6] proposed a new concept, "intelligent die casting" in which, seven kinds of sensors are simultaneously used to gather data. The sensors used were pressure, temperature, gap, deformation, toggle pin, tie bar, and 6-axis force sensors. Although such a complete system is not generally used, the sensors essential to the system have been produced. They produced and investigated a die surface temperature sensor to measure the temperature on the interior surface of the die and heat flux through the die surface. Temperature $\mathrm{T} 1$ and $\mathrm{T} 2$ are measured at two points $\mathrm{x} 1$ and $\mathrm{x} 2$, which are located along the same surface normal to the die surface, but at different depths from the surface. The surface temperature (Ts') and heat flux $(\varnothing)$ are calculated from these temperature measurements. The resulting measured and calculated values appear as shown in Fig 2.2 (b). The structure of the sensor is shown in Figure 2.3. Two chromel-alumel thermocouples are welded on to a detecting block at the bottom of holes which are located at distance of $0.4 \mathrm{~mm}$ and $0.8 \mathrm{~mm}$ from the sensing surface. With the die surface temperature sensor, they detected the arrival of molten metal in a cavity and a overflow; estimated the soundness of molten metal; determined suitable amount of die lubricant; and established suitable operating temperature of a die. The die cavity has a M-shape, serpentine path of $630 \mathrm{~mm}$ in length [6]. 


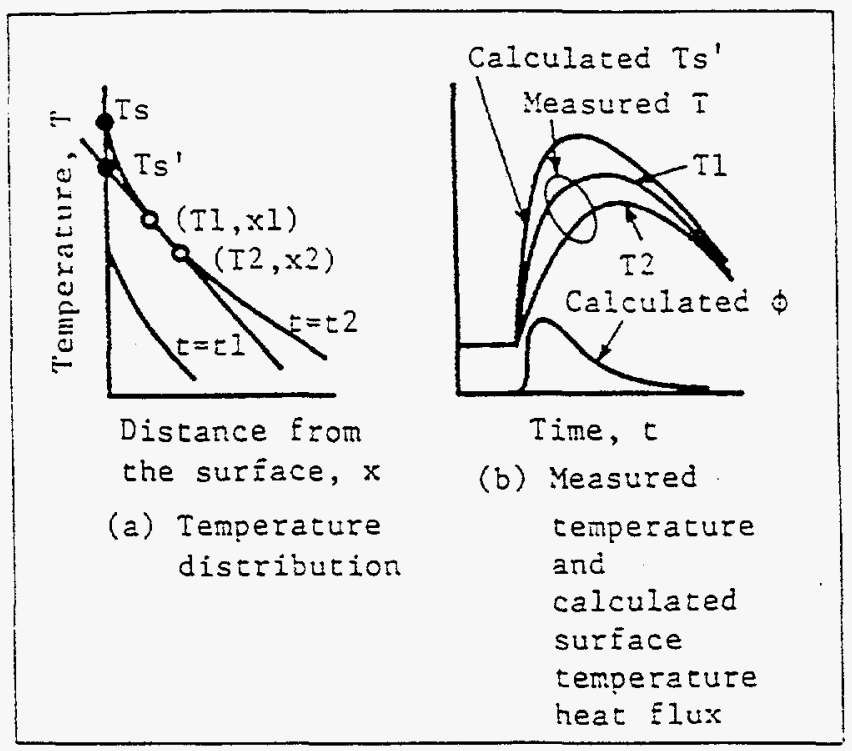

Figure 2.2 Temperature distribution, measured temperature and calculated surface temperature and heat flux vs. time [6].

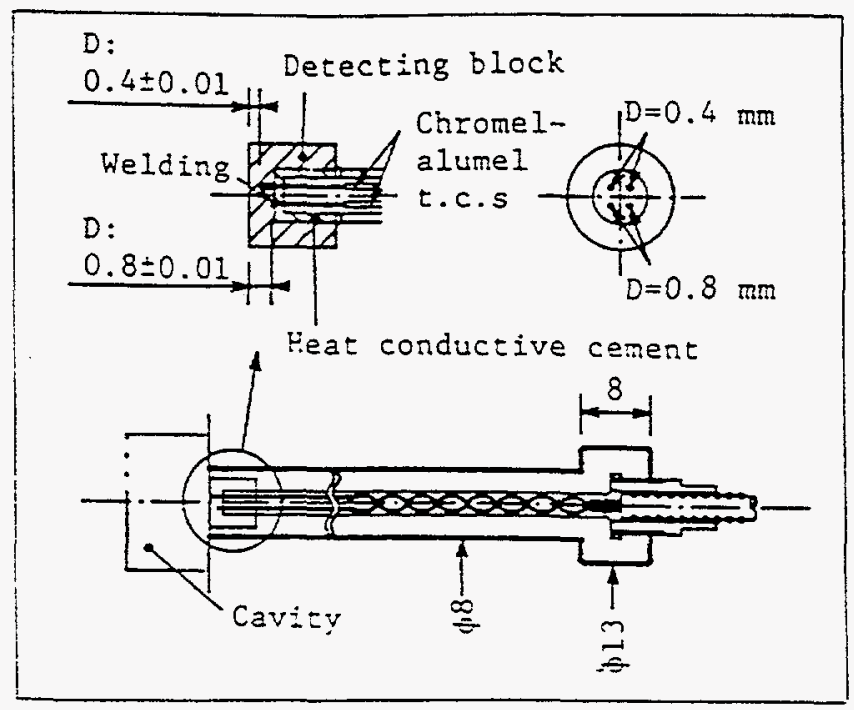

Fig 2.3 Structure of Mochiku et al. temperature sensor [6] 
Papai and Mobley [7] developed a procedure to measure the thermal field (including die-cavity interface temperatures) in $\mathrm{H}-13$ dies during the die casting of 380 aluminum alloy and applied a numerical method to the die thermal field data to determine the heat flux at the die-casting interface. They also investigated the effects of liquid alloy temperature, location on the casting, applied intensification pressure level, die surface roughness, and lubricant spraying duration on the heat transfer to the die. A bowl shaped casting with wall thickness varying from one section to another was selected. The thermocouples (chromel-alumel) were mounted in removable cores at depths of zero, $0.25,1.52$ and $12.7 \mathrm{~mm}$ relative to the casting-die interface, similar to the thermocouples used in this research. A thermocouple record for a selected die casting cycle is shown in Figure 2.4. Table 2.1 gives the information on this die casting system characterization. A photograph of the sectioned thermocouple probe tip is shown in Figure 2.5.

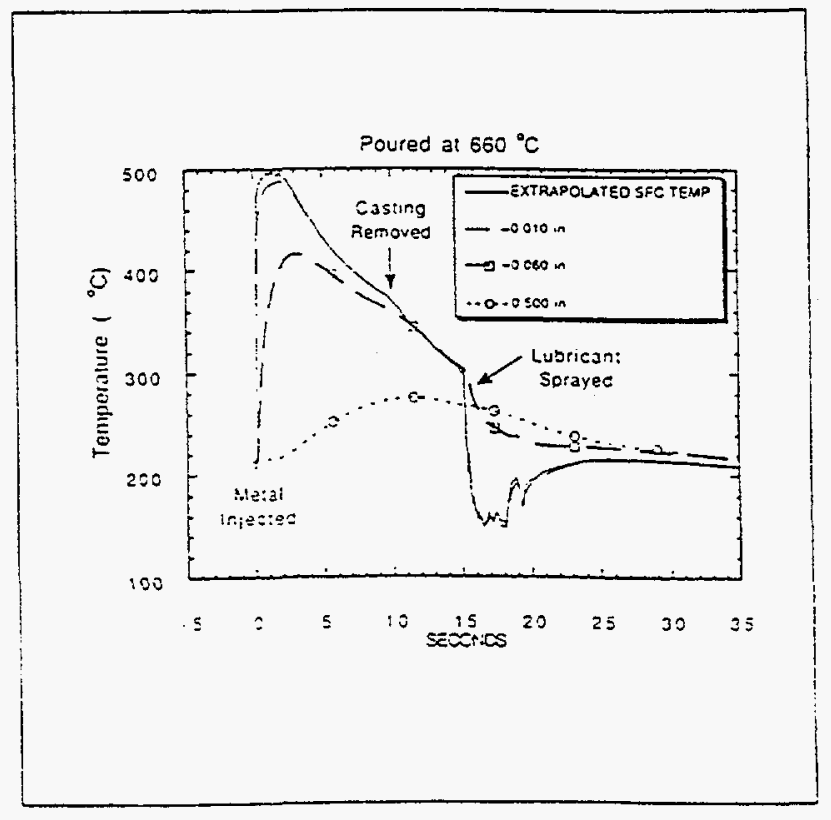

Figure 2.4 Thermocouple record for selected die casting cycle [7]. 


\begin{tabular}{|c|c|}
\hline Casting: & 380 Aluminum Alloy Bow: \\
\hline Bowl Casting Volume: & 13.9 cubic in. \\
\hline Total Casting Volume: & 19.5 cubic in. \\
\hline Total Casting Weight: & 1.7510 \\
\hline $\begin{array}{l}\text { Thermocouple Locations } \\
\text { (relative to die surface): }\end{array}$ & $\begin{array}{l}0.000,0.25,1.52,12.7 \mathrm{~mm} \\
(0.0,0.010,0.060,0.500 \mathrm{in} .)\end{array}$ \\
\hline Plunger Diameter: & $2.09 \mathrm{in} .(5.3 \mathrm{~cm})$ \\
\hline Sleeve Length: & $19.75 \mathrm{in} .(50.165 \mathrm{~cm})$ \\
\hline Percentage Fill: & $29 \%$ \\
\hline Plunger Velocity: & Two Stage; $10 \mathrm{in} . / \mathrm{sec}, 75 \mathrm{in} . / \mathrm{sec}$. \\
\hline Gate Area: & $0.07 \times 2.0 \mathrm{in} .=0.14$ square in. \\
\hline Ga:e Velocity: & $154 \mathrm{t} / \mathrm{sec}(47 \mathrm{~m} / \mathrm{sec})$ \\
\hline \multicolumn{2}{|l|}{ Alloy Pouring } \\
\hline Applied Pressure: & 5,600 and $15,000 \mathrm{psi}$ \\
\hline Locking Force: & 600 tons \\
\hline Lubricant: & $1 / 40$ dilution graphitic agent in water \\
\hline $\begin{array}{l}\text { Lubricant Spray } \\
\text { Duration: }\end{array}$ & Light $=2$ sec:; Heavy $=4 \mathrm{sec}$. \\
\hline Die Closed Time: & $10 \mathrm{sec}$. \\
\hline Die Open Time: & 15 to $25 \mathrm{sec}$ \\
\hline Total Cycle Time: & 25 to $30 \mathrm{sec}$ \\
\hline \multicolumn{2}{|c|}{ Thermal Properties of the $\mathrm{H}-13$ Steel Die $(9)$ : } \\
\hline \multicolumn{2}{|c|}{ Thermal Conductivity, $\mathrm{k}=0.058 \mathrm{~T}+8.6 \times 10^{-5} \mathrm{~T}(\mathrm{cal} / \mathrm{cm} \mathrm{C} \mathrm{sec})$} \\
\hline \multicolumn{2}{|c|}{ Density, $\rho=7.8-2.5 \times 10^{-\top} \mathrm{T}\left(\mathrm{g} / \mathrm{cm}^{3}\right)$} \\
\hline \multicolumn{2}{|c|}{ Specific Heat, c $0.110-1.12 \times 10 \mathrm{~T}+7.5 \times 10 \mathrm{~T}$ (cal $/ 9 \mathrm{O}$ ) } \\
\hline
\end{tabular}

Table 2.1 Die casting system characterization [7]

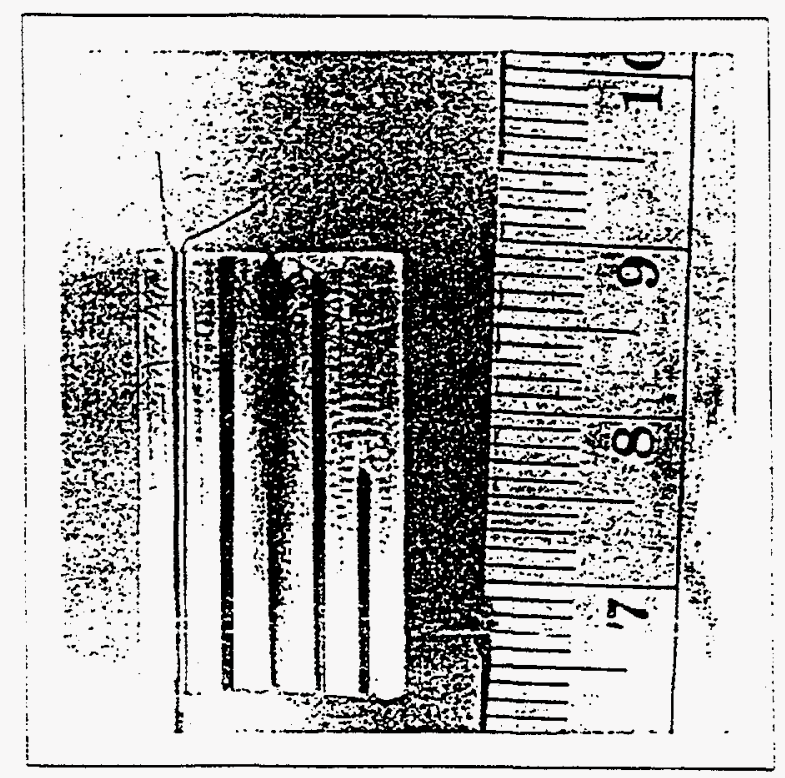

Figure 2.5 Sectioned Papai and Mobley thermocouple probe tip [7] 
Cavity pressure is a critical process variable to the quality of the product. Most investigations have shown that increasing the level of cavity pressure results in improved internal casting quality. The porosity associated with solidification shrinkage and insoluble gases present in the solidifying alloy can be reduced with increasing pressure. A relationship between the final pressure in injection cylinder and porosity of a small aluminum cylinder head is shown in Figure 2.6. The equation of the trendline of percent porosity, \%P, vs. final pressure, $\mathrm{P}_{\text {final, }}$ is $\% \mathrm{P}=16.59 \mathrm{P}_{\text {final }}^{-0.7845}\left(\mathrm{R}^{2}=0.9943\right)$ if it is assumed a power trendline or $\% \mathrm{P}=0.0277 \mathrm{P}_{\text {final }}{ }^{2}-0.7961 \mathrm{P}_{\text {final }}{ }^{2}-7.8714\left(\mathrm{R}^{2}=0.9995\right)$ if it is assumed a polynomial trendline.

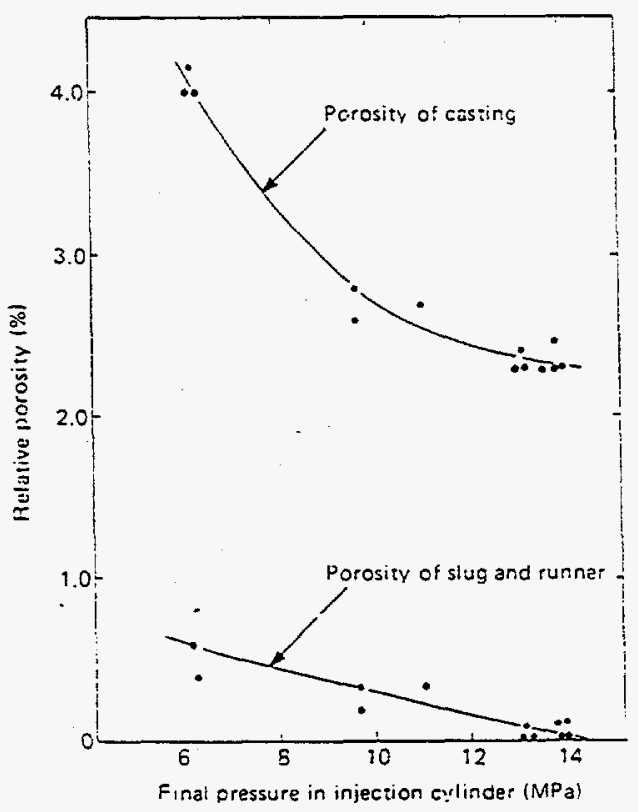

Figure 2.6 Relative porosity as a function of pressure applied during solidification [3] 
Babington and Klepinger [9] found that internal soundness improved with increasing the level of cavity pressure up to 15,000 psi and remained constant. Phlipot et al. [10] evaluated the effect of gate velocity during fast shot and cavity pressure $0.6 \mathrm{sec}$ after shot rod impact. Their results reveal that the theoretical cavity pressure, measured $0.6 \mathrm{sec}$ after impact, and the average gate velocity both have significant effects on internal casting quality. Lower gate velocities and higher cavity pressures yielded lower porosity castings. Tokui et al., [11] conducted research on the vertical pressure die casting process and found that if pressures above $30 \mathrm{Mpa}(4350 \mathrm{psi})$ are applied to the molten metal, castings of higher tensile strength and density could be obtained. The casting conditions and the size of the round bar test pieces are shown in Table 2.2. Figure 2.7 shows the results of the research.

\begin{tabular}{|c|c|c|}
\hline & $\begin{array}{c}\text { VERTICAL PRESSURE } \\
\text { DIE CASTING PROCESS }\end{array}$ & $\begin{array}{c}\text { CONVENTIONAL } \\
\text { DIE CASTING PROCESS }\end{array}$ \\
\hline MATERIAL & A330 & AJ80 \\
\hline $\begin{array}{c}\text { CASTING TEMPERATURE } \\
\left({ }^{\circ} \mathrm{C}\right)\end{array}$ & 740 & 680 \\
\hline $\begin{array}{c}\text { CASTING PRESSURE } \\
(M P a)\end{array}$ & 50 & 80 \\
\hline $\begin{array}{c}\text { DIAMETER OF THE } \\
\text { TEST PIECE (mM) }\end{array}$ & $8,10,14$ & $6.5,10,14$ \\
\hline $\begin{array}{c}\text { SURFACE OF THE } \\
\text { TEST PIECE }\end{array}$ & NS CAST & AS CAST \\
\hline HEAT TREATMENT & NO & NO \\
\hline
\end{tabular}

Table 2.2 Tensile strength test piece characterization [11] 


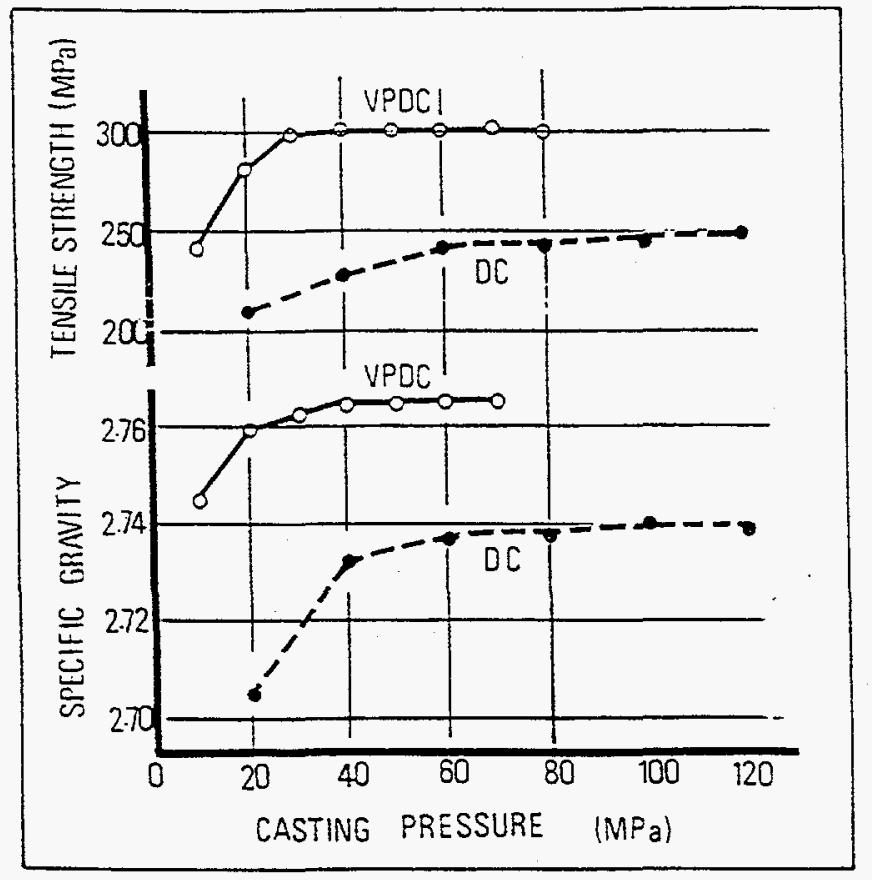

Figure 2.7 Effects of metal pressure on tensile strength and specific gravity of test piece[11]

Mochiku et al. [6] developed and used a pressure sensor to measure the pressure acting on the die during the casting process and the ejecting force during the ejection process. The pressure and force which act on top surface of the sensor are detected by four strain gages which are glued on the detecting block. The structure of the sensor is shown in Figure 2.8. As reported, the pressure sensor was able to measure the pressure during injection and solidification; detect soldering and sticking in ejection; detect abnormality in the total system and near a gate; establish suitable operating pressure and injection speed. 


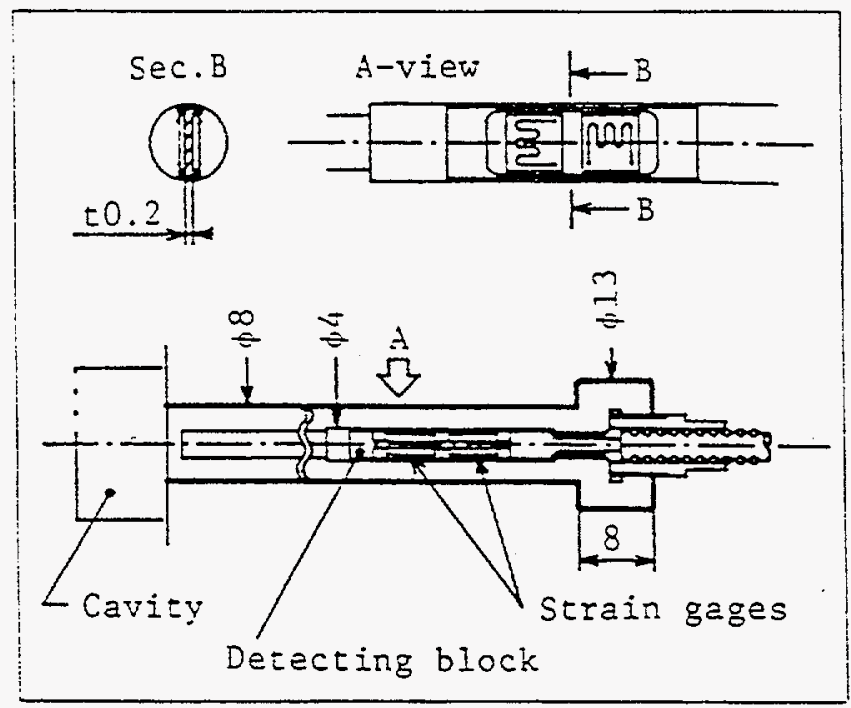

Figure 2.8 Structure of pressure sensor [6]

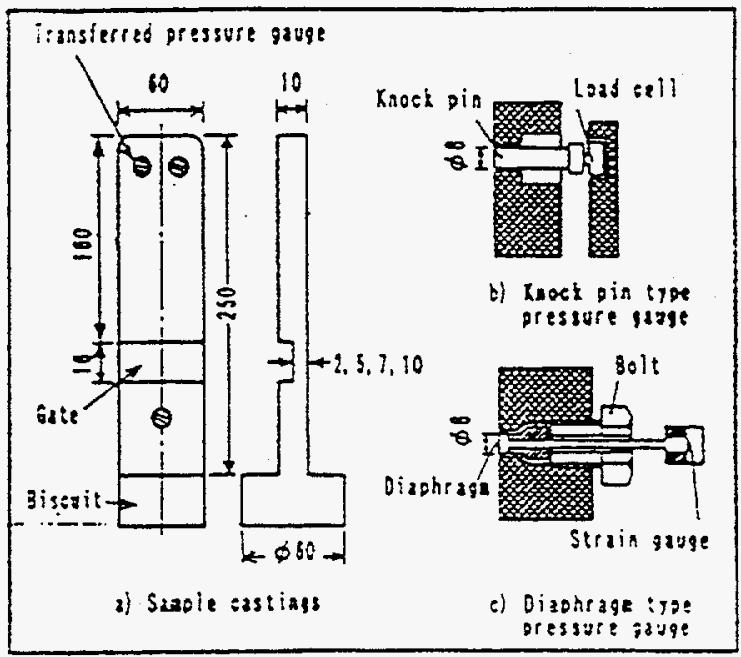

Figure 2.9 Schematic drawing of sample castings specimen and transferred pressure gauges [12] 
Sugiyama et al. [12] developed and evaluated another method of measuring transferred pressure on metal in a die cavity and related the effects of transferred pressure to the quality of aluminum diecastings. The schematic drawing of the molten metal pressure gauges is shown in Figure 2.9.

The indirect metal pressure sensor used by Sugiyama et al. could measure pressures to $100 \mathrm{Mpa}$ (14500 psi). The direct molten metal pressure sensor could measure the maximum pressure to $105 \mathrm{Mpa}(15225 \mathrm{psi})$ and have a heat resistance temperature of $773 \mathrm{~K}$. The cast alloy was 380 aluminum alloy and the molten metal was injected at about $853 \mathrm{~K}$. Figure 2.10 shows the transferred pressure curves measured by a diaphragm-type pressure gauge and two knock-pin-type gauges (with and without stainless steel film). Sugiyama et al. [12] found that when the knock-pin-type pressure gauge is used, the measured pressure value could be affected by the fins in the gap between the die and the gauge. By applying a $0.05 \mathrm{~mm}$ thick stainless steel film, the same value as that measured by diaphragm-type pressure gauge can be obtained. The pressure at the thickness center of a casting cannot be measured accurately by the measurement on the surface, owing to the pressure drop caused by the solidification layer near the surface. 


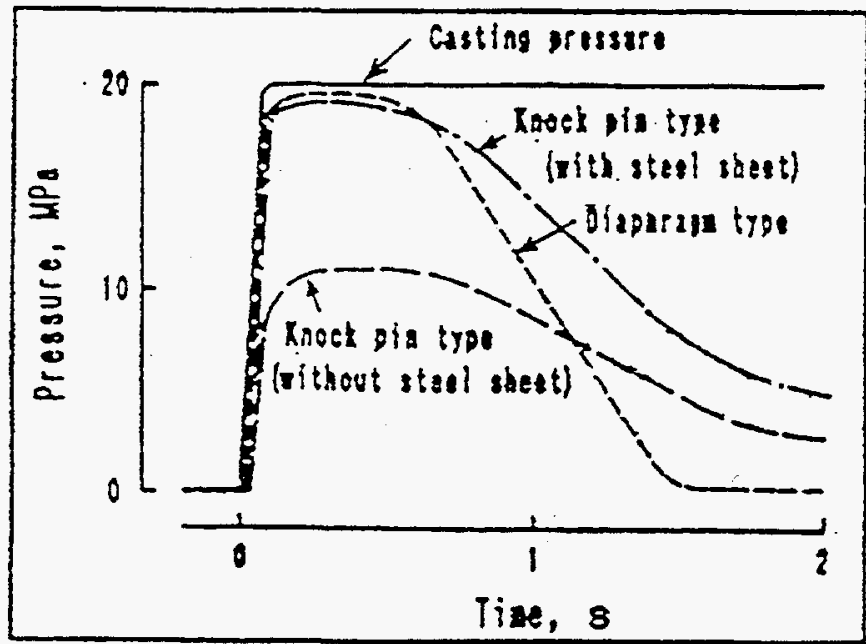

Figure 2.10 Transferred pressure curves by various measuring methods [12]

By applying a film of insulating material, Sugiyama et al. [12] measured the transferred pressure at the center of the section. Figure 2.11 shows the solidification time of the section of the sample castings of different thickness. Figure 2.12 shows the transferred pressure curves for $10 \mathrm{~mm}$ thickness sample castings with and without the insulating film. The gate thickness was $2,5,7$, and $10 \mathrm{~mm}$. They reported that the duration of pressure transfer was governed mainly by solidification at the gate and took only about $20 \%$ of the solidification time at the gate. 


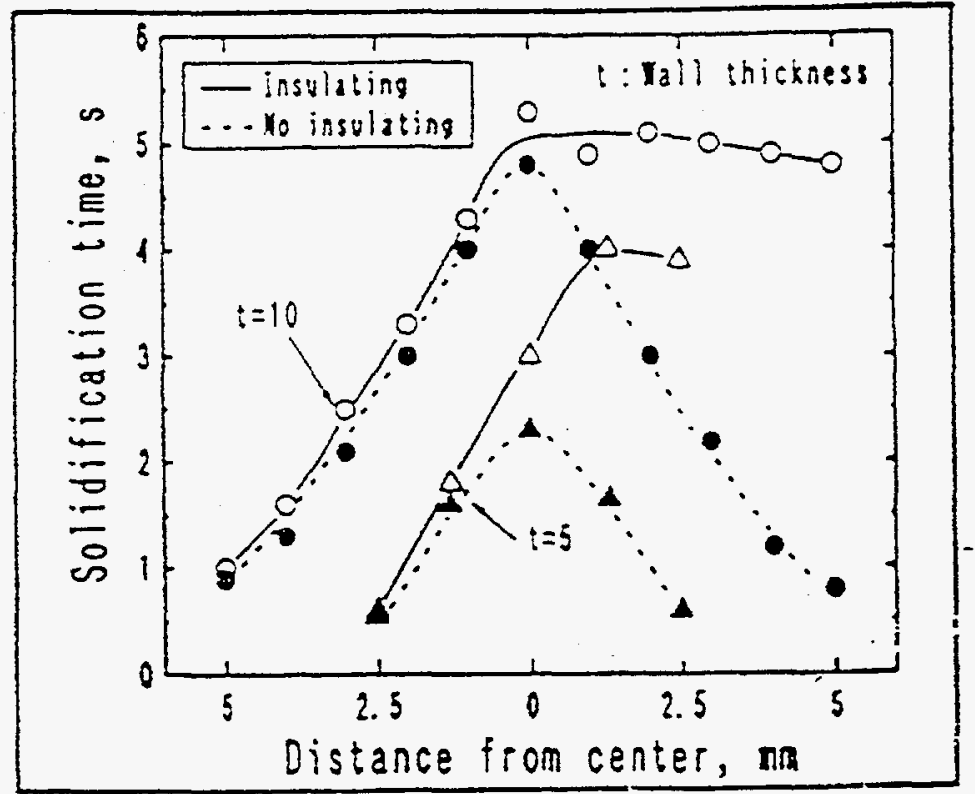

Figure 2.11 Change in solidification time for different sections of castings [12]

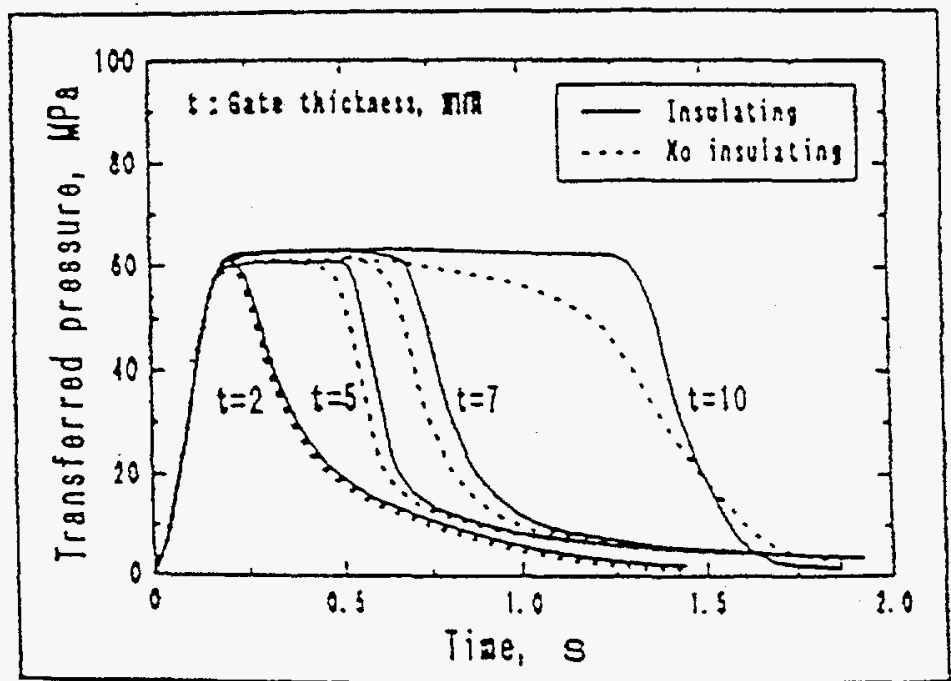

Figure 2.12 Transferred pressure curves for various gate thickness with and without insulating film [12]. 
The relation between gate thickness and the duration of the maximum transferred pressure measured using insulating film is shown in Figure 2.13. The duration of the maximum transferred pressure at a location, just in front of the gate was constant at about $1.4 \mathrm{sec}$. However, at the point a, beyond the gate, the duration of the maximum transferred pressure became longer with increasing gate thickness.

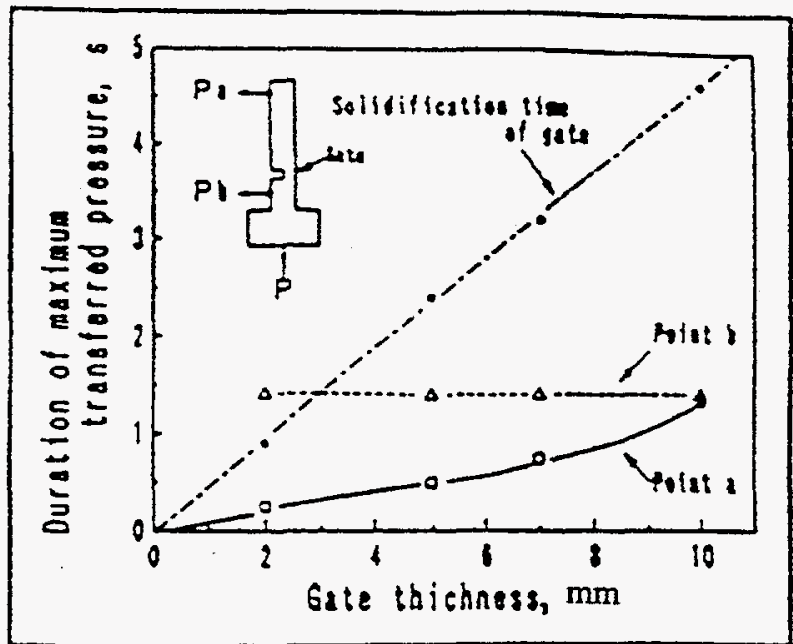

Figure 2.13 Relation between gate thickness solidification time of gate and duration of the maximum transferred pressure [12]. 
Figure 2.14 gives an example of the transferred pressure curves obtained by measuring pressure in the runner and at two points within the cavity. The maximum transferred pressure within the cavity was slightly lower than in the runner and much lower in the end of the cavity. The duration of the maximum transferred pressure was 0.4 $\mathrm{sec}$ in the runner, $0.25 \mathrm{sec}$ in the cavity and slightly shorter at the end of the cavity. The relationships between molten metal velocity, maximum transferred pressure and surface roughness of castings and between molten metal velocity, maximum transferred pressure and internal defects was reported as shown in Figure 2.15 and Figure 2.16. It was reported that surface roughness of the diecastings decreased with increasing transferred pressure and molten metal velocity and internal defects, like blowholes, diminished with increasing transferred pressure and disappeared at pressures of $75 \mathrm{Mpa}$ and larger.

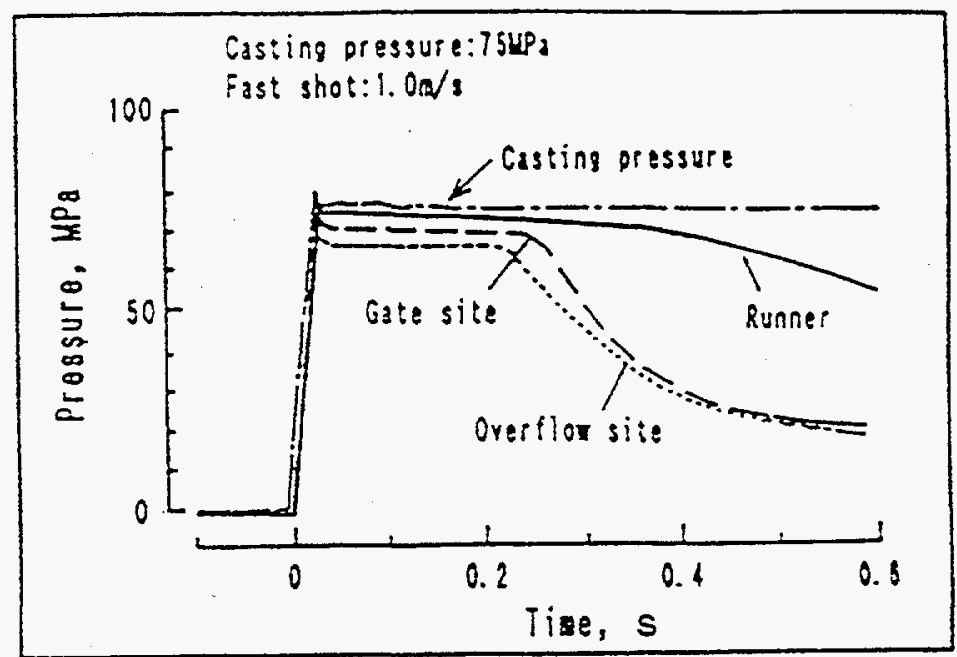

Figure 2.14 Transferred pressure curves for diecasting [12] $(1 \mathrm{Mpa}=145 \mathrm{psi})$ 


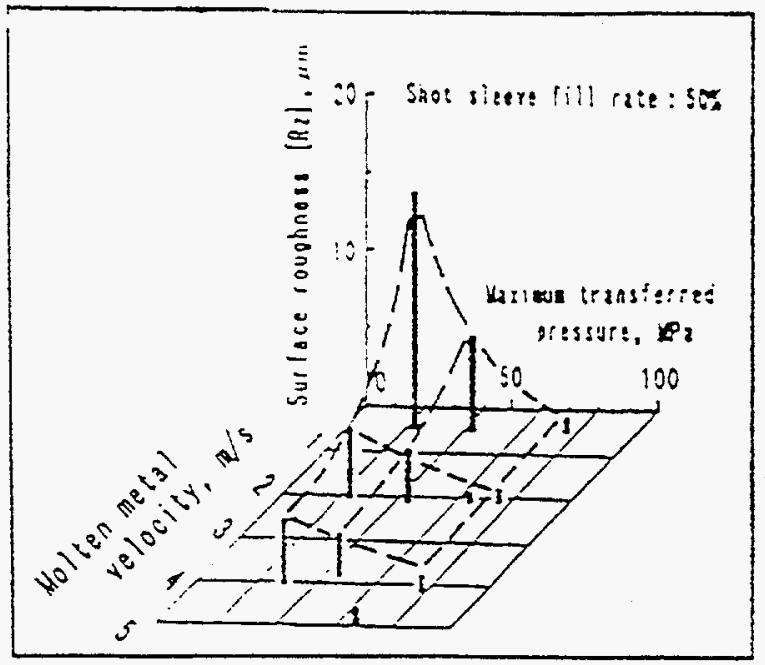

Figure 2.15 Relation between surface roughness, maximum transferred pressure and molten metal velocity [12]

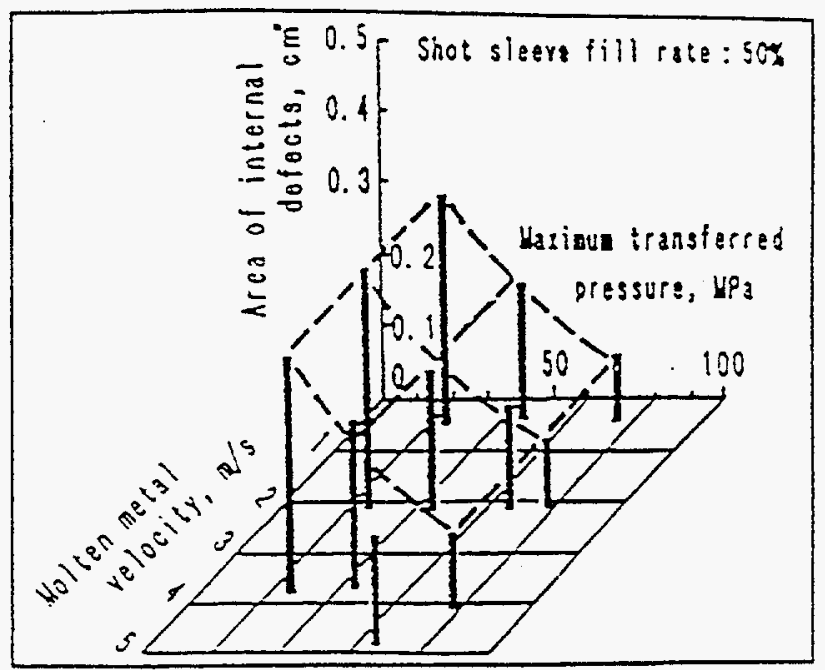

Figure 2.16 Relation between internal defects, maximum transferred pressure and molten metal velocity [12]. 
In the last decade, quality requirements have moved beyond configuration and dimensional control to internal defects control. Porosity is usually considered deleterious because it reduces the load-bearing cross-sectional area, causes stress concentration, may give rise to blisters on the surface and leakage. The porosity originates from two sources [13] : solidification shrinkage and gas.

The gas porosity originates from

1. Solubility differences during solidification (i.e., gas species which are dissolved in the solidifying alloy)

2. Reactions which form gases in the system (i.e., lubricant-metal reactions)

3. Physically entrained gases which become entrapped in the solidifying system

The vent is an important part of die. It acts as a gate to release air or gas in the die cavity. Sometimes the vent may be blocked. If the air is not able to go out, the air pressure will rise during injection. To get the information on the situations of air pressure in die cavity, Yamamoto et al., [14] developed a device for measuring gas pressure at each position in a die cavity during injection of molten metal. As shown in Figure 2.17, a 3mm dia. hole was bored through the die to insert a gas pressure conduit pipe. A gas pressure gage with a measuring range of $1.0 \mathrm{~kg} / \mathrm{cm}^{2}$ was attached on one end of the pipe. A porous material filled the hole at the other end. The time-dependent changes in pressure in a die cavity were automatically recorded on an electromagnetic oscillograph just after the injection of the molten metal. 


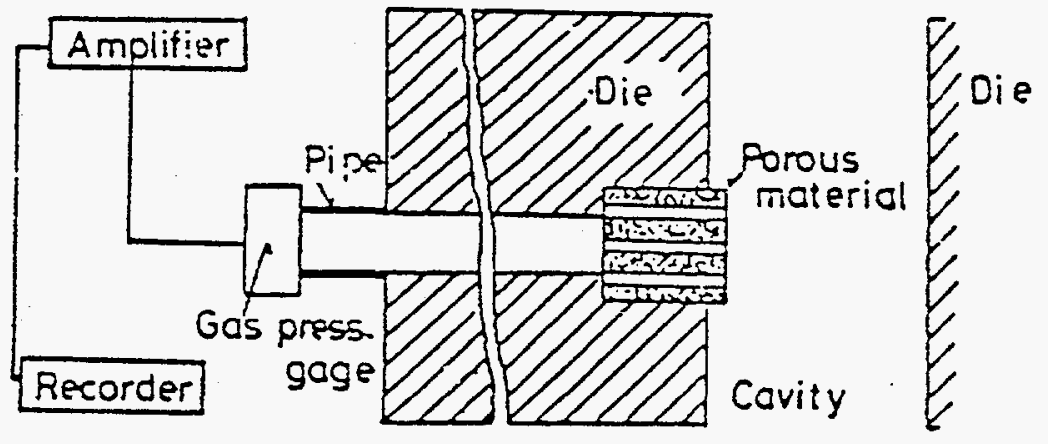

Figure 2.17 System for measuring gas pressure in die cavity [14].

Gas pressure in the die cavity of a boxed-shape casting was measured at positions 1-3 along the molten metal flow. Typical gas pressure vs. time curves in the die cavity are shown in Figure 2.18. The gas pressure in the cavity gradually becomes higher with the passage of time from injection. The changeover of the shot velocity from slow shot to fast shot abruptly increases the gas pressure. They reported that the increase in gas pressure decreases the velocity of the molten metal at the final filling position. The die casting defects frequently appear near the gate and at the final filling positions. They studied the correlations of casting defects with molten metal velocity and gas pressure in the cavity. They found that it is necessary to decrease the pressure and increase the molten metal velocity at the final filling position to prevent casting defects. 


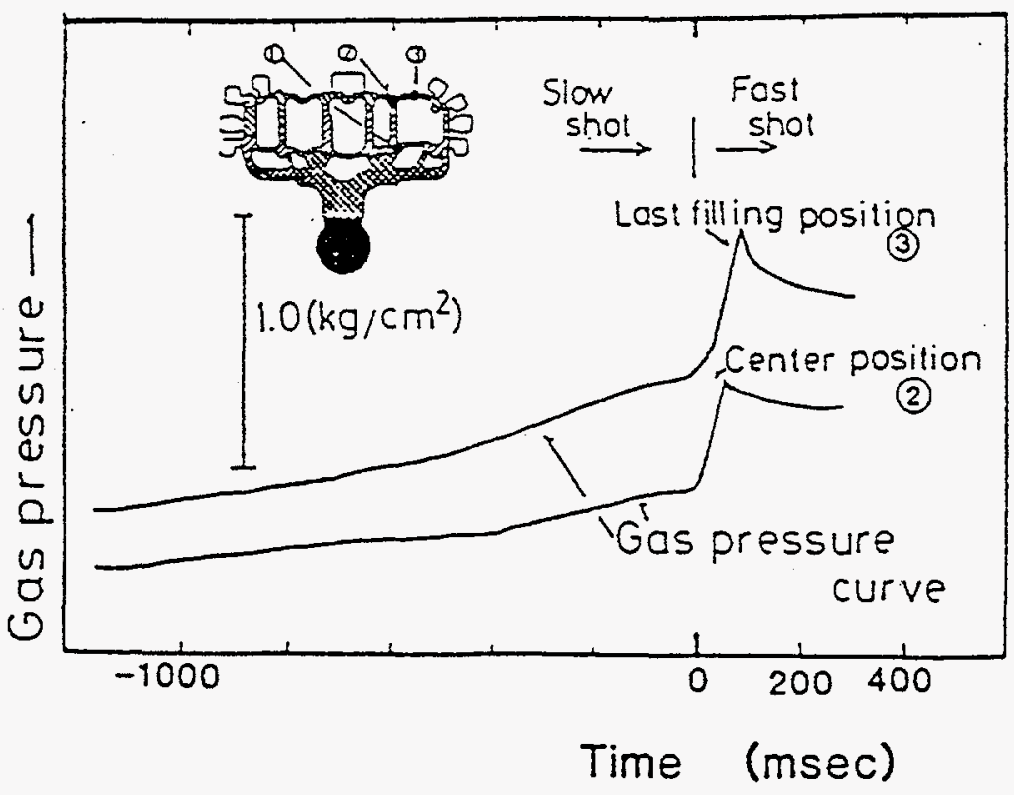

Figure 2.18 Gas pressure curve of thin wall box castings cast in 1200-ton machine [14].

Several kinds of sensors necessary for the realization of die casting process have been developed and investigated. Among these sensors, the surface temperature sensor and the shot profile pressure sensor are the most significant. Their performance during the die casting process and usefulness have been investigated through experiments. These researches indicate that to precisely monitor the die casting process is fundamental and critical for understanding of die casing process. To be accepted for industrial application, these sensors still need evaluation and development. 


\subsection{INDUSTRIAL SURVEY [5]}

Shortly after initiation of this DoE-sponsored project, a survey questionnaire was prepared and sent to NADCA corporate members and distributed to company representatives attending NADCA Chapter meetings to obtain the situation of the current usage of thermal, pressure and gas flow rate sensors in die casting industry. A sample questionnaire is included as APPENDIX A. Of the 63 completed survey questionnaires, 60 were completed by U.S. die casting companies, 1 by a non-North American die casting company, and 2 by U.S. die casting equipment companies. The responding die casting companies operate 937 cold chamber die casting machines and 343 hot chamber die casting machines. The 1249 die casting machines of the U.S. die casting companies that responded represent $15.6 \%$ of the available U.S. die casting machines, based on the estimated 8000 die casting in $1994.91 \%$ of the companies indicated that they possess the equipment to monitor the position and velocity of the plunger as a function of time during the filling process. $50 \%$ of the companies indicated that they used temperature and pressure measuring sensors near the die cavity as part of the process monitoring or control practices. Only $15 \%$ indicated that they use or have systems to monitor the gas vent condition. Only $12 \%$ indicated that they use or have systems for measuring the amount of gas removed from the die cavity. The OSU investigators surmised that the companies indicating that they monitored the amount of gas removed from the die cavity used die cavity vacuum assisted practices. 


\section{CHAPTER 3}

\section{EVALUATION OF KISTLER DIRECT PRESSURE SENSORS IN DIE CASTING CAMPAIGNS}

\subsection{INTRODUCTION}

The primary objective of the U.S. DoE sponsored project "Die Carity Instrumentation" is to evaluate and develop in-cavity thermal, pressure, and gas flow sensors to monitor filling, solidification, and gas entrapment in the die cavity(s) of cold chamber die casting process and to relate the measurements of these variables to the quality of the resultant die castings. The sensors should allow the measurement of (a) the die temperature field near the die cavity surface, (b) the pressure of the liquid in the die cavity, and (c) the amount of gas exiting the die cavity during filling. These measurements are to be correlated with the plunger position-time and hydraulic pressuretime records, and related to the porosity of the resultant castings [5]. A literature review and a survey of industrial practices revealed that sensors for measuring the alloy pressure in die casting cavities are commercially available. 


\subsection{PRESSURE SENSOR}

There are two principle types of pressure sensors for the measurement of the liquid alloy pressure. They are:

1. indirect pressure sensors, which use the pin's displacement to transfer the cavity pressure

2. direct pressure sensors, which use the diaphragm to transfer the cavity pressure

The indirect pressure sensors have been used by the die casting industry for many years. The major problem associated with their usage is the reliability of the measurements. Since the cavity pressure is transferred to the load cell or strain gauge of the sensor via the pin's displacement, the friction between the pin and the die or small fins in the gap between the die and the pin affects the response and the measured pressure value. The deviation from the real value is difficult to estimate due to the inconsistencies from shot to shot.

A direct quartz-based pressure sensor developed by Kistler Instrument Corp. was acquired for evaluation as an in-cavity liquid metal pressure sensor [5]. Figure 3.1 illustrates the geometry and specifications of the sensor. This pressure sensor is designed for use up to $700^{\circ} \mathrm{C}$ and 2000 bars $(29,000 \mathrm{psi})$. It has a pressure overload capacity up to 2500 bars $(36,250 \mathrm{psi})$. The body of the pressure sensor is $6.3 \mathrm{~cm}$ long and $1.2 \mathrm{~cm}$ diameter. 
To generate an electrical output from a pressure input, pressure must first be converted into a proportional displacement or strain. This strain is then transmitted to an electrical element which generates the required signal. The Kistler pressure sensors consist of three basic parts: the sensor housing, the quartz sensing element and the diaphragm for transferring the pressure to the element. The Kistler piezoelectric pressure sensors are quartz. While quartz-based pressure sensors are ideally suited for measuring dynamic events, they cannot perform truly static measurements. Although the electrical charge delivered under a static load can be registered, it cannot be stored for an indefinite period of time. Quartz-based piezoelectric system can routinely measure large static pressure for minutes and perhaps even hours. Low level static pressures can be measured "statically" for much shorter intervals. For this reason Kistler piezoelectric pressure sensors are often described as being "quasistatic". However, quantitative information is not provided on this issue. Temperature variations may also affect a sensor's output.

Unit conversions which are helpful for comparison of data from various sources are listed in Table 3.1

\begin{tabular}{|c|c|c|}
\hline & English to S.I. & S.I. to English \\
\hline Length & 1 inch $=25.4 \mathrm{~mm}$ & $1 \mathrm{~mm}=0.0394$ inch \\
\hline Weight & $1 \mathrm{lb}=0.4536 \mathrm{~kg}$ & $1 \mathrm{~kg}=2.205 \mathrm{lb}$ \\
\hline Pressure & $1 \mathrm{psi}=6.9 \times 10^{-3} \mathrm{Mpa}$ & $1 \mathrm{Mpa}=145 \mathrm{psi}$ \\
\hline Pressure & $1 \mathrm{bar}=0.101 \mathrm{Mpa}$ & $1 \mathrm{Mpa}=9.864 \mathrm{bar}$ \\
\hline Density & $1 \mathrm{lb} /$ inch $^{3}=27.679822 \mathrm{~g} / \mathrm{cc}$ & $1 \mathrm{~g} / \mathrm{cc}=0.036127486 \mathrm{lb} /$ inch $^{3}$ \\
\hline
\end{tabular}

Table 3.1 Table of unit conversions 


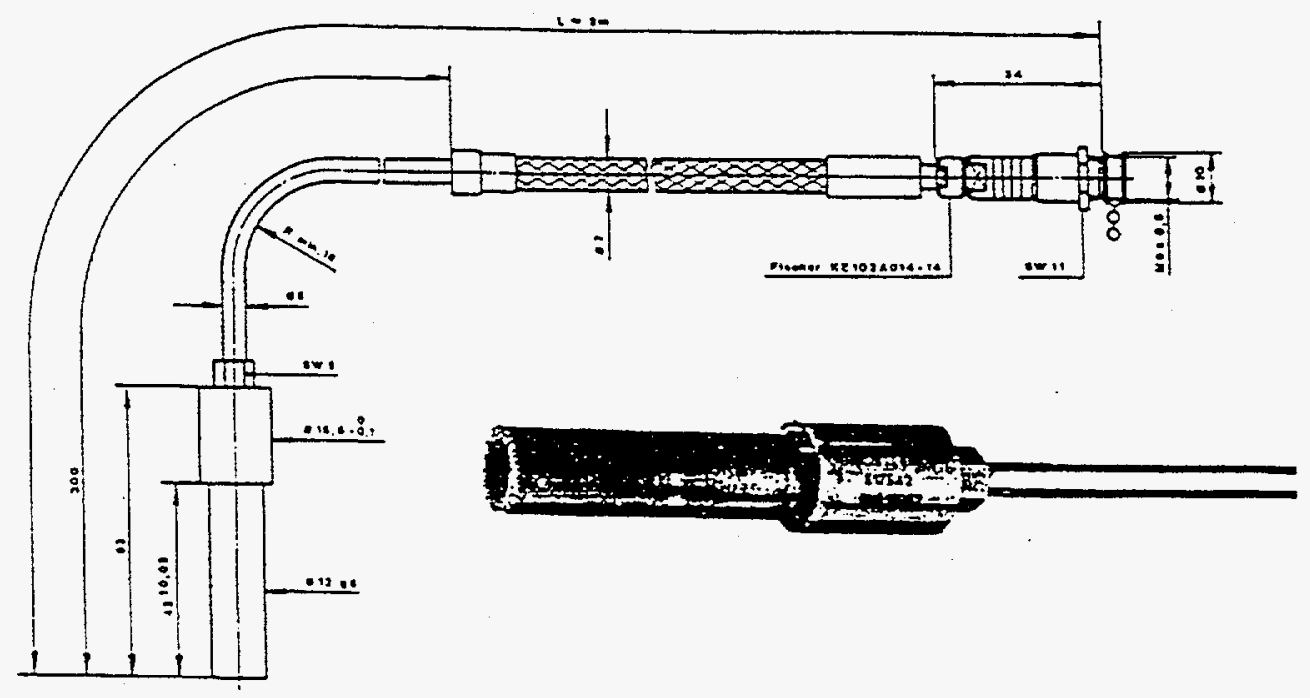

\begin{tabular}{|c|c|c|}
\hline \multicolumn{2}{|c|}{ Technical Data } & \multirow[b]{2}{*}{$0 . .2000$} \\
\hline Rinngo & bar & \\
\hline Overtand & bar & 2500 \\
\hline Untform sansiturtty (at $250^{\circ} \mathrm{C}$ ) & ocl t tar & -6.7 \\
\hline Unexitty, all rances & $\approx$ FSO & $s \pm 2$ \\
\hline Netural trequency & $\mathrm{kHz}$ & -30 \\
\hline Accoleration senultivity & bar 10 & $<0.07$ \\
\hline $\begin{array}{l}\text { Operating temporaturo range } \\
\text { Sonser. cable } \\
\text { Connecio }\end{array}$ & ${ }^{\circ} \mathrm{c}$ & $\begin{array}{l}0 \ldots 300= \\
0 \ldots 200=\end{array}$ \\
\hline $\begin{array}{l}\text { Tomporature coetriclent } \\
\text { of sensitiviny }\end{array}$ & $\approx 1 * \mathrm{C}$ & $=0.01$ \\
\hline $\begin{array}{l}\text { Inaulation malsuncos } \\
\text { at } 20^{\circ} \mathrm{C} \\
\text { at } 300^{\circ} \mathrm{C}\end{array}$ & $\begin{array}{l}\Omega \\
\Omega\end{array}$ & $\begin{array}{l}10^{13} \\
10^{11}\end{array}$ \\
\hline Woight (type $61522-10.4$ ) & $\sigma$ & $2 \approx 0$ \\
\hline
\end{tabular}

Figure 3.1 Kistler direct pressure sensor and specifications [5] 
The Kistler pressure sensors were calibrated before their application in the OSU die casting campaign. Two pressure sensors were used in the OSU campaign, which is a part of this U.S. DoE sponsored project. A given load was applied by means of a press and the measurements were recorded. The plots of applied and measured pressure for each sensor are shown in Figure 3.2 and Figure 3.3, respectively. The duration of each load was not recorded and the calibration was conducted at room temperature. The maximum deviation of the measured pressure from the applied pressure over the range of 0 through 1000 bars was 30 and 50 bars for sensors 1 and 2, respectively [15]. The maximum deviation from the actual can be expected to be 70 to 100 bars at the maximum cavity temperatures of 400 to $450^{\circ} \mathrm{C}$ and at cavity pressure of 1000 bars due to the $0.01 \% /^{\circ} \mathrm{C}$ temperature coefficient of sensitivity [15]. Figure 3.4 illustrates the applied and measured pressures when the applied pressure exceeds the operating range $(0-1000$ bars). Figure 3.5 illustrates the response of the two sensors during dynamic loading and unloading. In this figure the Kistler pressure sensors recorded a constant pressure 9.6 bars for over 2 seconds. For higher pressure, the period during which the pressure is constant is even longer. Two seconds are adequate for recording most events associated with the die casting process. The pressure is dynamic throughout most of the die casting process. 


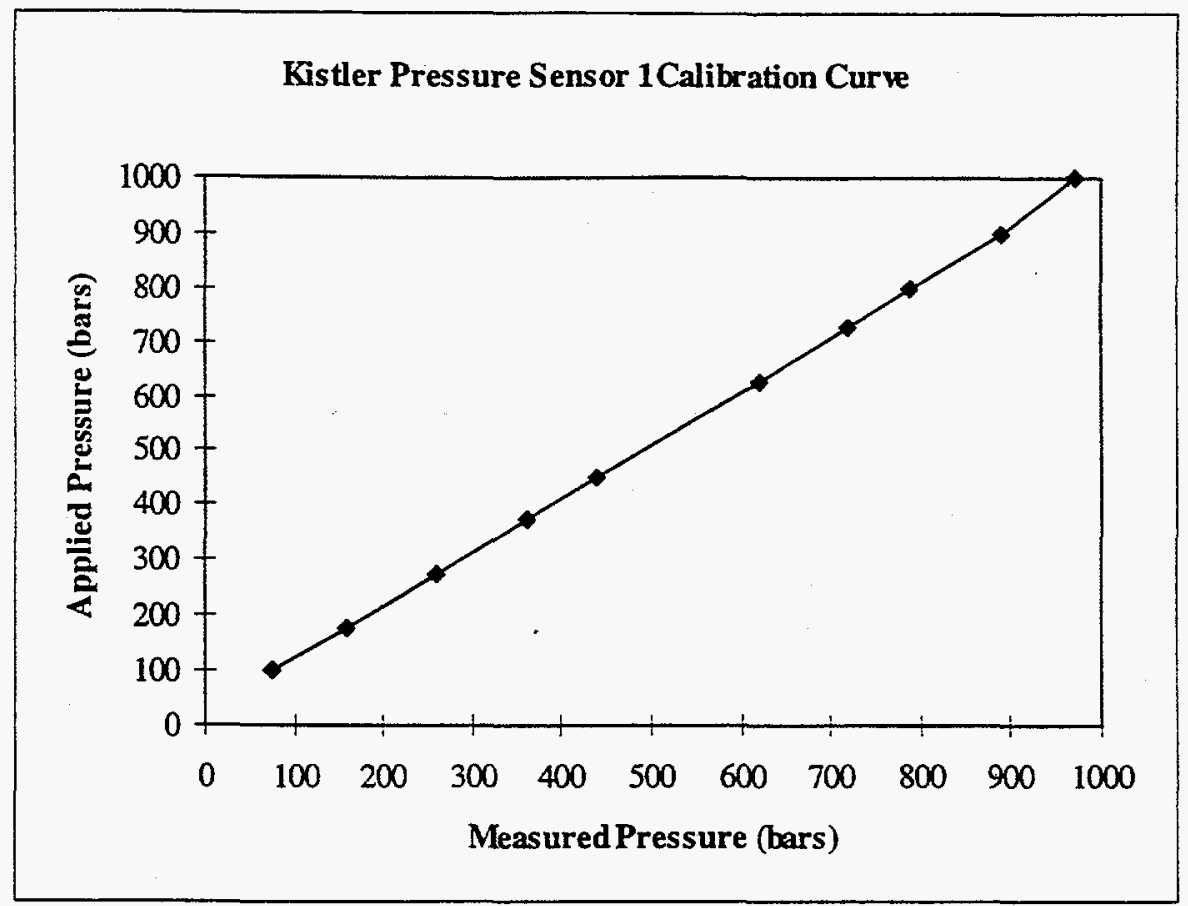

Figure 3.2 Kistler pressure sensor 1 calibration curve [15] ( $1 \mathrm{bar}=0.101 \mathrm{Mpa})$

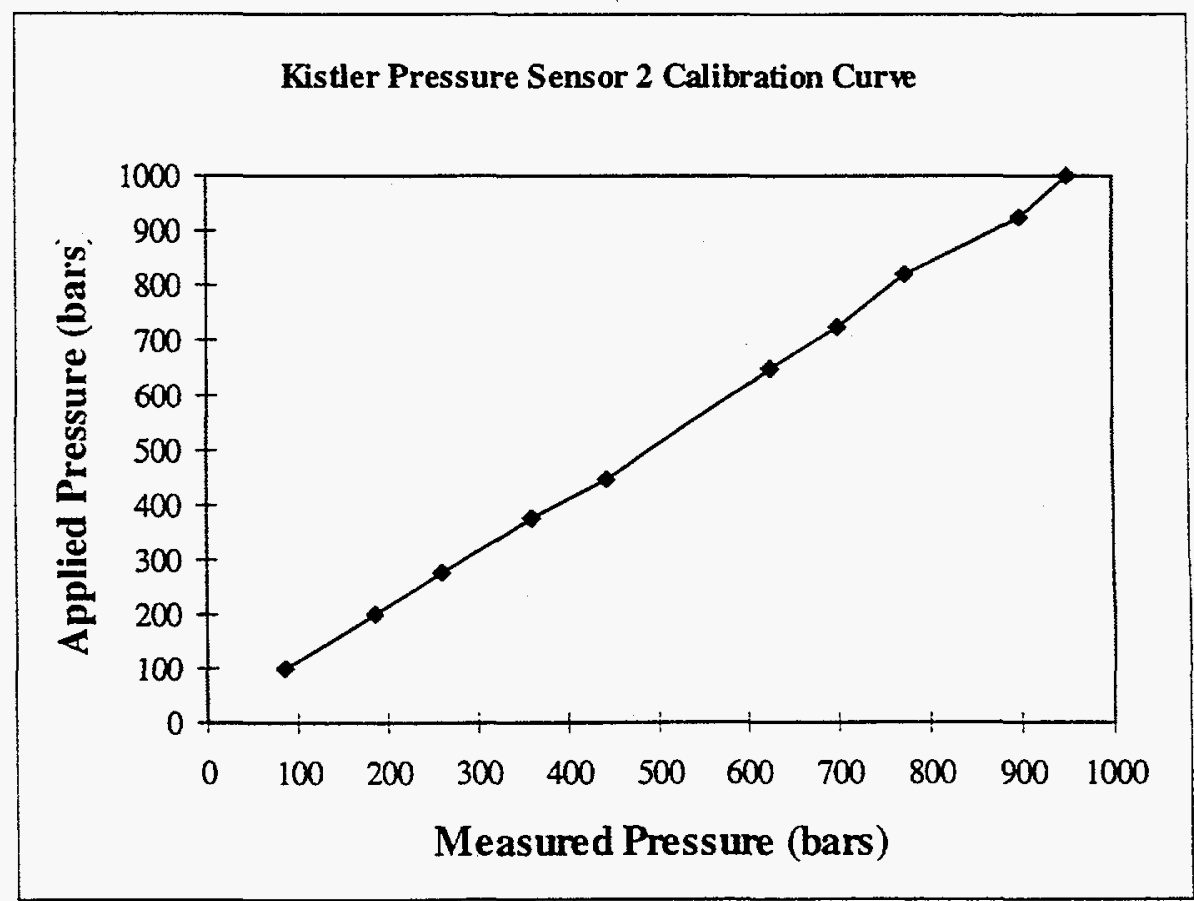

Figure 3.3 Kistler pressure sensor 2 calibration curve [15] ( $1 \mathrm{bar}=0.101 \mathrm{Mpa})$ 


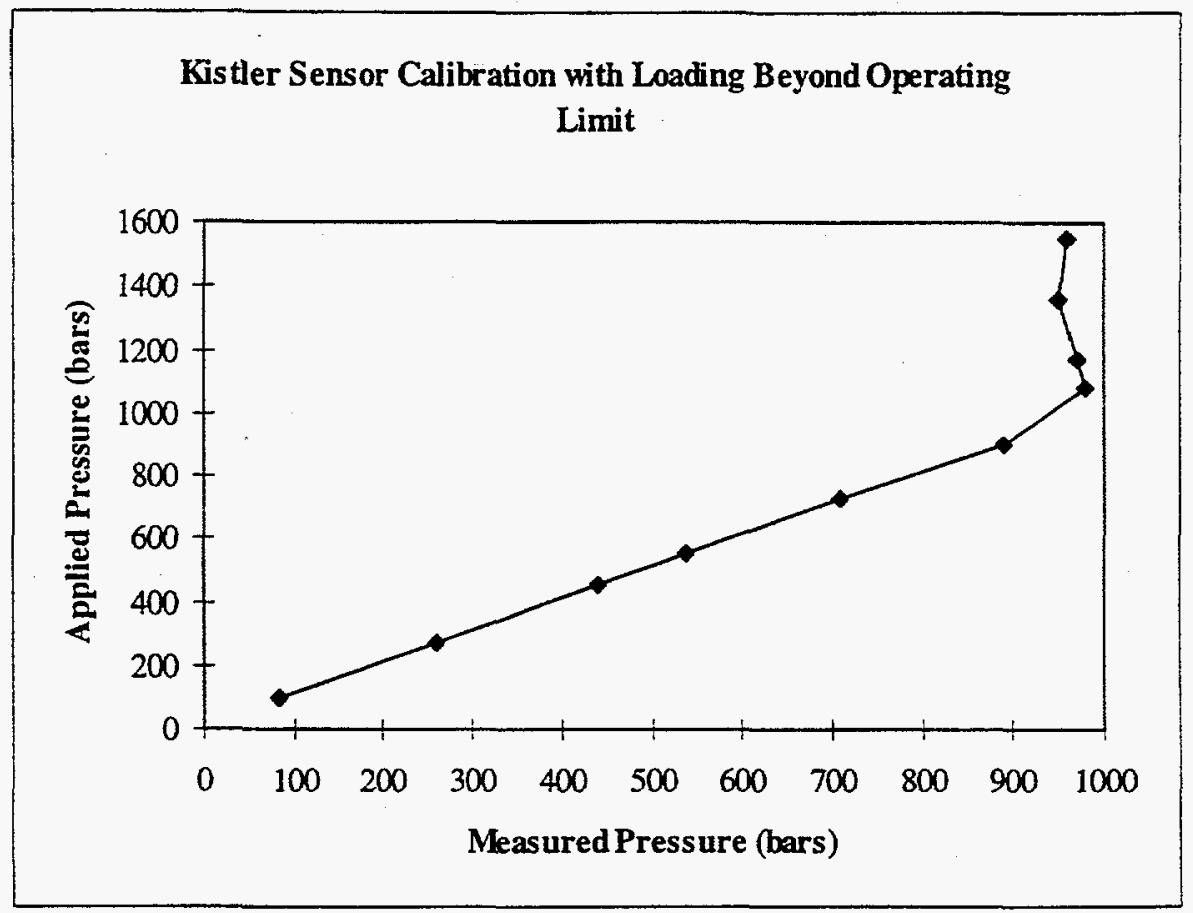

Figure 3.4 Calibration loading beyond configured operating limits [21] $(1 \mathrm{bar}=0.101 \mathrm{Mpa})$

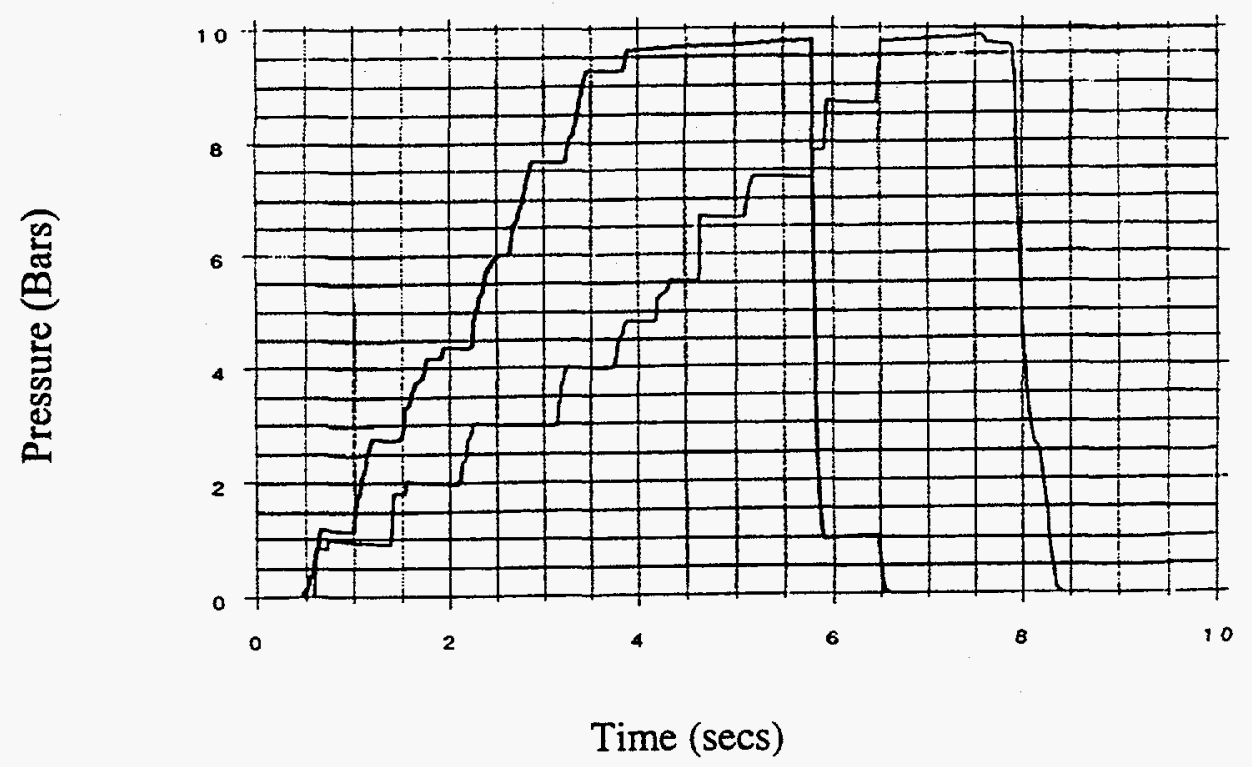

Figure 3.5 Dynamic calibration curve of Kistler pressure sensors [15] (The darker line is sensor $1,1 \mathrm{bar}=0.101 \mathrm{Mpa}$ ) 


\subsection{EXPERIMENT SET-UP FOR OSU DIE CASTING CAMPAIGN [15]}

The die casting machine used for the OSU campaign was a Buhler H-250SC system located in the Manufacturing Laboratory of the Engineering Research Center for Net Shape Manufacturing (ERC/NSM) at The Ohio State University. The technical specifications of Buhler $\mathrm{H}-250 \mathrm{SC}$ are listed in APPENDIX B. The Buhler SC machine has an improved shot control system and the ability to collect plunger position-time data used to interpret the die cavity filling and solidification phenomena. The temperature and pressure versus time records to be taken from the die cavity sensors were synchronized with the plunger position-time record and the cylinder hydraulic pressure-time record taken directly from the Buhler die casting machine. The selection of a die casting geometry and the associated die is an important factor in the evaluation of the process variables and the sensors measuring them. The die casting die was provided by OSU ERC/NSM and had been used in previous research. Its dimensions and configurations allowed it to be modified to install these sensors. A drawing of the diecasting, called the "Wall Die Casting", is shown in Figure 3.6. The advantages of this selection for this study are:

1. the presence of a relatively flat, uniform thickness gate area, which is preferred for the location of opposing temperature probes for an accurate measurement of the gate freezing time,

2. the availability of flat, uniform thickness regions in the casting for the location of pressure sensors and thermal probes, 
3. the convenient location of vents which allow the placement of vent flow sensors,

4. the presence of walls which allow for assessing the effect of the process variables on the quality of the casting in the blind (unvented) wall area versus the ventable areas,

5. the diecasting size and shape which allow for easy radiographic determination of porosity distribution and Archimedes' density measurements.

For the campaign at OSU ERC/NSM, four temperature probes (two on opposing sides of the gate, and two on opposing sides of the pressure sensors) and two pressure probes were used at the locations indicated in Figure 3.7. The thickness of the gate was 0.08 inch and the gate area was $0.32 \mathrm{inch}^{2}$. The thickness of wall was 0.20 inch. The operation variables decided for the chosen alloy, die and machine is provided in APPENDIX C. 11.05 inch $^{3}$ of $\mathrm{Al}$ alloy 390 melt was injected into the die cavity at a gate velocity of $1400 \mathrm{inch} / \mathrm{sec}$ and at an injection pressure of 70.64 psi to achieve a cavity fill time $12.1 \mathrm{~ms}$. A looking force of $63,505 \mathrm{lbs}$ was required to counter the intensification pressure of $1413 \mathrm{psi} . \mathrm{A} \mathrm{PQ}^{2}$ analysis was performed and a flow rate $504 \mathrm{inch}^{3} / \mathrm{sec}$ at the required injection pressure was decided for a plunger diameter of 19.37 inches as shown in APPENDIX D. The output of each sensor was collected using computer based data acquisition system. The frequency of data collection was rather high because most of the die casting events, such as cavity filling, pressure intensification, and vent exhausting, occur in time frames of tens of milliseconds. 

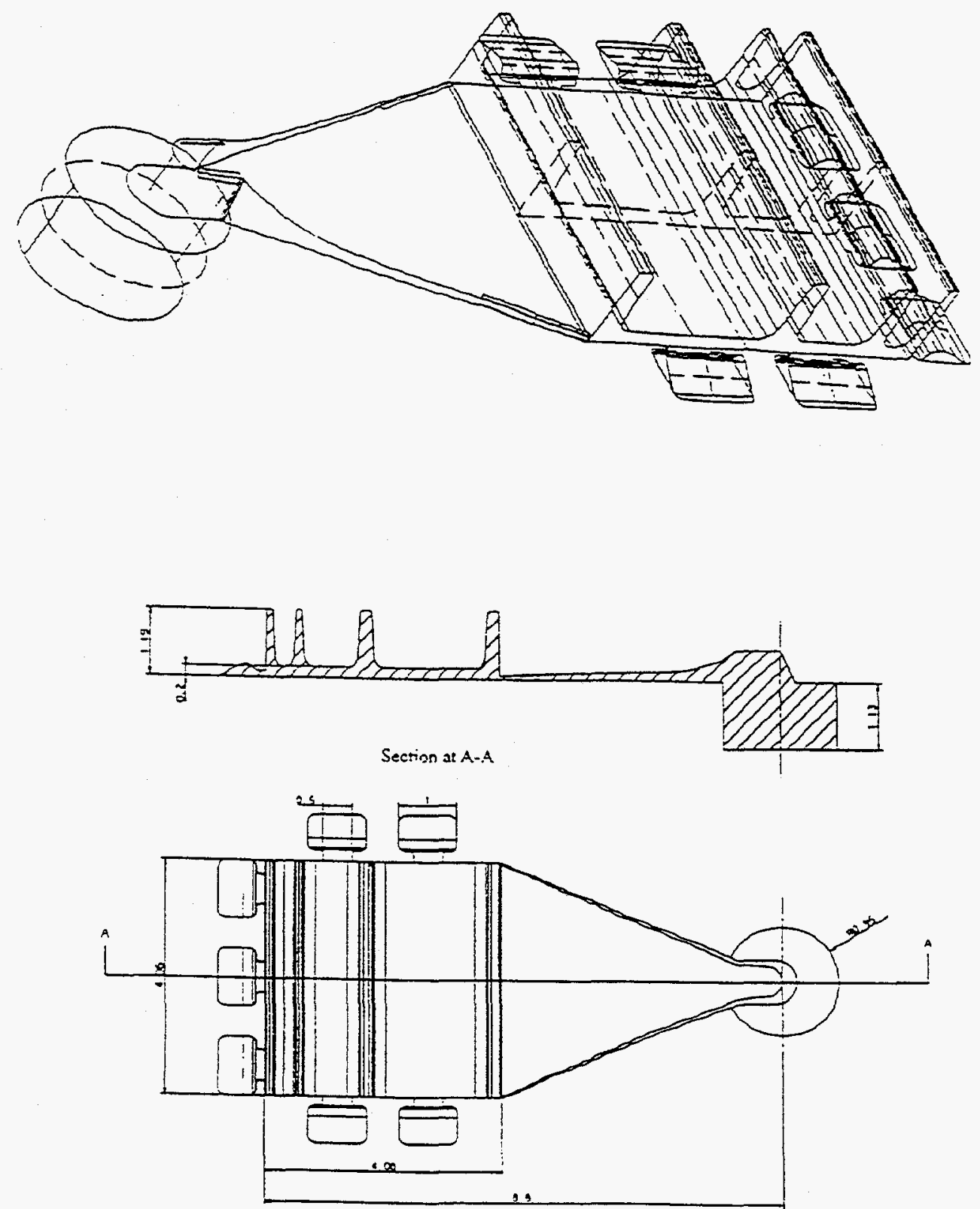

Figure 3.6 Wall die casting for OSU die casting campaign [15] 


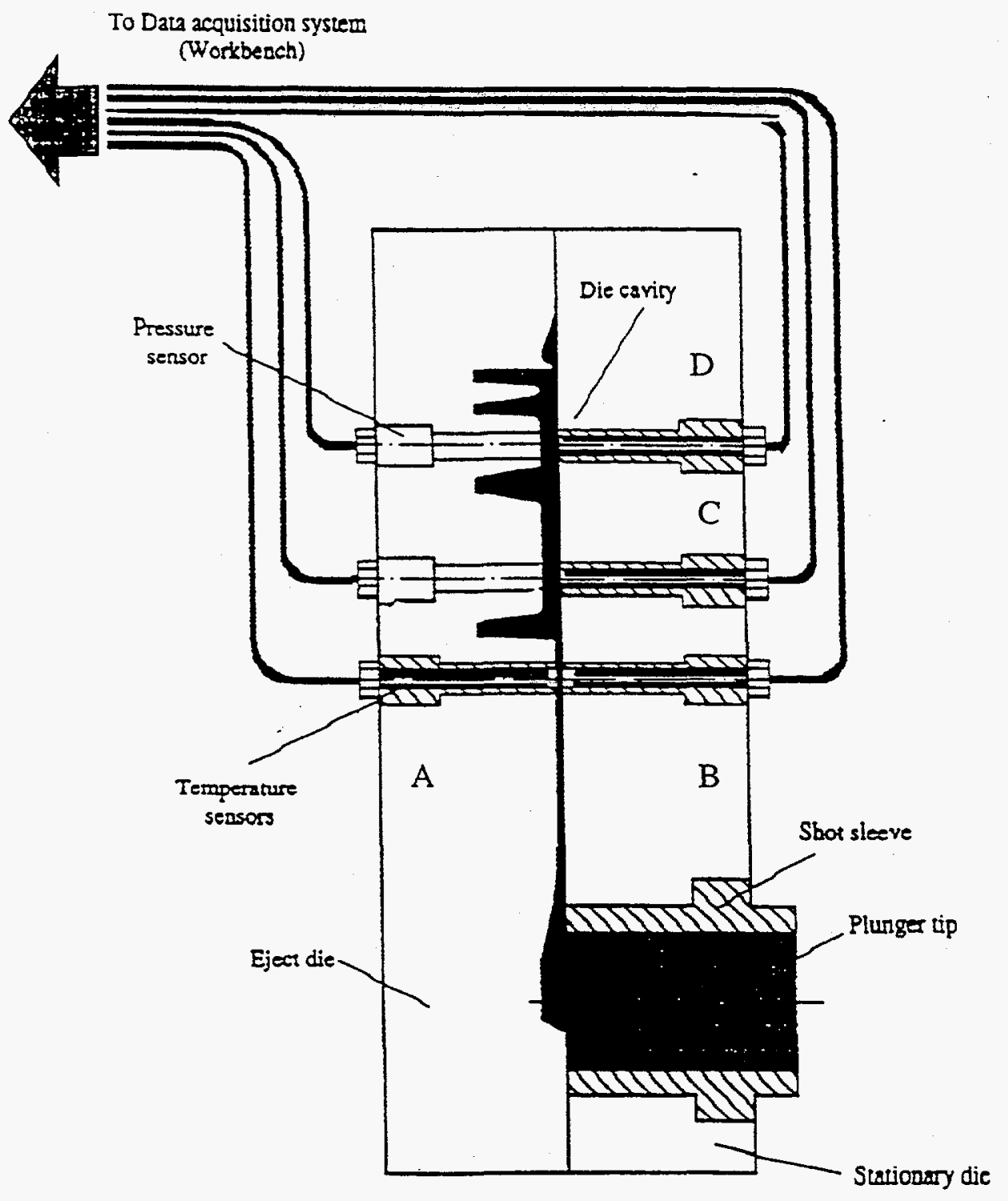

Figure 3.7 Locations of pressure sensors and thermocouple probes [5] 


\subsection{RESULTS FROM OSU ERC/NSM CAMPAIGN AND DISCUSSION}

A die casting campaign was conducted on the Buhler H-250SC die casting machine using the wall die with the pressure and thermal probes installed. The machine was programmed according to the results of the machine set-up analysis. Because of shot sleeve to plunger tip friction, no intensification pressure was applied and the injection pressure was set at 200 bars, not the calculated value. Since the machine was run in the manual mode, the cycle time is not consistent from shot to shot, a quasi steady state condition in the dies was never reached. The data shown below are for the same shot.

The time that the melt entered into the cavity from the gate can be identified when the thermocouples at the gate increased in temperature. The freezing time of the gate can be estimated by the time that the temperature reached a peak and started to decay. This reason is that there was no latent heat left at that time to be transferred into the die. The observed gate freezing time is 0.4 second. The calculated freezing time of 0.45 second was obtained using a one-dimensional-finite-element-analysis program BINORM. The maximum temperature, associated with the local time to completed solidification. The freezing time was about 0.8 second at location $\mathrm{C}$ and 1.4 seconds at location D. It should be noticed that the location $\mathrm{D}$ is farther from the gate than location $\mathrm{C}$. The calculated freezing time of 1.5 seconds was obtained using BINORM analysis. 
Figure 3.8 compares the metal pressure calculated from the hydraulic pressure to the metal pressure measured by two Kistler direct pressure sensors. Both the Kistler sensor and machine hydraulic record indicated an impact pressure spike during the initial stage of metal injection. Then the metal pressure calculated from hydraulic pressure decayed with vibration to the programmed injection pressure of 200 bars (2940 psi) and remained relatively constant, while the metal pressures measured by pressure sensors continued to decrease with vibration until they reached zero. The freezing time at the locations of these pressure probes can be decided from the point where the pressure measured is zero. The pressures recorded by the pressure probes went to zero in 1.4 seconds and 1.1 seconds as illustrated in Figure 3.9 and Figure 3.10 respectively. The time to complete solidification determined from the pressure probes is fairly consistent with the time determined from the thermal probe and the calculated solidification time using BINORM. The little difference maybe due to the different response times of thermal probes and pressure probes and the limitation of the one dimensional finite element analysis program BINORM.

Generally, the agreement between the metal pressure based on the hydraulic record and the pressure sensors was relatively close because the size of the casting is small. Pressure records from pressure probes and hydraulic pressure reached their peak at same time. The large difference between the peak pressure measured by the in-cavity sensors and the hydraulic pressure during metal injection (0-50 millisecond) was attributed to the plunger tip sticking situation clearly. This demonstrated one of the 
benefits of the Kistler in-cavity pressure sensors. Without them, the reason for the large hydraulic pressure spike during injection (which caused significant flashing problems) would have been much more difficult to discover.

The pressures measured from pressure probes were about 200 bars when the gate froze at about 0.4 second according to the thermal record. After that the pressures from pressure probes continuously decreased due to the shrinkage from solidification. The vibration may be due to the control problem with the machine injection system. The frequency of the vibration is about $20 \mathrm{~Hz}$ in Figure 3.9 and Figure 3.10. 


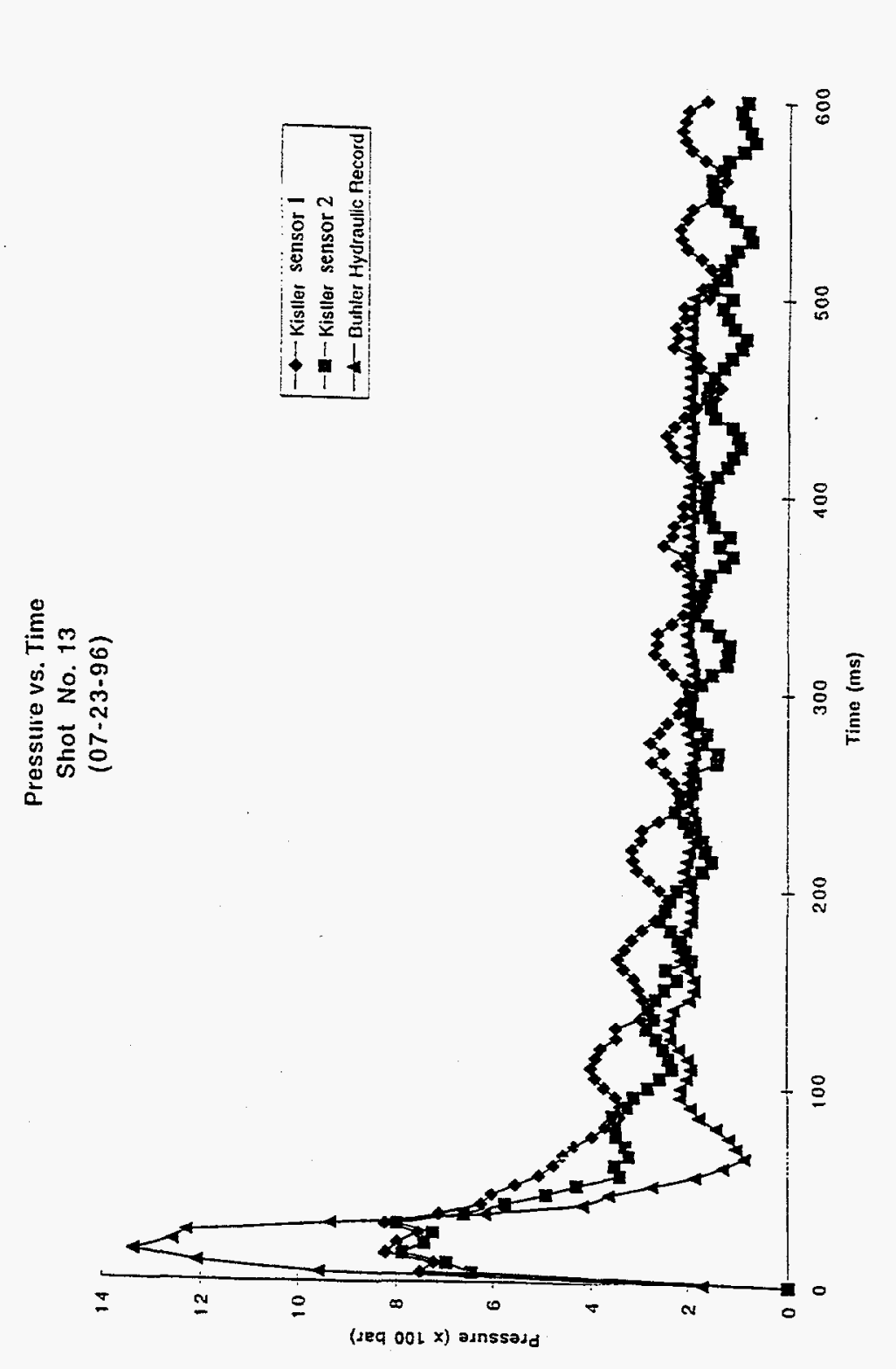

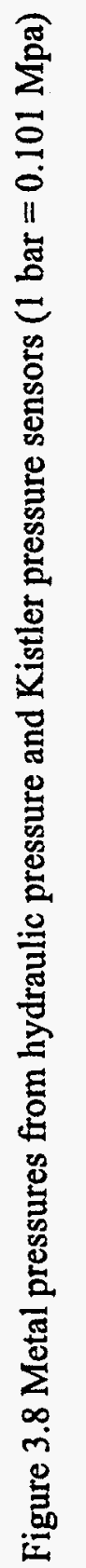




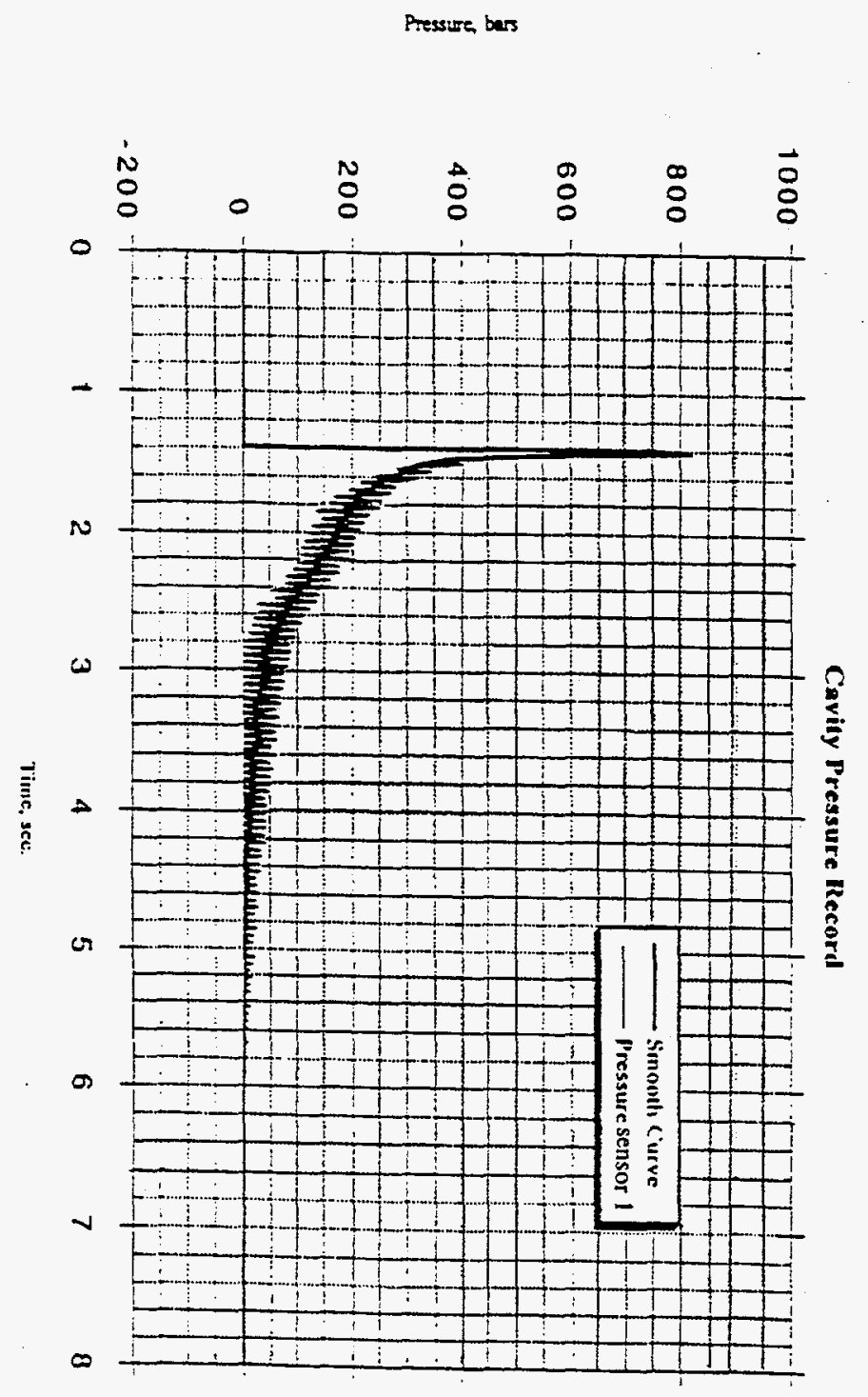




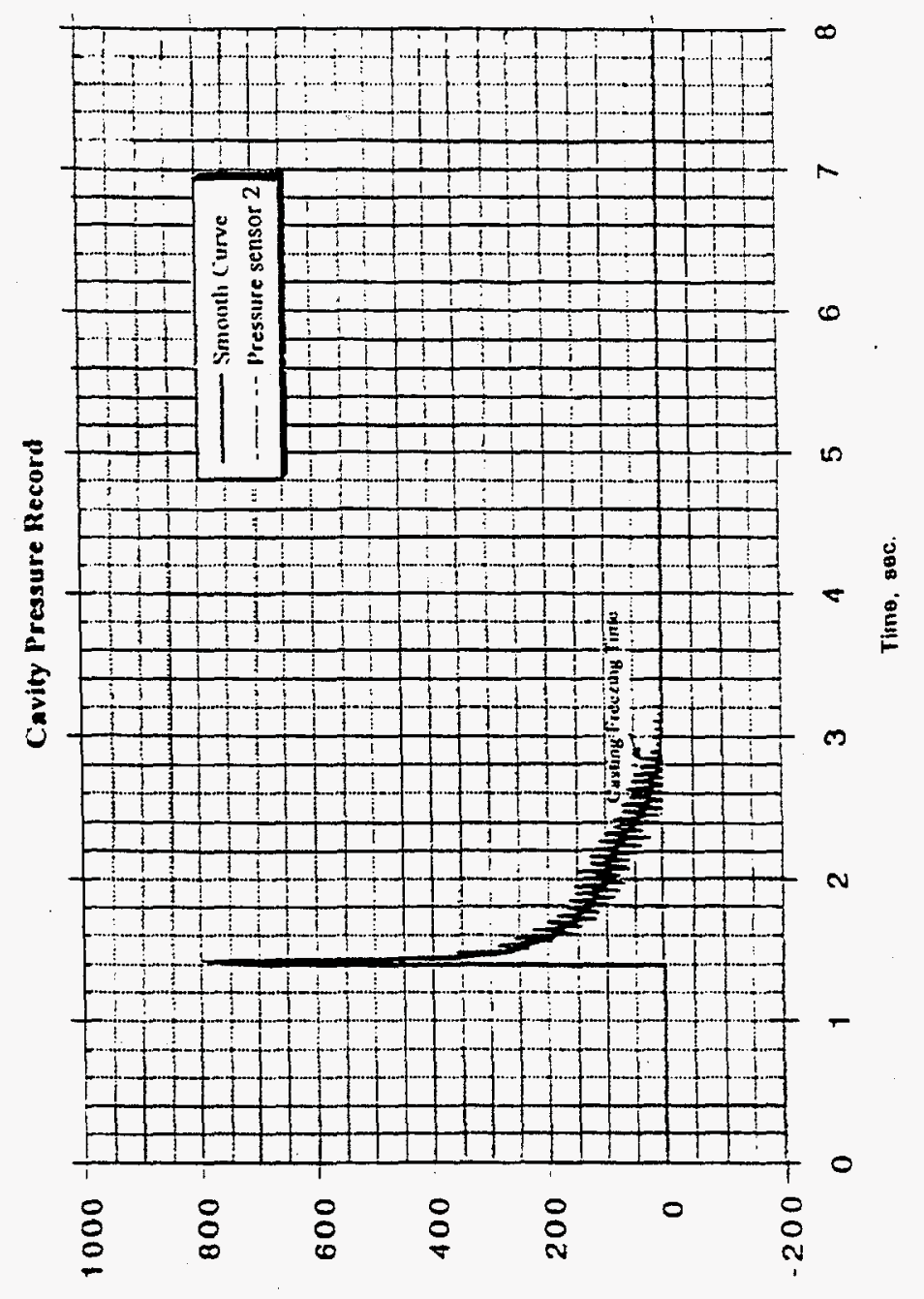

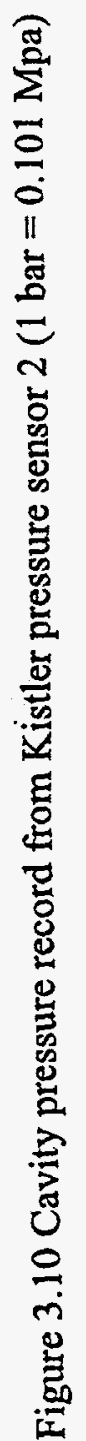

sroq 291504 


\subsection{RESULTS FROM GM CADC BEDFORD CAMPAIGN AND DISCUSSION}

A die casting campaign was conducted at GM Casting Advanced Development Center (CADC) at Bedford, Indiana using a 3000 tons (U.S.) Prince die casting system to die cast a rear axle transmission case. The trimmed transmission case weight ranges from 11.8 to $12.7 \mathrm{~kg}$. The die included a Kistler direct cavity pressure sensor on a sliding core located about $25.4 \mathrm{~cm}$ from the nearest ingate. More than fourteen individual thermocouples were installed at various locations throughout the die. All of the thermocouples were $1 / 2$ inches or more from the die-cavity interface. Shot profiles were acquired using the Pro-Manager program on the Prince Machine. The purpose of this beta site campaign was to evaluate the Kistler pressure sensor as a complementary and/or improved sensor to the shot profile record for better understanding die casting process and predicting product quality measurements, such as part weight, volume, and density.

The shot profile contains velocity, head pressure, and rod pressure versus position and time records. Position based sampling is used while the shot is moving. Time based sampling is used once the shot has slowed to an operator determined value which is referred to as the 'End of Shot Velocity'. Figure 3.11 illustrates a typical pressure record in die casting process shot profile. In the intensification stage, increasing pressure is exerted to force more melt into the die cavity to feed shrinkage and gas porosity. In the dwell stage, the metal is held under a pressure (intensification pressure) until the metal solidifies. 


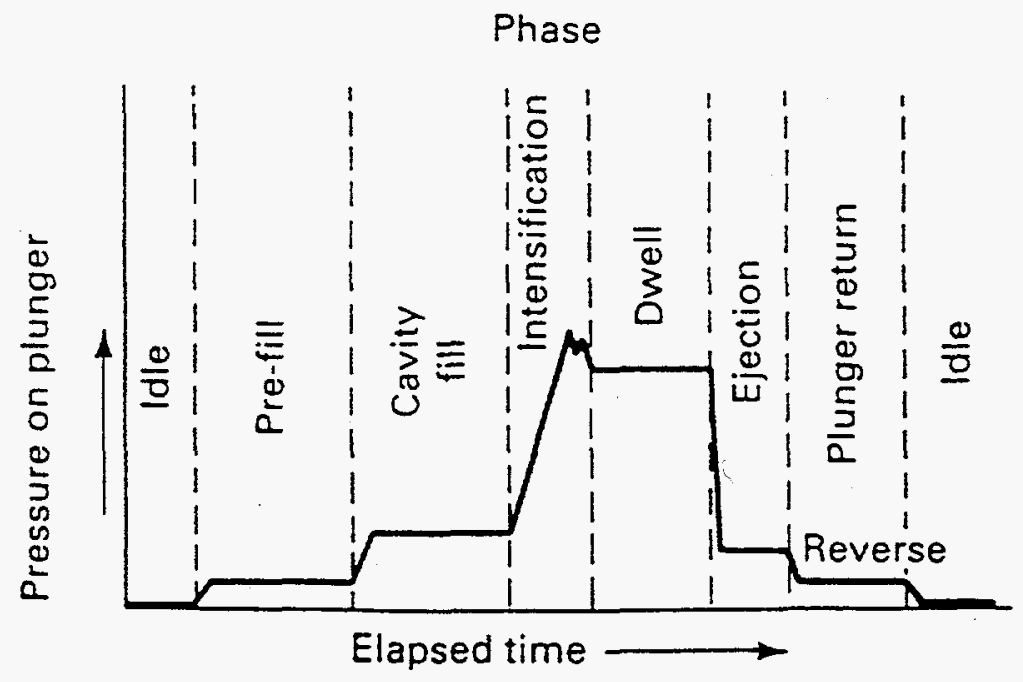

Figure 3.11 Plunger Pressure-Time Curve [1]

Only part of the pressure record, from the end of cavity fill, intensification, to dwell, will be analyzed. In the GM CADC campaign, 156 rear axle transmission cases were produced. The values of the process variables of earlier stages before intensification stage starts are relatively stable in 156 shots. Cavity fill pressures for all shots were set to about 4000 psi. The average, $\bar{X}$, and standard deviation, $\sigma$, of these process variables are listed in Table 3.1. The meanings of all the abbreviated names of process variables used in this thesis are[21]:

$P_{\text {final, } H}=$ final pressure (hydraulic), the average head pressure over a usersetable window after end of shot, where the position based shot profiles end

Slow $\mathrm{Vel}=$ slow velocity

Inter $\mathrm{Vel}=$ intermediate velocity 
Fast $\mathrm{Vel}=$ fast velocity

Act Ft Pos $=$ actual fast velocity start position

Vel Rise $=$ velocity rise time, the amount of time for the velocity to

change from the user defined start and end velocity

Pres Rise $=$ intensification pressure rise time, the amount of time for the head

pressure to rise to an operator set value

Fil time srt $=$ fill time start position

Fill time $=$ the time for the shot plunger to move from the fill time start position to the end of shot position

B_L = biscuit length

Inten Strk $=$ intensification stroke length

End Pos = end of shot position, where the shot has slowed to an operator

determined value and the time based sampling starts

End Vel = end of shot velocity, the velocity when the time based sampling starts

T_Sleeve $=$ the alloy temperature in shot sleeve

$\mathrm{T} \_$Ladle $=$the alloy temperature in ladle

\begin{tabular}{|c|c|c|c|c|c|c|}
\hline & $\begin{array}{l}\text { Slow Vel } \\
\text { (inch/sec) }\end{array}$ & $\begin{array}{l}\text { Inter Vel } \\
\text { (inch/sec) }\end{array}$ & $\begin{array}{c}\text { Fast Vel } \\
\text { (inch/sec) }\end{array}$ & $\begin{array}{l}\text { Act Ft Pos } \\
\text { (inch) }\end{array}$ & $\begin{array}{l}\text { Vel Rise } \\
\text { (ms) }\end{array}$ & $\begin{array}{c}\text { Fil time srt } \\
\text { (inch) }\end{array}$ \\
\hline$\overline{\bar{X}}$ & 10.0 & 24.9 & 98.1 & 27.41 & 15 & 26.76 \\
\hline$\sigma$ & 0.2 & 0.1 & 0.9 & 0.07 & 3 & 0.19 \\
\hline & $\begin{array}{l}\text { Fill time } \\
\text { (ms) }\end{array}$ & $\begin{array}{l}\text { End Pos } \\
\text { (inch) }\end{array}$ & $\begin{array}{l}\text { End Vel } \\
\text { (inch/sec) }\end{array}$ & $\begin{array}{c}\text { T_Sleeve } \\
\left({ }^{\circ} \mathrm{F}\right)\end{array}$ & $\begin{array}{c}T_{\text {T_Ladle }} \\
\left({ }^{\circ} \mathrm{F}\right)\end{array}$ & \\
\hline $\bar{X}$ & 154 & 39.46 & 61.1 & 1214.3 & 1251.7 & \\
\hline$\sigma$ & 7 & 0.19 & 4.2 & 5.6 & 5.1 & \\
\hline
\end{tabular}

Table 3.2 Average and standard deviation of some process variables of earlier stages before intensification starts 
The 156 shots were divided into six sets based on the hydraulic pressure levels used and the status of the die casting system. During the first set, consisting of shots No. 1 through No. 20, the die and shot sleeve system were heating up due to system start up, after which die casting system (die and shot sleeve) reached a thermal quasi-steady state. Figure 3.12 shows the temperatures from various thermocouples in the die at the time the die closed for each shot.

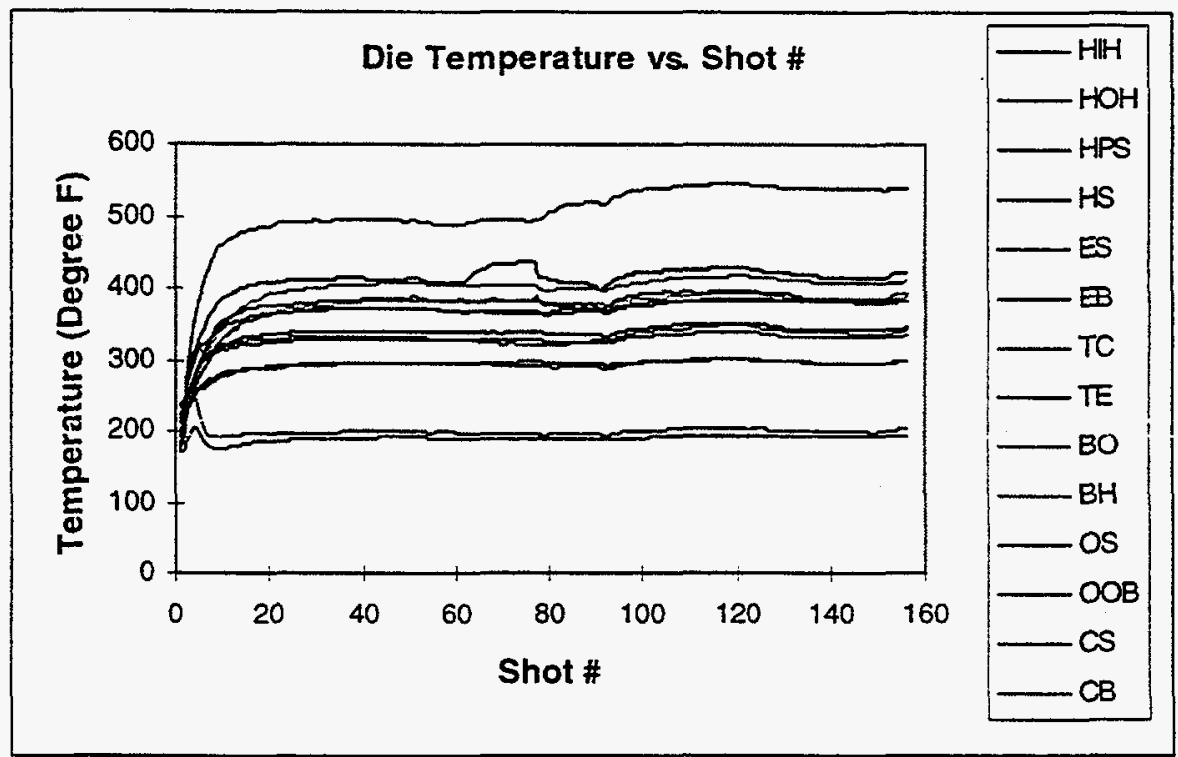

Figure 3.12 Temperatures at the time the die closed at different locations in the die for each shot

The die temperature at various locations remained relatively constant throughout the production campaign indicating that the system was in thermal quasi steady state. The temperature changes in two locations, which can be seen from the two highest temperature-time records from thermocouples $\mathrm{TC}$ and TE in Figure 3.12, may be attributed to variation in the local die spray to that region. 
In the first set, the hydraulic intensification pressures of shot No. 2, 3, 4 and 5 were 1300 psi (hydraulic) while the others were about $2500 \mathrm{psi}$ (hydraulic). In the second set (shots No. 21 through 50), the die was at thermal quasi steady state and the hydraulic intensification pressures were about 2500 psi (hydraulic). In the third set (shots No. 51 through 90), the hydraulic intensification pressures were about 1300 psi (hydraulic). In the forth set (shots No. 91 through 121), the intensification pressures were about 3900 psi (hydraulic). To check the reproducibility of the die casting system and experiment, the intensification pressures were again about 2500 psi (hydraulic) for the fifth set (shots No.122 through 151). The hydraulic pressure was increased in the sixth set (shots No. 152 through 156) to investigate the onset of flashing. The final pressure (hydraulic) of each shot is plotted in Figure 3.13.

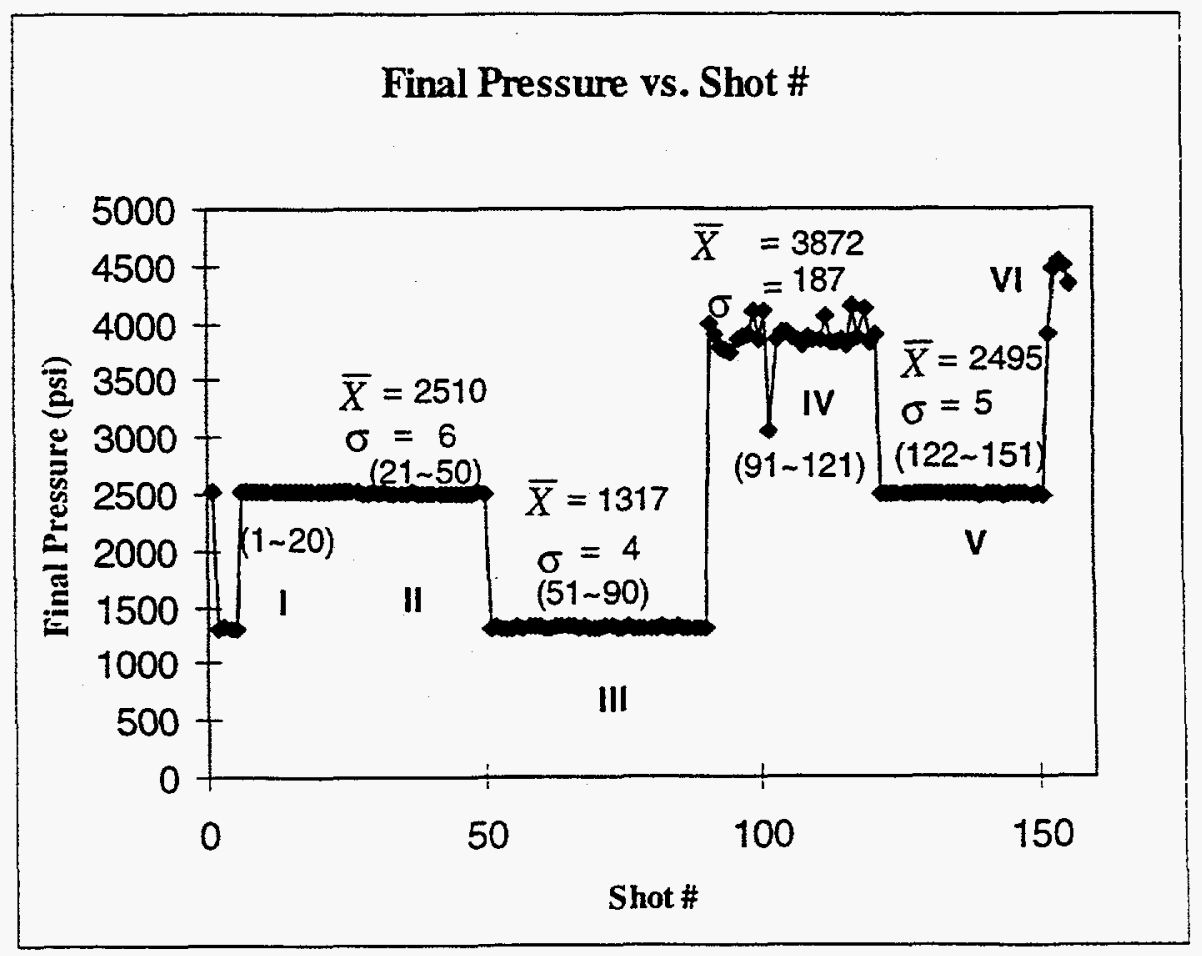

Figure 3.13 The final pressures (hydraulic) of each shot 
As shown in Figure 3.13 the average final pressure was $2510,1317,3872$ and 2495 psi for sets II, III, IV, and V, respectively. Standard deviations were 4 to 6 psi for sets II, III, IV, and 187 psi for set IV.

To evaluate the behavior the Kistler pressure probe, six shot profiles were selected . from each of sets of $I, I, I V$ and V. The first seven shots (shots No.1 through 7) and the last five shots (shots No.152 through 156) were also selected. The criteria for the selection in four sets (from set II through set V) is based on the values of intensification stroke, two with smallest values, two with medium values and two with the largest values. The hydraulic pressure of the shot profiles for these shots was converted to metal pressure by multiplying by the ratio of cross section areas of the plunger tip and the rod. The ratio used was 3.64. The pressure unit used was pounds per square inch (psi), and the pressure measured from Kistler pressure sensor (Kistler pressure) was converted from volts to pounds per square inch (psi). Both the hydraulic and Kistler pressure-time records were re-plotted using a Microsoft Excel spreadsheet. The plots of the pressure difference between the metal pressure converted from hydraulic pressure record and the pressure measured using Kistler pressure sensor were also made using the data of above re-plotted pressure-time records (pressure difference $=$ the metal pressure converted from hydraulic pressure minus the Kistler pressure). 
Conceptually, several possible pressure difference curves could occur. Figure 3.14 illustrates these situations and the following are the associated explanations.

1. For case $\mathrm{A}$, the Kistler pressure reaches the cavity filling pressure and remains zero when the Kistler pressure equals the metal pressure from hydraulic pressure

2. For case $B$, the pressure difference increases when the intensification starts, since the metal pressure from hydraulic pressure is larger than the Kistler pressure

3. For case $\mathrm{C}$, the intensification starts as soon as the Kistler pressure reaches the cavity filling pressure.

4. For case $D$, before the Kistler pressure reaches the cavity filling pressure the intensification starts and the metal pressure from the hydraulic pressure is larger than the Kistler pressure.

5. For case $\mathrm{E}$, in some region of the pressure difference curve the pressure difference is negative, where Kistler pressure is larger than the metal pressure from hydraulic pressure. This can be explained by impact occuring in the die cavity. During the cavity filling, the moving parts of the system contain considerable kinetic energy. The hydraulic fluid, hydraulic cylinder piston, plunger, plunger rod and molten metal all have mass and are moving at high speeds. When the cavity fills, these masses must stop moving. The energy is dissipated by causing higher pressure in the die cavity and creating a pressure spike or flashing [17].

6. For case $F$, due to larger intensification pressure, the pressure difference is larger than that with smaller intensification pressure. 


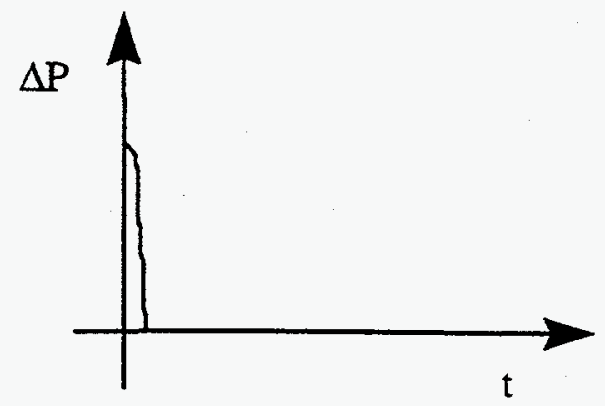

Case A: No impact

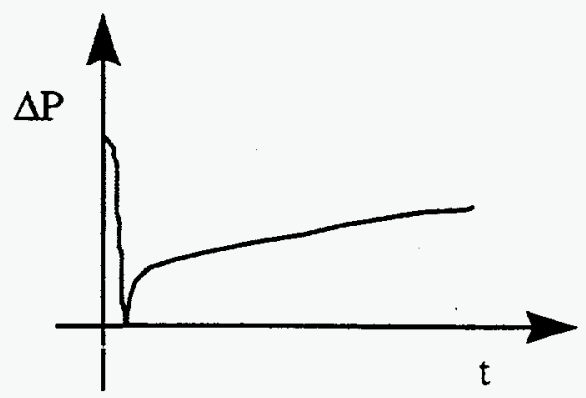

Case C: Intensification, no impact

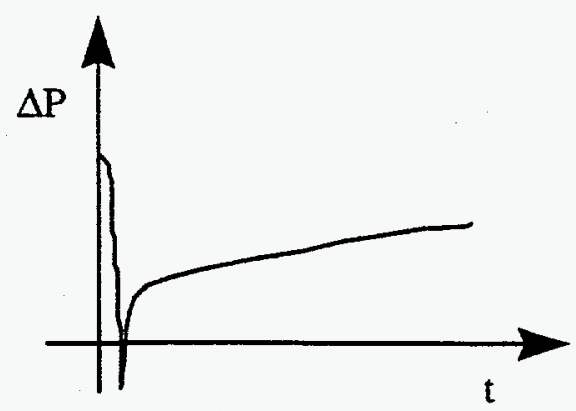

Case E:Impact, intensification

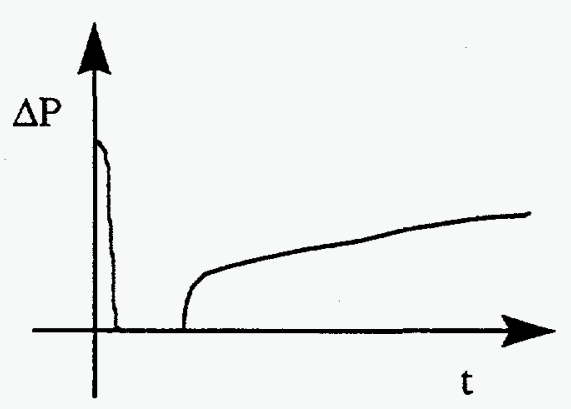

Case B: No impact, delayed intensification

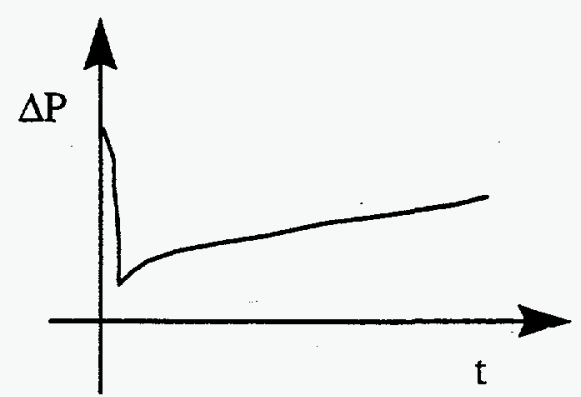

Case D: No impact, earlier intensification

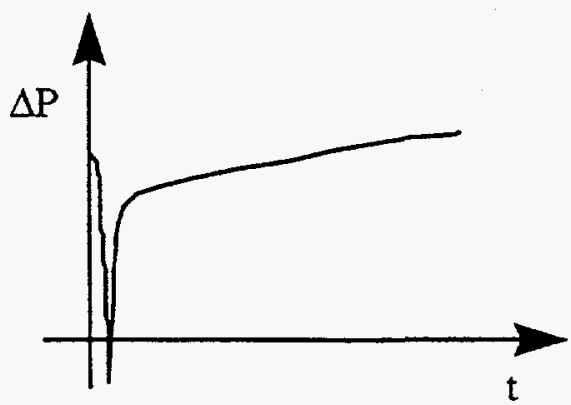

Case F:Impact, higher intensification pressure

Figure 3.14 Basic types of pressure difference curves 
Figures 3.15 through 3.20 show the pressure and pressure difference records of three different experimental intensification pressures. Flashing of the die was not observed in these three shots.

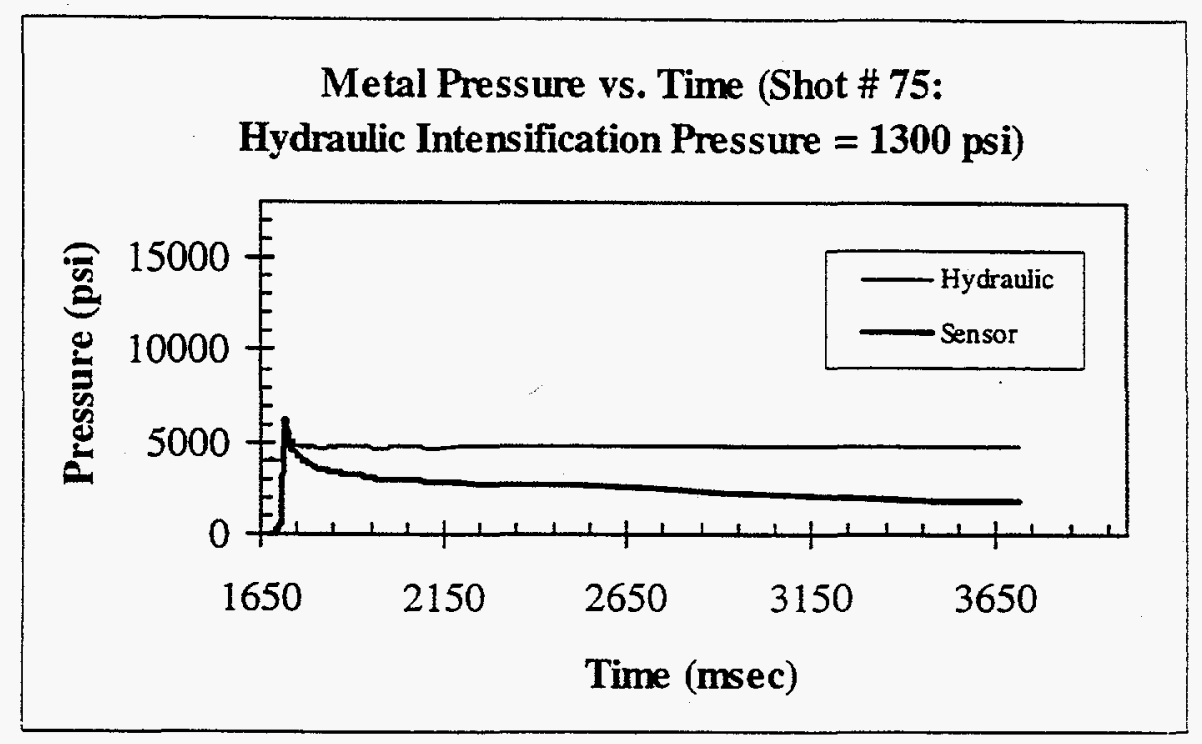

Figure 3.15 Pressure records of shot No. 75

In Figure 3.15, spikes induced from impact that occur on both pressure curves are noticeable. This fact is further confirmed by the corresponding pressure difference record as shown in Figure 3.16, where the value of the minimum pressure difference is negative.

In pressure record of shot No. 41, Figure 3.17, a small spike can be noticed on the Kistler pressure curve. The fact that impact occurred in the die cavity is also confirmed by its corresponding pressure difference record (Figure 3.18), even if no spike can be seen on pressure curve from hydraulic pressure. 


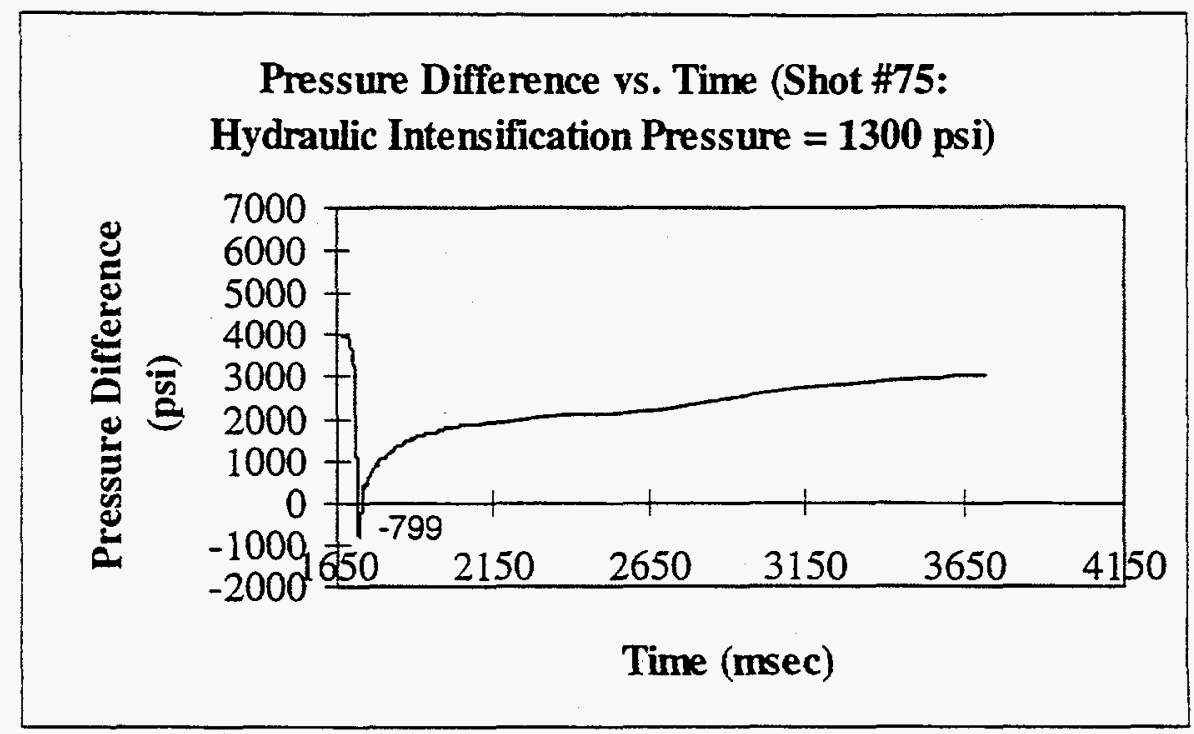

Figure 3.16 Pressure difference record of shot No. 75

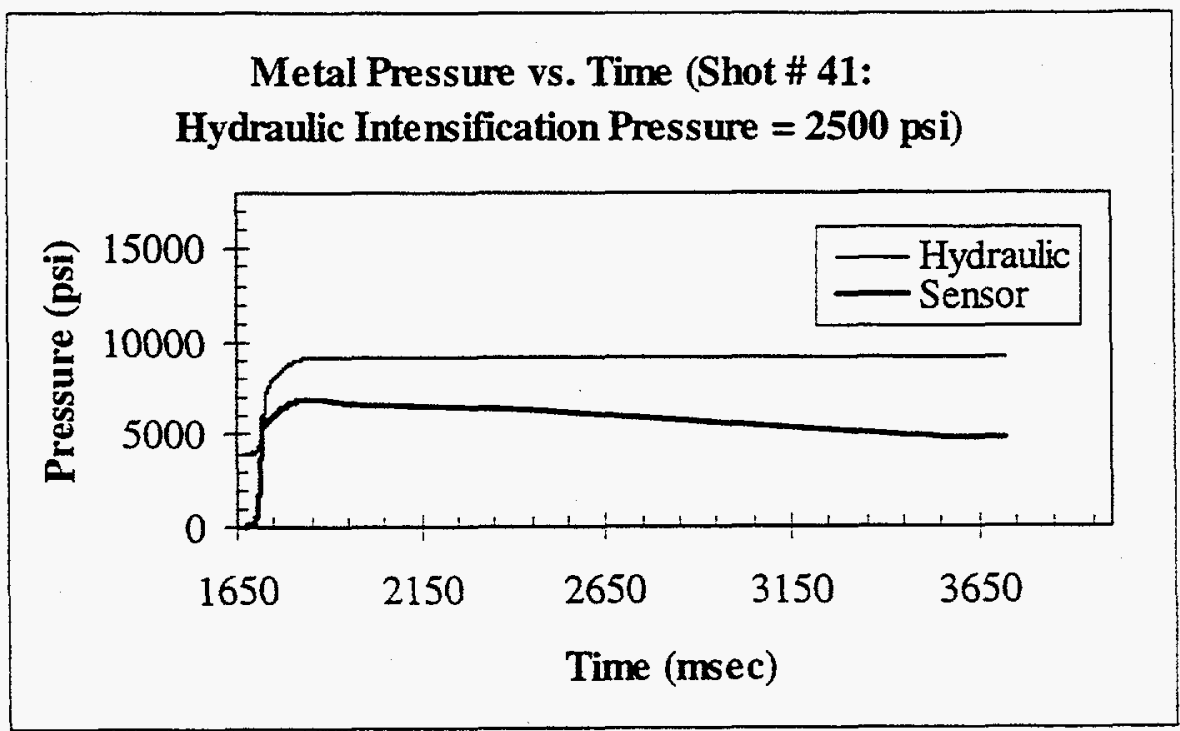

Figure 3.17 Pressure records of shot No. 41 


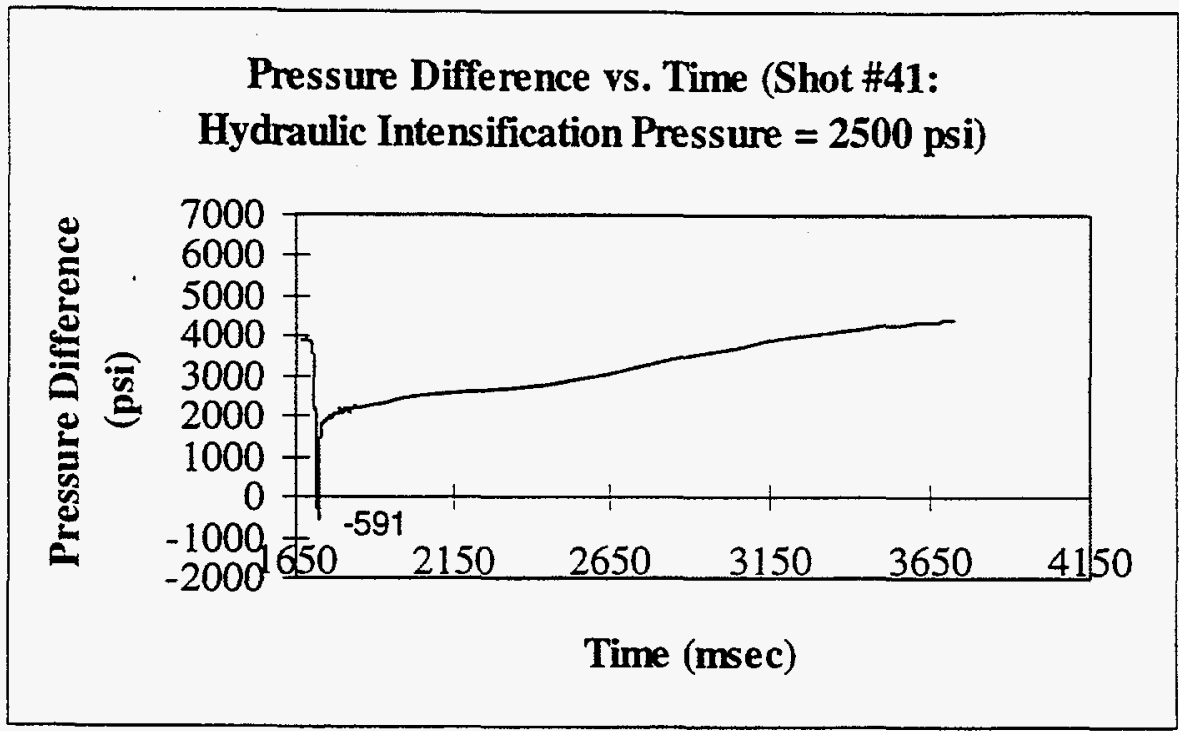

Figure 3.18 Pressure difference record of shot No. 41

Because of the higher intensification pressure, the pressure difference after the impact with higher intensification pressure is larger than that with lower intensification pressure. This is also confirmed by comparing the pressure difference curves of shot \#41 and shot \# 75 .

For shot \# 97 in Figure 3.19, spikes induced from impact that occur on both pressure curves are noticeable. This fact is further confirmed by the corresponding pressure difference record as shown in Figure 3.20, where the value of the minimum pressure difference is negative. In Figure 3.20 the metal pressure from hydraulic pressure record takes longer time to reach the desired intensification pressure than shot \# 41 and shot \# 75. The Kistler pressure also takes longer time to reach the peak value. The pressure difference of shot \# 97 just after impact is smaller than that of shot \# 41 . This 
can be explained by the fact that the pressure rise time of the hydraulic pressure of shot \# 97 are larger than that of shot \# 41 .

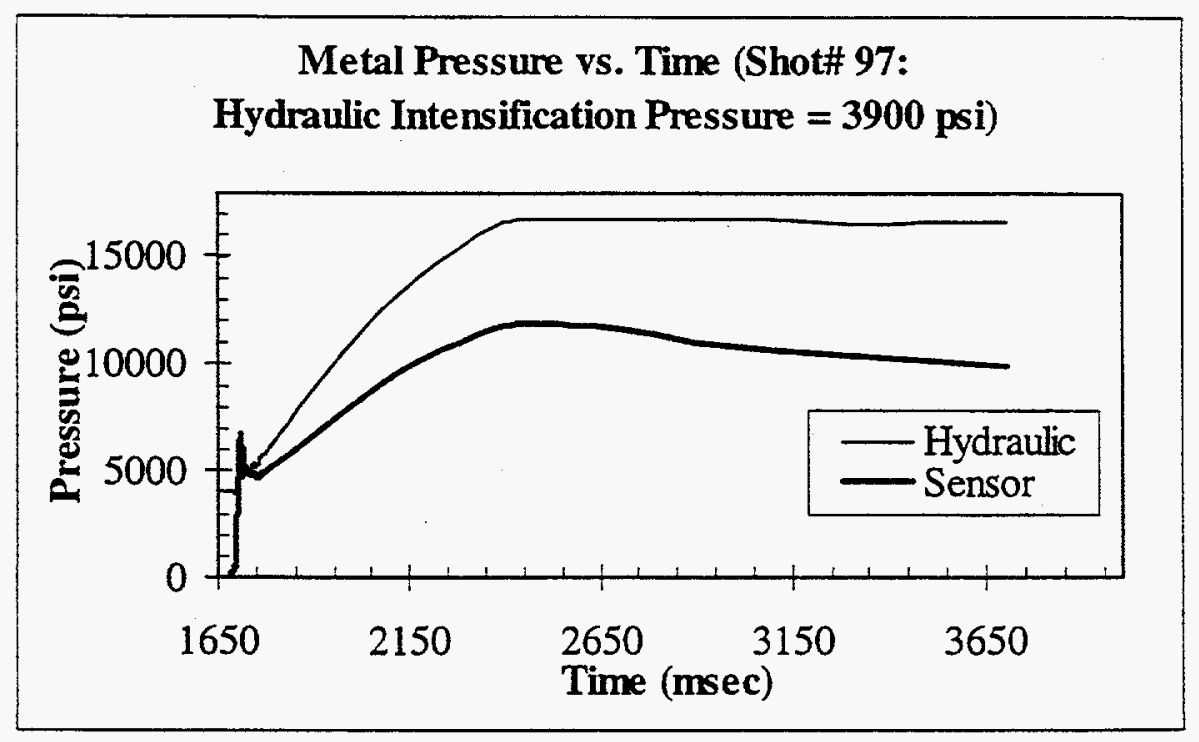

Figure 3.19 Pressure records of shot No. 97

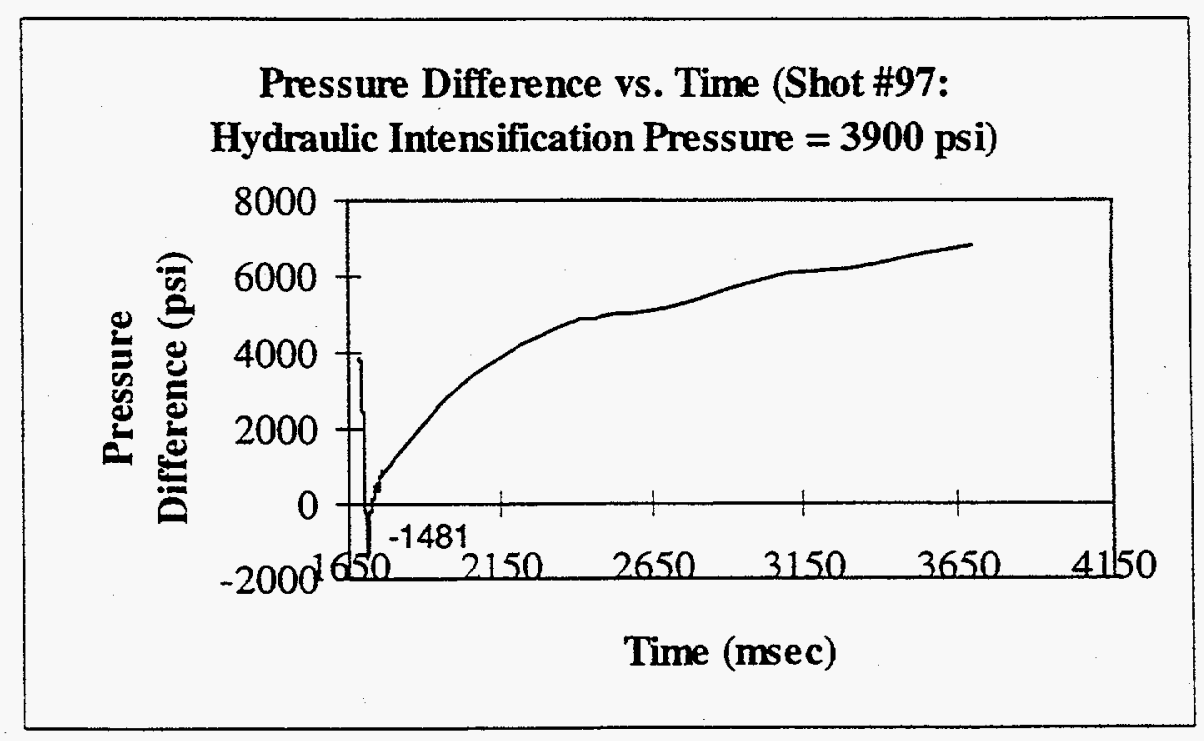

Figure 3.20 Pressure difference record of shot No. 97 
Several parameters such as the pressure rise time of the hydraulic pressure, $\mathrm{PRt} H$, pressure rise time of the Kistler pressure, PRt $\mathrm{K}$, maximum metal pressure from the hydraulic pressure, $\mathrm{P}_{\mathrm{H}, \max }$, maximum Kistler pressure, $\mathrm{P}_{\mathrm{K}}, \max$, impact pressure or minimum pressure difference, $P_{\text {impact, }}$, pressure difference $100 \mathrm{~ms}$ after impact, $\Delta \mathrm{P}_{100 \mathrm{~ms}}$ and pressure difference $1900 \mathrm{~ms}$ after impact, $\Delta \mathrm{P}_{1900 \mathrm{~ms}}$ were taken from pressure records to analyze the performance of the Kistler direct cavity pressure probe with respect to the hydraulic pressure records. The following are the list of various pressure parameters and related variables used in this thesis:

$P_{K, 2000 m s}=$ pressure value measured from Kistler pressure sensor at $2000 \mathrm{~ms}$ after end of shot or time based sampling starts

$\mathrm{P}_{\mathrm{H}, \max }=$ the maximum metal pressure converted from hydraulic pressure

$t_{H, \max }=$ the time of the $\mathrm{P}_{\mathrm{H}, \max }$ when it was measured

$\mathrm{P}_{\mathrm{K}, \max }=$ the maximum pressure measured from Kistler pressure sensor

$t_{K, \max }=$ the time of the $P_{K, \max }$ when it was measured

$\mathrm{P}_{\mathrm{H} \text {, impact }}=$ the metal pressure converted from hydraulic pressure when the impact

occurred

$P_{K, \text { impact }}=$ the pressure measured from Kistler pressure sensor when the impact occurred

$P_{\text {impact }}=P_{H, \text { impact }}-P_{K, \text { impact }}$

$t_{\text {impact }}=$ the time when the impact occurred

$\Delta P_{100 \mathrm{~ms}}=$ pressure difference at $100 \mathrm{~ms}$ after minimum pressure difference 
$\Delta \mathrm{P}_{1900 \mathrm{~ms}}=$ pressure difference at $1900 \mathrm{~ms}$ after minimum pressure difference PRt $\mathrm{H}=$ pressure rise time of the hydraulic pressure is the time to take to go from $10 \%$ of the pressure range (from cavity filling pressure to maximum hydraulic pressure) to $90 \%$ of the pressure range

PRt $\mathrm{K}=$ pressure rise time of the pressure measured from Kistler pressure sensor, or Kistler pressure, is the time to take to go from $10 \%$ of the pressure range (from zero to maximum Kistler pressure) to $90 \%$ of the pressure range

All the data collected are in APPENDIX E.

The maximum metal pressures from the hydraulic pressure records of selected shots are plotted in Figure 3.21. As shown in the figure the average maximum metal pressure from the hydraulic pressure was $9223,5626,16758$ and 9425 psi for sets II, III IV and V, respectively. The standard deviations are 76 psi and 59 psi for 1300 psi (hydraulic) set and 3900 psi (hydraulic) set, respectively. For the two 2500 psi (hydraulic) sets, the standard deviation values of the set $\Pi$ and set $V$ are 35 psi and 281 psi respectively. The fact that the standard deviation of set $\mathrm{V}$ is so high and the discontinuity occurs in set V can not be explained by the final pressure in Figure 3.22. 


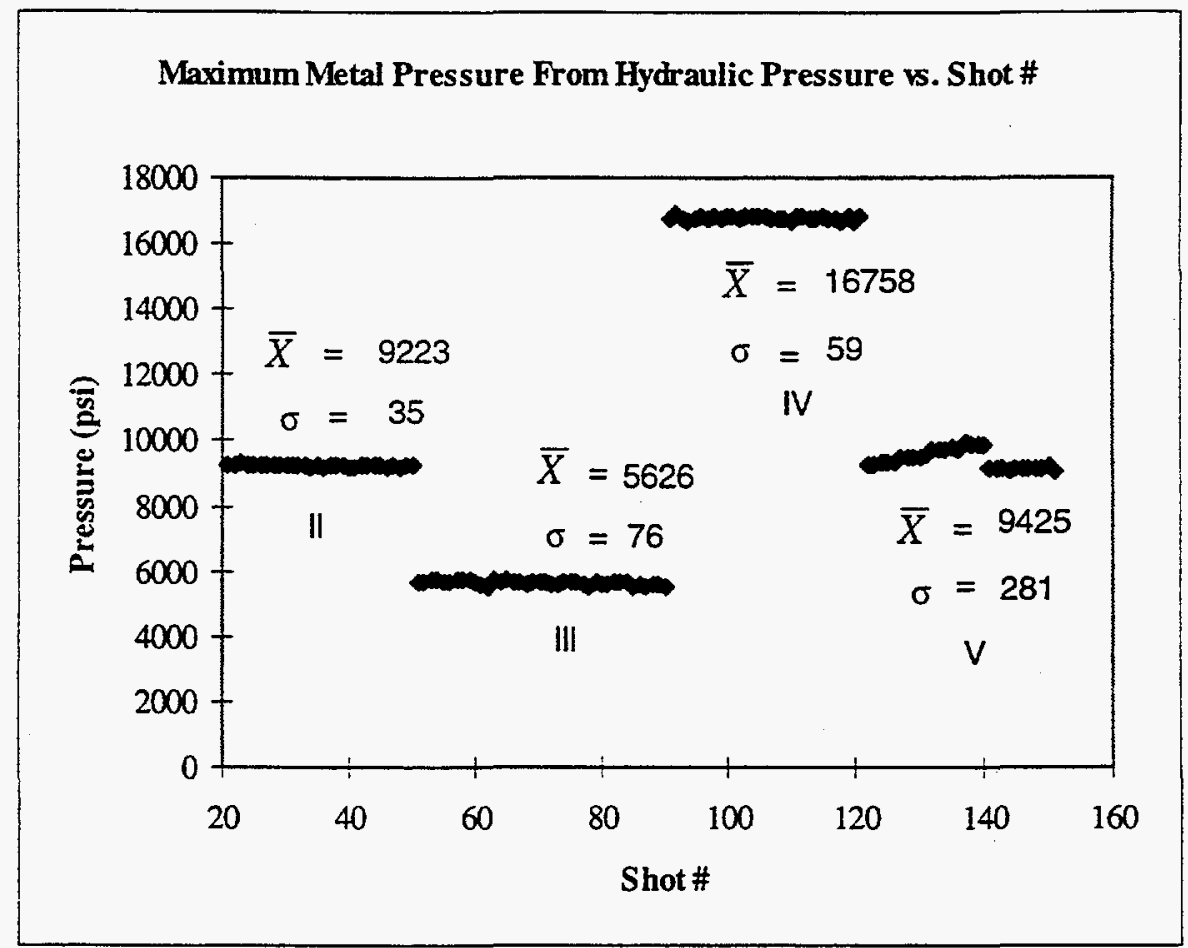

Figure 3.21 The maximum metal pressure pressures from the hydraulic pressure of selected shots

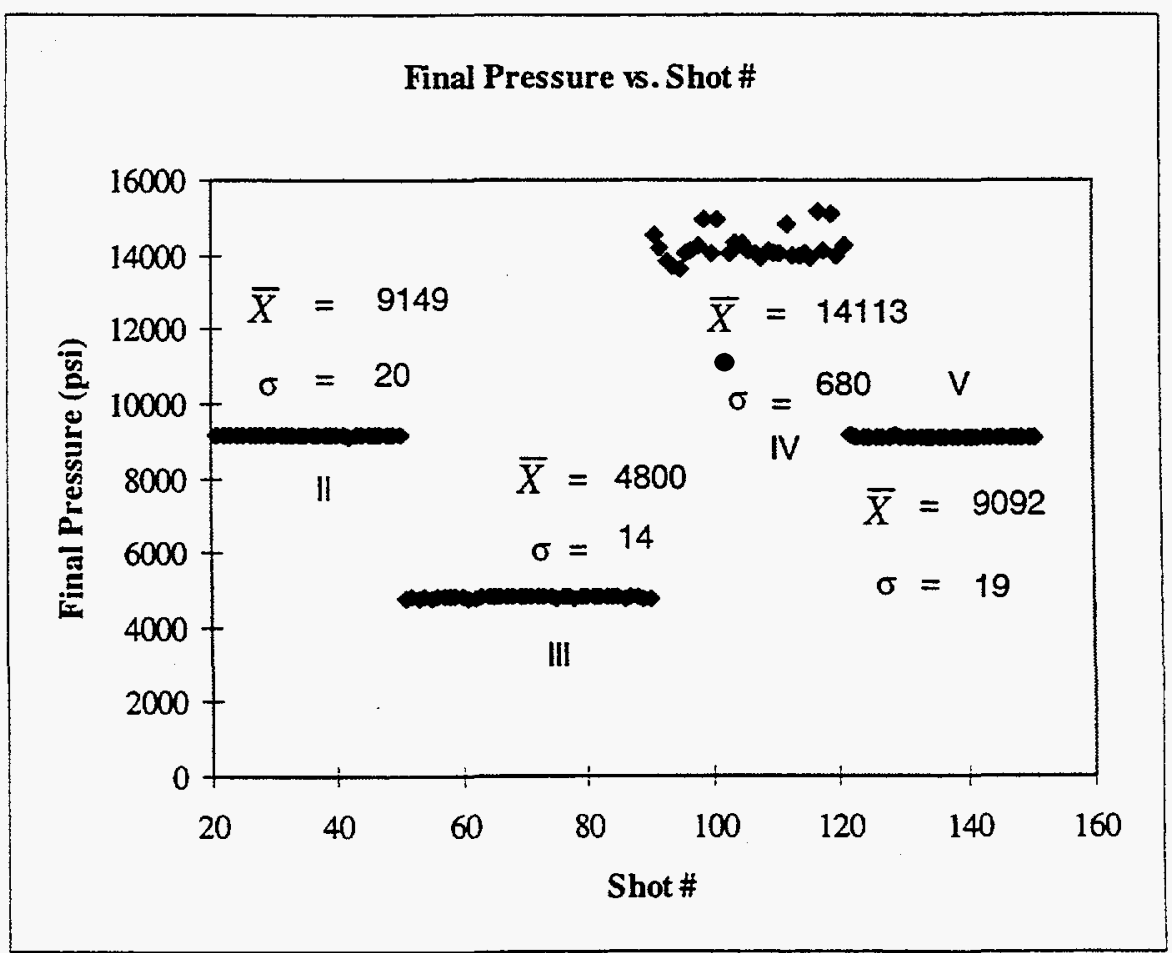

Figure 3.22 The final pressures of selected shots 
For the two 2500 psi (hydraulic) sets in Figure 3.23, the average intensification stroke lengths are 0.37 and 0.4 inch for sets II and V, respectively. The standard deviation values of the set $I$ and set $V$ for the intensification stroke length are 0.03 and 0.09 inch, respectively. The higher average and larger standard deviation of set $\mathrm{V}$ in intensification stroke length versus shot \# in Figure 3.23 explain the higher average value and bigger standard deviation of set $\mathrm{V}$ as compared to the set II. However, the discontinuity can not be explained by both figures.

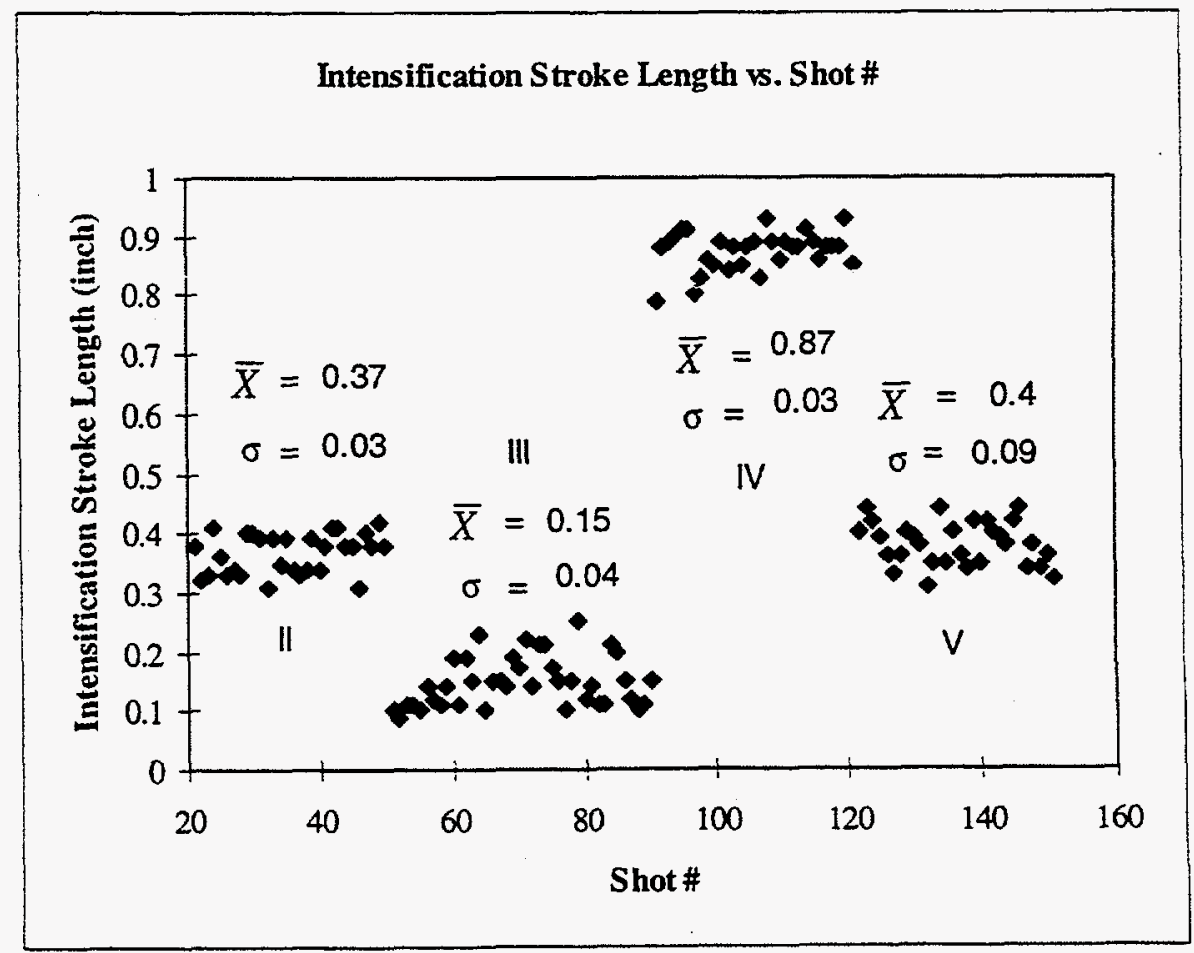

Figure 3.23 The intensification stroke length of selected shots 
The maximum Kistler pressure versus shot \# confirms the existance of the discontinuity in set $\mathrm{V}$ in Figure 3.21. For the two 2500 psi (hydraulic) sets in Figure 3.24, the standard deviation values are 178 and 473 psi and the average maximum Kistler pressure are 7037 and 7354 psi for sets II and V, respectively.

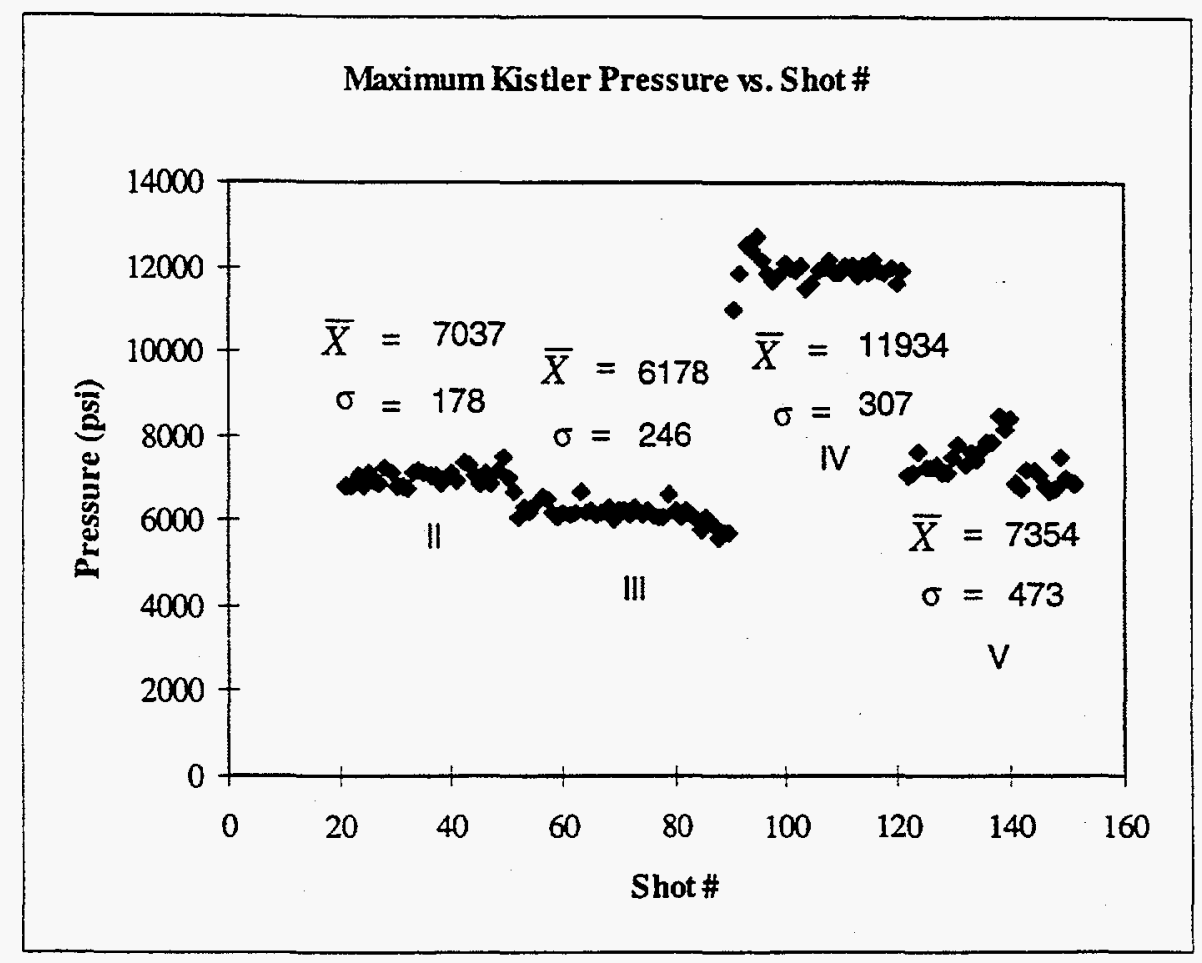

Figure 3.24 The maximum Kistler pressure of selected shots

Figures 3.25 and 3.26 show the Kistler pressure and hydraulic pressure records are nearly identical for the pressure rise time. The time resolution and accuracy of the Kistler pressure record is equal in capability to the hydraulic pressure record. In both figures, the average value of pressure rise time for the $3900 \mathrm{psi}$ (hydraulic) set is larger than those of the $2500 \mathrm{psi}$ (hydraulic) sets and the average values of pressure rise time for the $2500 \mathrm{psi}$ 
(hydraulic) sets is larger than that of the 1300 psi (hydraulic) set. The average value of pressure difference $100 \mathrm{~ms}$ after minimum value (Figure 3.27) for the $2500 \mathrm{psi}$ (hydraulic) set is larger than the $3900 \mathrm{psi}$ (hydraulic) set due to the longer pressure rise time of the 3900 psi (hydraulic) set. Since the intensification pressures of $1300 \mathrm{psi}$ (hydraulic) set are smaller than the 2500 psi (hydraulic) sets, the average value of pressure difference for the $1300 \mathrm{psi}$ (hydraulic) set is still smaller than that of $3900 \mathrm{psi}$ (hydraulic) set. Except the highest point, it is found that in each set in Figure 3.25 and Figure 3.26 the data points with longer pressure rise time usually accompany big impact spikes on the hydraulic and the Kistler pressure-time records. The larger the hydraulic pressure rise time, the largerer the Kistler pressure rise time.

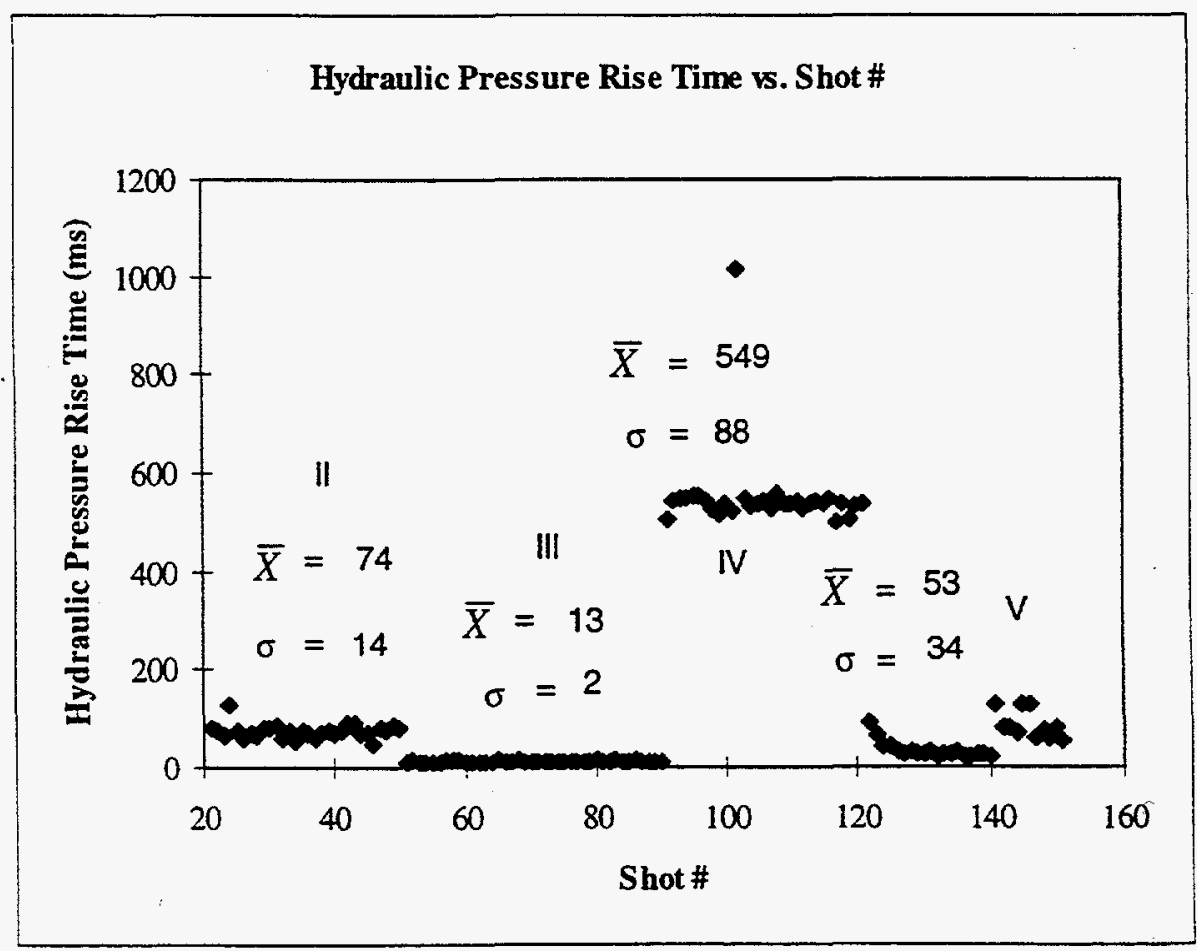

Figure 3.25 Pressure rise time of selected hydraulic pressure records 


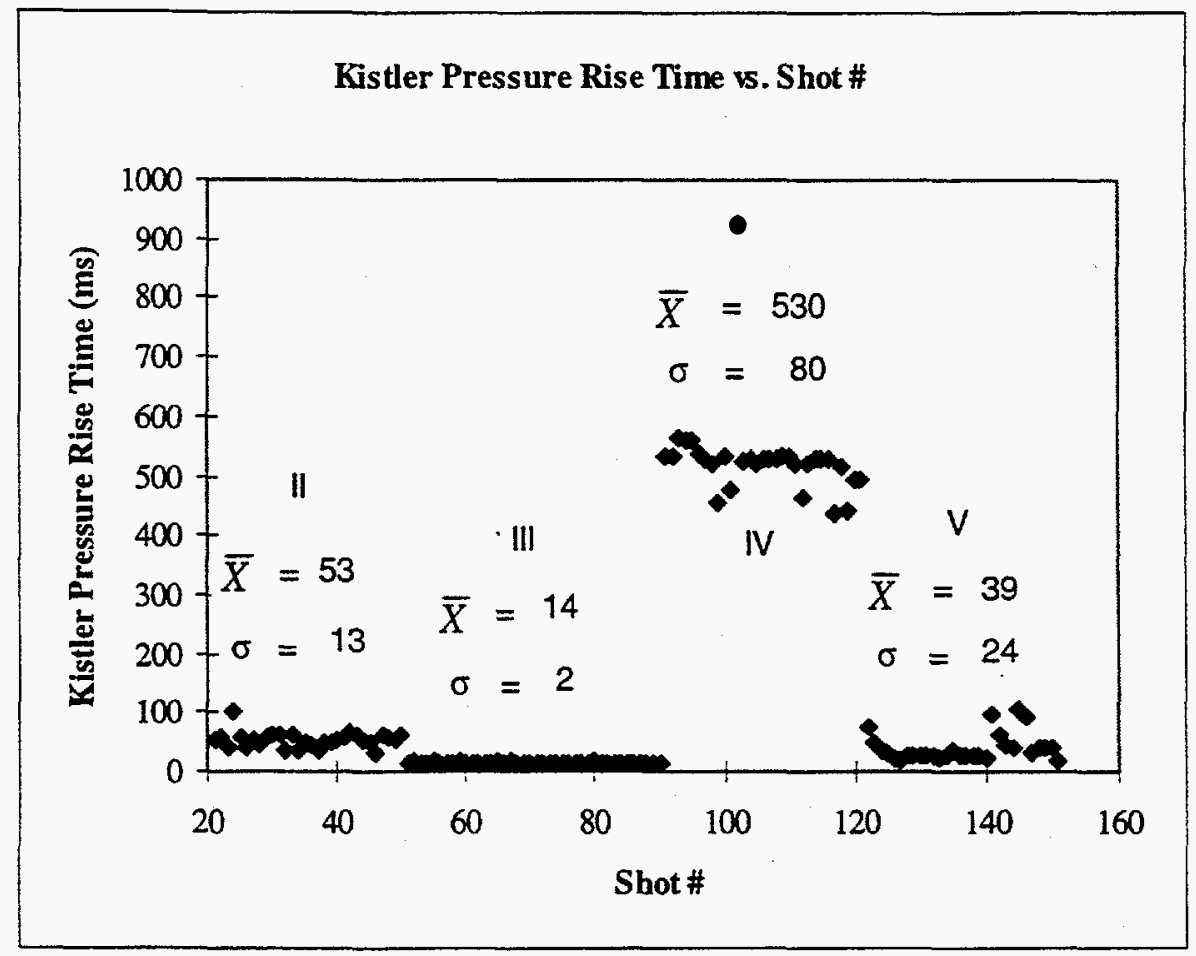

Figure 3.26 Pressure rise time of selected Kistler pressure records

From Figure 3.27, it can also be noticed that the data points of second 2500 psi set has more scatter than the first 2500 psi set; the 3900 psi set has even more scatter than late 2500 psi set. Figure 3.28 illustrates the pressure difference $1900 \mathrm{~ms}$ after minimum pressure difference. As shown in figure the average impact pressure was 4374,2968 , 6528 and 4627 psi for sets II, III, IV, and V respectively. The standard deviations are 195 and 526 psi for the 1300 psi (hydraulic) set and the 3900 psi (hydraulic) set, respectively. For the two 2500 psi (hydraulic) sets, the standard deviation values of the set II and set V are 293 and 292 psi respectively. There exist a very good correlation between the Kistler pressure and hydraulic pressure in Figure 3.25 since if the Kistler pressure increases with 
increasing intensification pressure, the pressure difference also increases with increasing intensification pressure. It also noticed in Figure 3.28 that the higher the pressure the larger the scatter.

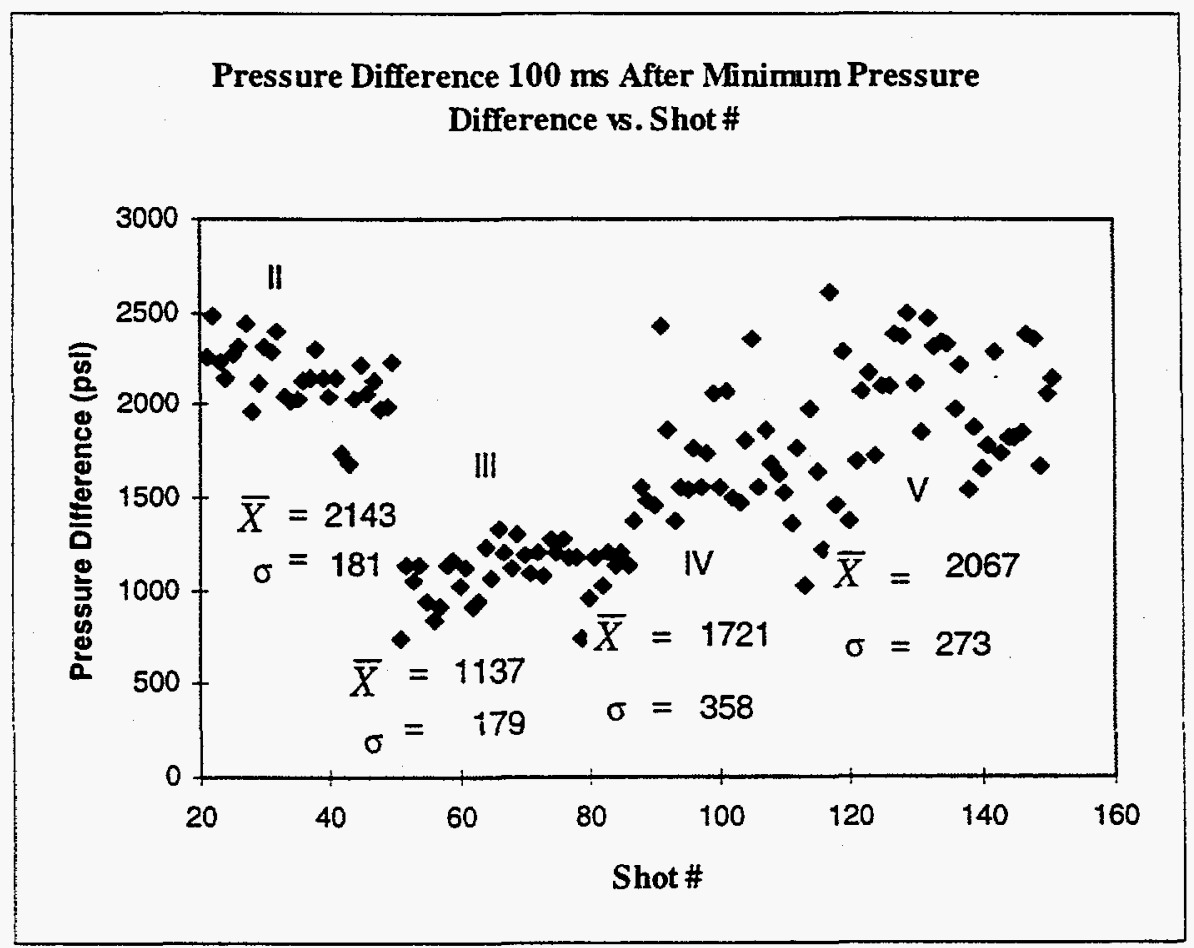

Figure 3.27 Pressure difference $100 \mathrm{~ms}$ after minimum pressure difference 


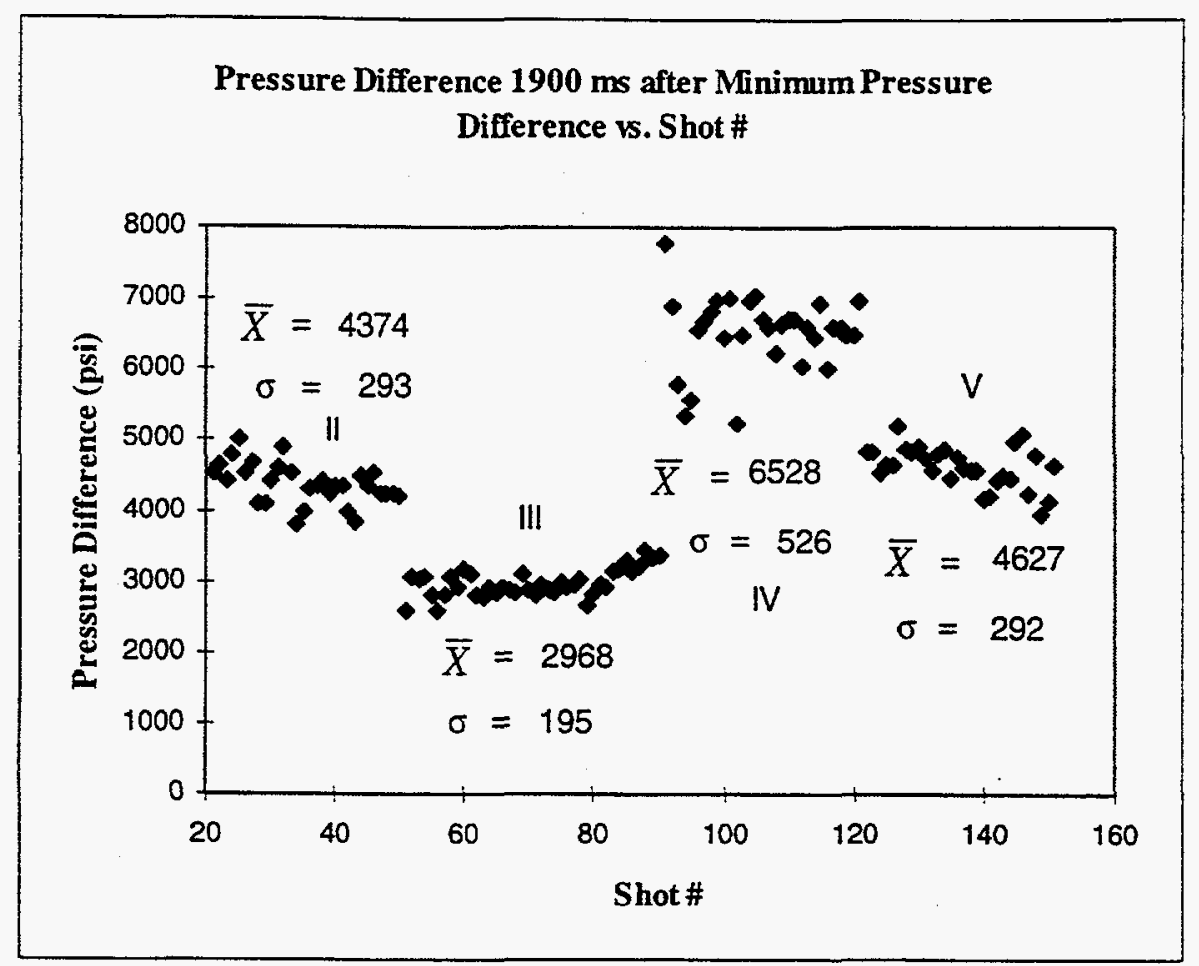

Figure 3.28 Pressure difference $1900 \mathrm{~ms}$ after minimum pressure difference

Figure 3.29 illustrates impact pressure of selected shots. As shown in the figure, the average impact pressure was $-520,-771,-1012$ and -651 psi for sets II, III IV and V respectively. The standard deviations are $152 \mathrm{psi}$ and $439 \mathrm{psi}$ for $1300 \mathrm{psi}$ (hydraulic) set and 3900 psi (hydraulic) set respectively. For the two 2500 psi (hydraulic) sets, the standard deviation values of the set II and set $V$ are 265 psi and 402 psi respectively. From this figure, it can be inferred that the average impact pressure of set IV is higher than set $I I$ and the average impact pressure of set $I I$ is higher than set II and set V; the scatter increases with increasing number of shots; and the impact pressure of shots 22 , $123,128,132$ is zero. The first conclusion means that even if the intensification pressure is lower it may cause bigger impact as compared to the sets II and V. Negative value 
indicates that the die is closed with the required clamping force to resist the impact in the die cavity and no flashing occurs. For shots $22,123,128,132$, if no flashing occurred, maybe the intensification started earlier or something blocked the movement of the plunger or something remained on the parting line of the die preventing the die from closing tightly or the moving part such as slides retracted.

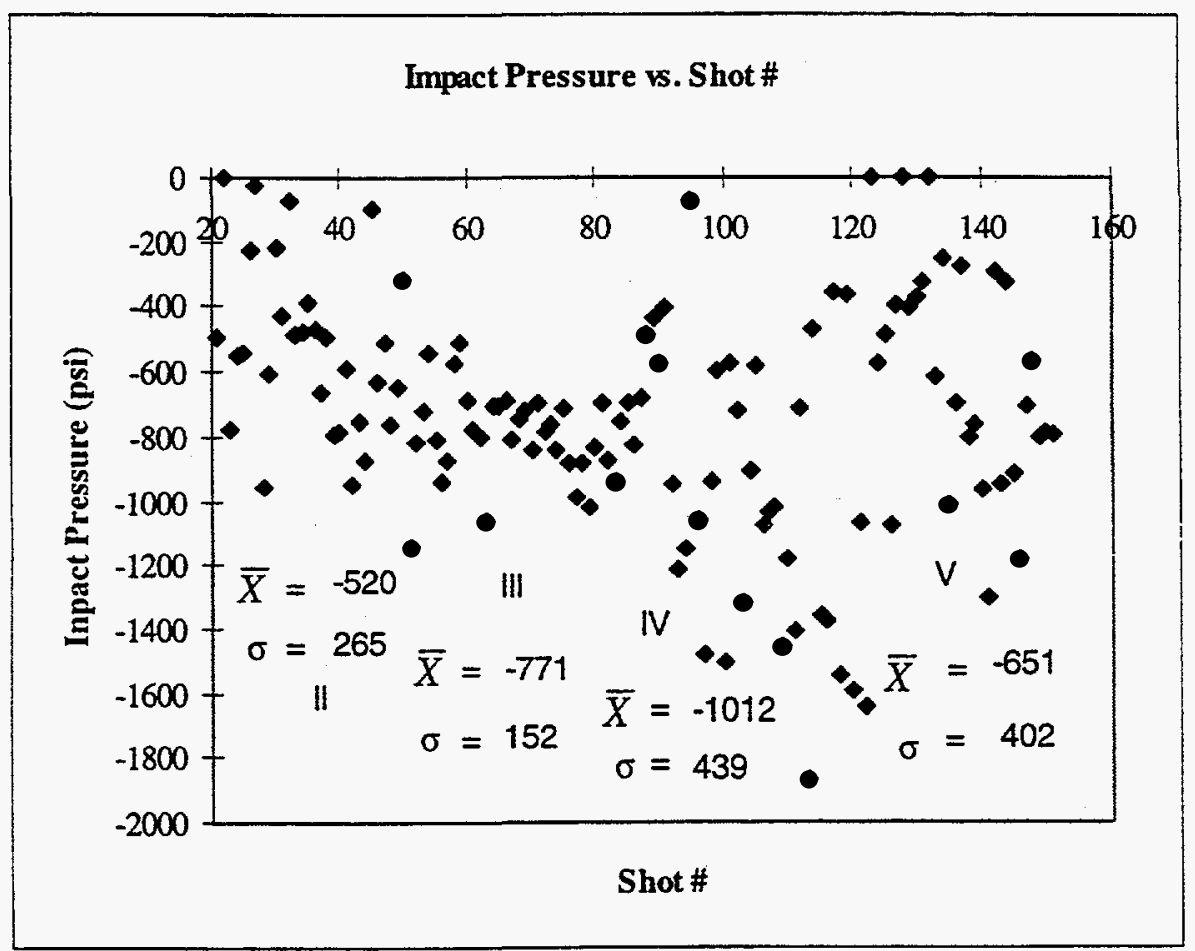

Figure 3.29 Impact pressure of selected shots

The other three shots that have no impact pressure are shots 1,155 and 156. In shot 1 , it is conjectured that the die was still cold and the gap between the die parts was not closed by thermal expansion. The last two belong to the flashing test set with die flashing and the metal pressure from the hydraulic pressure and Kistler pressure are quite 
low. These facts indicate that the clamping force was not large enough to suppress die opening. As soon as the die opens, flashing occurs and the pressure in the die cavity drops. Even if the hydraulic pressure had not reached the desired final pressure, the pressure difference is large. Figure 3.30 and Figure 3.31 show the pressure and pressure difference records of the shot 156 . The minimum pressure difference is positive because of the flashing; and the pressure difference is high because of low cavity pressure.

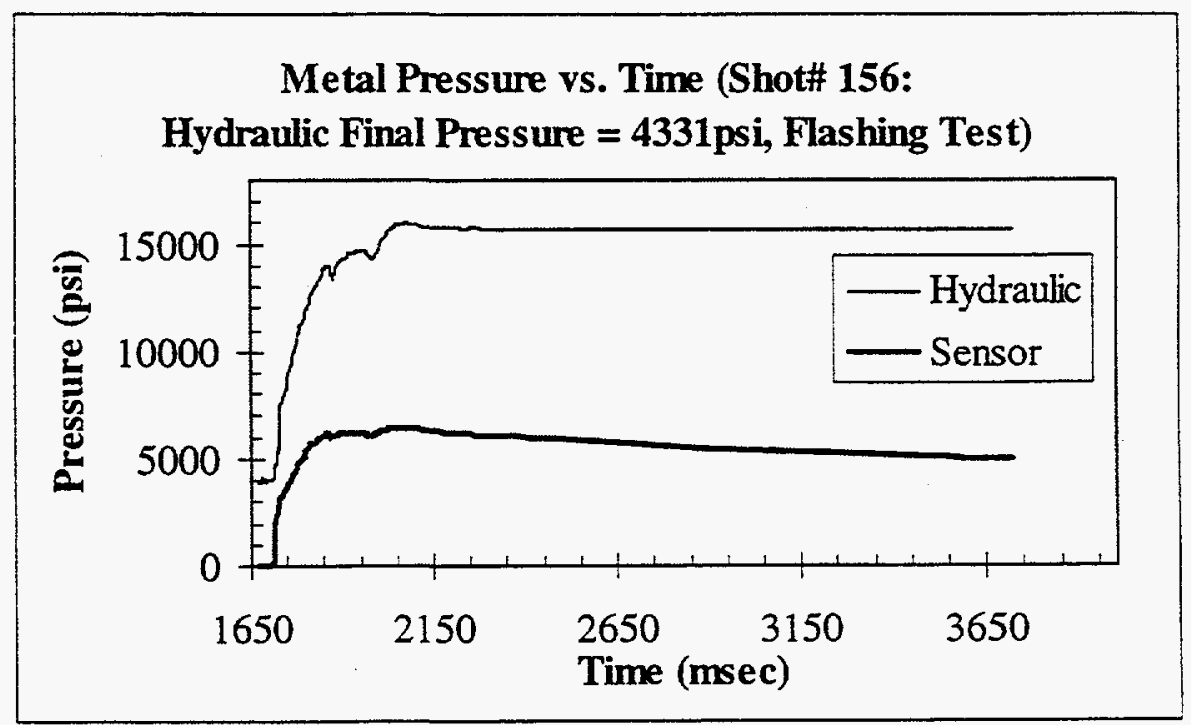

Figure 3.30 Pressure records of shot No. 156 


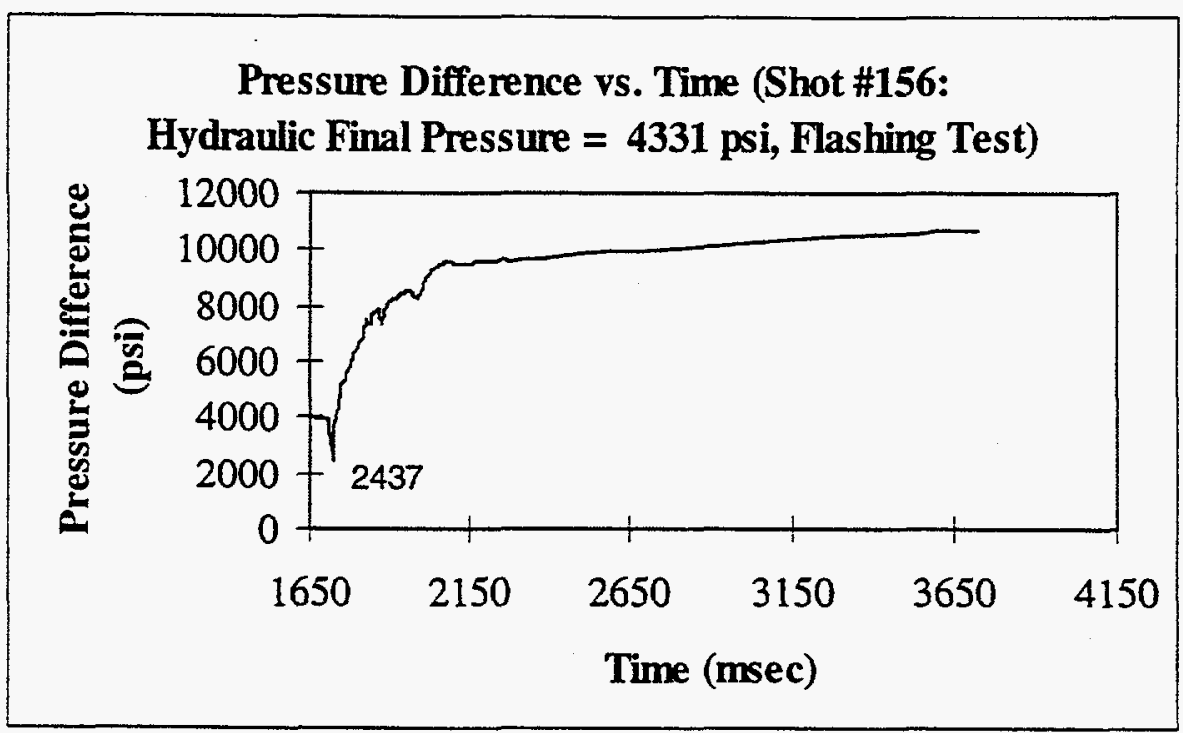

Figure 3.31 Pressure difference records for shot No. 156

The average values and standard deviation values of sets $I, I I, I V, V$ in figures from Figure 3.21 through Figure 3.28, and Figure 3.31 are listed in Table 3.1.

\begin{tabular}{|c|c|c|c|c|c|c|c|c|}
\hline & \multicolumn{2}{|c|}{ set II } & \multicolumn{2}{c|}{ set III } & \multicolumn{2}{c|}{ set IV } & \multicolumn{2}{c|}{ set V } \\
\hline & Average & Stdev & Average & Stdev & Average & Stdev & Average & Stdev \\
\hline $\mathrm{P}_{\text {final }}$ & 9149 & 20 & 4800 & 14 & 14113 & 680 & 9092 & 19 \\
\hline $\mathrm{P}_{\mathrm{H}, \max }$ & 9223 & 35 & 5626 & 76 & 16758 & 59 & 9425 & 281 \\
\hline $\mathrm{P}_{\mathrm{K}, \max }$ & 7037 & 178 & 6178 & 246 & 11934 & 307 & 7354 & 473 \\
\hline $\mathrm{P}_{\text {impact }}$ & -520 & 265 & -771 & 152 & -1012 & 439 & -651 & 402 \\
\hline$\Delta \mathrm{P}_{100 \text { ms }}$ & 2150 & 186 & 1148 & 208 & 1631 & 237 & 2005 & 186 \\
\hline$\Delta \mathrm{P}_{1900 \text { ms }}$ & 4374 & 293 & 2968 & 195 & 6528 & 526 & 4627 & 292 \\
\hline $\mathrm{PRt}_{\mathrm{H}} \mathrm{H}$ & 74 & 14 & 13 & 2 & 549 & 88 & 53 & 34 \\
\hline $\mathrm{PRt}_{\mathrm{N}} \mathrm{K}$ & 53 & 13 & 14 & 2 & 530 & 80 & 39 & 24 \\
\hline$\delta$ & 0.37 & 0.03 & 0.15 & 0.04 & 0.87 & 0.03 & 0.40 & 0.09 \\
\hline
\end{tabular}

Table 3.3 The average and standard deviation values of pressure parameters, intensification stroke, pressure difference and pressure rise time of sets II, III, IV, and V

In this table the pressure unit used is pound per square inch (psi), the time unit used is millisecond, and the distance unit is inch. 
CHAPTER 4

\section{EXAMINING THE CORRELATIONS BETWEEN THE KISTLER DIRECT PRESSURE SENSOR OUTPUTS AND CASTING VOLUME, DENSITY, AND WEIGHT}

\subsection{INTRODUCTION}

Density is an index of the casting quality. The effects of pressure applied during intensification on the density of casting were evaluated on seventeen trimmed transmission cases from the.GM die casting campaign (shots $20,50,60,90,91,120,121$, $123,126,131,136,151,152,153,154,155$, and 156), biscuit and runner of shots 20,50 , $60,90,91,120$, and overflows of shots $50,60,90,91,120$. All these shots were made after the thermal quasi steady state was reached. Shots 60 and 90 were cast with 1300 psi (hydraulic). Shots 91, 120, and 121 were cast with 3900 psi (hydraulic). Shots 20 and 50 were cast with 2500 psi (hydraulic) and belong to set $\Pi$. Shots $123,126,131,136$ and 151 were cast with 2500 psi (hydraulic) and belong to set V. Shots 152 through 156 
belong to the flashing test. Shots 155 and 156 are the two shots that had flashing. As shown in Chapter 2 Figure 2.6 from Kay and Street [3] and Figure 2.7 from Tokui [11], the porosity decreases, or the density increases, with increasing applied pressure. A model for predicting the porosity in the die castings was developed and presented in NADCA Transactions [17]. This model also indicates that the increasing applied pressure should produce decreasing porosity parts. In the measurements of the casting weight, volume and density of the trimmed transmission cases from GM CADC Bedford, it was found that the casting weight increased from 26.3789 to $28.5599 \mathrm{lbs}$; the casting volume increased from 266.33 to 285.02 inch $^{3}$; the casting density increased from 0.09923 to $0.10022 \mathrm{lbs} / \mathrm{inch}^{3}$ if the intensification pressure was increased from 1300 psi (hydraulic) to 4598 psi (hydraulic).

\subsection{ARCHIMEDES' DENSITY MEASUREMENT}

The casting material of these transmission cases is die cast Aluminum Alloy 380 . The nominal composition range for this alloy is given in Table 4.1.

Table 4.1 Nominal Composition Range for Aluminum Alloy 380 (weight percent)

$\underline{\text { Silicon Copper Iron Zinc Magnesium Manganese Tin Nickel Aluminum }}$

$\begin{array}{lllllllll}7.5-9.5 & 3.0-4.0 & 2.0 & 3.0 & 0.10 & 0.50 & 0.35 & 0.50 & \text { balance }\end{array}$


Using Archimedes' density measurement method, the castings were weighed in air and then weighed in water. The density and porosity can be calculated from these data. The following formula was used to determine the density of the casting:

$$
\begin{aligned}
& \rho_{\mathrm{C}}=\frac{\mathrm{W}_{\mathrm{A}}}{\mathrm{V}_{\mathrm{C}}} \\
& \mathrm{V}_{\mathrm{C}}=\frac{\mathrm{W}_{\mathrm{A}}-\mathrm{W}_{\mathrm{w}}}{\rho_{\mathrm{w}}-\rho_{\mathrm{A}}} \\
& \rho_{\mathrm{c}}=\text { Casting density } \\
& \mathrm{W}_{\mathrm{A}}=\text { Casting weight in air } \\
& \mathrm{V}_{\mathrm{C}}=\text { Casting volume } \\
& \mathrm{W}_{\mathrm{w}}=\text { Casting weight in water } \\
& \rho_{\mathrm{w}}=\text { Density of water } \\
& \rho_{\mathrm{A}}=\text { Density of air }
\end{aligned}
$$

The following formula was used to determine the porosity:

$$
\begin{aligned}
\mathrm{f} p & =\frac{\rho_{\mathrm{t}}-\rho_{\mathrm{c}}}{\rho_{\mathrm{t}}} \times 100 \\
\mathrm{f}_{\mathrm{p}} & =\text { Percent porosity }(\%) \\
\rho_{\mathrm{t}} & =\text { Theoretical density, assumed equal to } 2.7941 \mathrm{~g} / \mathrm{cc}[19]
\end{aligned}
$$


An example calculation for the shot \#1 casting is as follows. The average dry weight of casting is $27.7512 \pm 0.0002 \mathrm{lbs}$ and the wet weight of casting is $17.7048 \pm$ $0.0002 \mathrm{lbs}$ (The accuracy that the balance can measure is $\pm 0.0002 \mathrm{lbs}$ ); the density of water is $0.99754 \pm 0.00001 \mathrm{~g} / \mathrm{cc}$ and the density of air is $0.001161 \pm 0.000001 \mathrm{~g} / \mathrm{cc}(1 \mathrm{~g} / \mathrm{cc}$ $\left.=0.036127486 \mathrm{lb} / \mathrm{inch}^{3}\right)$. The casting volume upper limit equals $(27.7512+0.0002-$ $17.7048+0.0002) /[0.036127486(0.99754-0.00001-0.001161-0.000001)]=$ 279.10669. The casting volume lower limit equals $(27.7512-0.0002-17.7048-$ $0.0002) /[0.036127486(0.99754+0.00001-0.001161+0.000001)=279.07835$. The casting weight is $279.09252 \pm 0.014169$. If the accuracy is rounded to $\pm 0.02 \mathrm{lbs}$. The casting weight is $279.09 \pm 0.02 \mathrm{lbs}$. Likewise, the casting density upper limit equals $(27.7512+0.0002) /(279.09-0.02)=0.0994424 \mathrm{lb}$; the casting density lower limit equals $(27.7512-0.0002) /(279.09+0.02)=0.0994267 \mathrm{lbs}$. The casting density is $0.0994345 \pm$ 0.00000787465 . If the accuracy is rounded to $\pm 0.00001 \mathrm{lbs}$. The casting density is $0.09943 \pm 0.00001 \mathrm{lbs}$.

The facilities needed for density measurement using the Archimedes' method include [20]:

1. A scale with sensitivity to at least 0.0002 lbs. The balance has bottom weighing capability so that the casting can be submerged in the water bath

2. A calibration standard and pure silicon block to test the accuracy of the system

3. Tap or distilled water 
4. A container large enough to hold the water and part

5. A means of attaching the casting to the balance while submerging the casting in the water. Here thin wires and a plate are adequate

The schematic of Archimedes' density measurement system is shown in Figure 4.1.

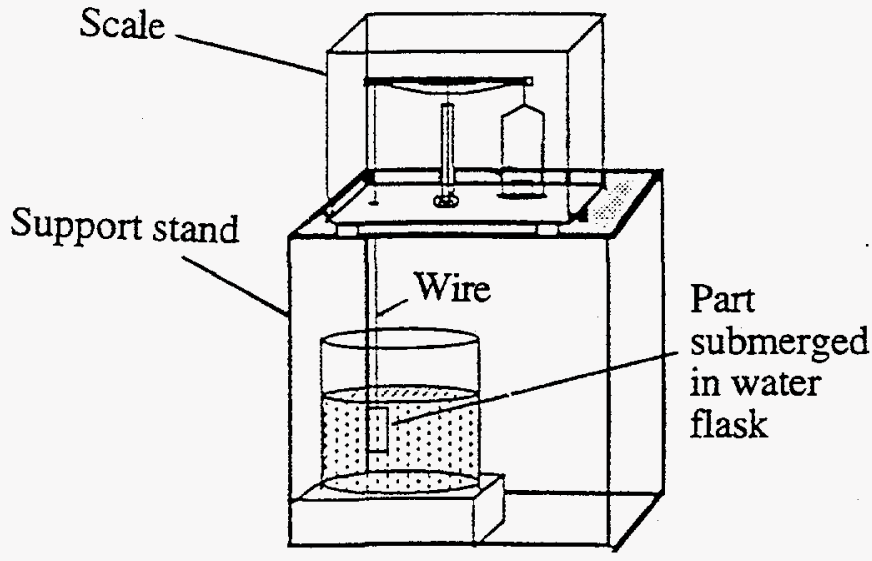

Figure 4.1 Schematic of Archimedes's measurement system[20]

(The scale used here is Mettler MultiRange FBB30 together with Mettler MultiRange ID1 plus weighing terminal)

The procedures are:

1. Attach one end of the wire through the hole in the support stand to the balance and the other end to the plate

2. Measure and record the weight required to balance the wire and plate in air

3. Measure and record the weight required to balance the wire and plate in water

4. Clean the casting

5. Submerge the casting in water and attach the casting to the balance by placing the plate behind a hole in casting, the size of the hole is smaller than the plate, 
and attach one end of the wire to the plate-

6. Remove bubbles with a water tube

7. Weigh the casting three times

The results of Archimedes' density measurement, casting weight $\mathrm{Wt}_{c}$, casting volume $\mathrm{Vol}_{c}$, and casting density $\rho_{c}$ data of the selected shots are listed in Table 4.2. The casting plus the overflow weight $\mathrm{Wt}_{\mathrm{c}+\mathrm{o}}$ data provided by $\mathrm{GM}$ are also listed in Table 4.2 .

\begin{tabular}{|c|c|c|c|c|}
\hline Shot & $\begin{array}{c}\text { Wt } \\
(\mathrm{lbs})\end{array}$ & $\begin{array}{c}\mathrm{Wt}_{\mathrm{c}} \\
(\mathrm{lbs})\end{array}$ & $\begin{array}{c}\mathrm{Vol}_{\mathrm{c}} \\
\left(\mathrm{inch}^{3}\right)\end{array}$ & $\begin{array}{c}\rho_{\mathrm{c}} \\
\left(\mathrm{lbs}_{\mathrm{inch}}{ }^{3}\right)\end{array}$ \\
\hline 1 & 29.15 & 27.7512 & 279.09 & 0.09943 \\
\hline 2 & 28.30 & 26.9367 & 272.35 & 0.09891 \\
\hline 3 & 28.15 & 26.8030 & 270.34 & 0.09915 \\
\hline 4 & 28.05 & 26.6731 & 269.03 & 0.09915 \\
\hline 6 & 28.70 & 27.0038 & 270.87 & 0.09969 \\
\hline 20 & 28.45 & 26.9149 & 270.01 & 0.09968 \\
\hline 50 & 28.40 & 26.8553 & 269.46 & 0.09966 \\
\hline 60 & 28.10 & 26.4673 & 266.72 & 0.09923 \\
\hline 90 & 27.90 & 26.3789 & 266.33 & 0.09905 \\
\hline 91 & 29.30 & 27.5936 & 275.59 & 0.10013 \\
\hline 120 & 29.45 & 27.7135 & 276.93 & 0.10007 \\
\hline 121 & 29.40 & 27.6856 & 276.45 & 0.10015 \\
\hline 123 & 28.45 & 26.8595 & 269.33 & 0.09973 \\
\hline 126 & 28.55 & 26.8494 & 268.59 & 0.09996 \\
\hline 131 & 28.60 & 26.8883 & 269.67 & 0.09971 \\
\hline 136 & 28.55 & 26.9427 & 270.07 & 0.09976 \\
\hline 151 & 28.50 & 26.8934 & 269.55 & 0.09977 \\
\hline 152 & 29.4 & 27.6933 & 276.59 & 0.10012 \\
\hline 153 & 29.75 & 28.0081 & 279.62 & 0.10017 \\
\hline 154 & 29.95 & 28.1923 & 281.31 & 0.10022 \\
\hline 155 & 30.30 & 28.5048 & 284.44 & 0.10021 \\
\hline 156 & 30.35 & 28.5599 & 285.02 & 0.10020 \\
\hline & & & & \\
\hline
\end{tabular}

Table 4.2 Casting weight plus overflows, and trimmed casting weight, volume, and density data of selected shots 
Shot 154 had the highest density among these shots. Shots 155 and 156 have the largest volume and casting weight. Their density values are next to shot 154 . Shots 155 and 156 will not be included in the following plots because of the flashing.

\subsection{THE EFFECTS OF APPLIED PRESSURE ON THE CASTING VOLUME}

The shot number, final pressure, $P_{\text {final, }}$ maximum metal pressure from hydraulic pressure, $\mathrm{P}_{\mathrm{H}, \max }$, maximum Kistler pressure, $\mathrm{P}_{\mathrm{K}, \max }$, Kistler pressure at $2000 \mathrm{~ms}$ after intensification starts, $P_{K}$, 2000ms, average Kistler pressure, $P_{K}$, average $\left(P_{K}\right.$, average $=\left(P_{K}\right.$, max + $\left.P_{K, 2000 m s}\right) / 2$ ), the mean value between the final pressure and average Kistler pressure, $\mathrm{P}_{\text {mean }}\left(\mathrm{P}_{\text {mean }}=\left(\mathrm{P}_{\text {final }}+\mathrm{P}_{\mathrm{K} \text {, average }}\right) / 2\right)$ are listed in Table 4.3 .

\begin{tabular}{|c|c|c|c|c|c|c|}
\hline Shot & $\begin{array}{c}\mathrm{P}_{\text {final }} \\
(\mathrm{psi})\end{array}$ & $\begin{array}{c}\mathrm{P}_{\mathrm{H}, \max } \\
(\mathrm{psi})\end{array}$ & $\begin{array}{c}\mathrm{F}_{\mathrm{K}, \max } \\
(\mathrm{psi})\end{array}$ & $\begin{array}{c}\mathrm{P}_{\mathrm{K}, 2000 \mathrm{~ms}} \\
(\mathrm{psi})\end{array}$ & $\begin{array}{c}\mathrm{P}_{\mathrm{K}, \text { average }} \\
(\mathrm{psi})\end{array}$ & $\begin{array}{c}\mathrm{P}_{\text {mean }} \\
(\mathrm{psi})\end{array}$ \\
\hline 20 & 9167 & 9251 & 7018 & 4872 & 5945 & 7556 \\
\hline 50 & 9120 & 9236 & 6989 & 4901 & 5945 & 7532 \\
\hline 60 & 4811 & 5635 & 6162 & 1668 & 3915 & 4363 \\
\hline 90 & 4786 & 5456 & 5684 & 1436 & 3560 & 4173 \\
\hline 91 & 14507 & 16767 & 10976 & 8889 & 9933 & 12220 \\
\hline 120 & 13993 & 16639 & 11774 & 9976 & 10875 & 12434 \\
\hline 121 & 14248 & 16782 & 11992 & 9643 & 10818 & 12533 \\
\hline 123 & 9102 & 9269 & 7134 & 4205 & 5670 & 7386 \\
\hline 126 & 9105 & 9320 & 7236 & 4394 & 5815 & 7460 \\
\hline 131 & 9080 & 9520 & 7786 & 4263 & 6025 & 7552 \\
\hline 136 & 9109 & 9685 & 7873 & 4336 & 6105 & 7607 \\
\hline 151 & 9061 & 9120 & 7018 & 4379 & 5699 & 7380 \\
\hline 152 & 14208 & 16760 & 11673 & 9904 & 10789 & 12498 \\
\hline 153 & 16290 & 16545 & 12441 & 10237 & 11339 & 13814 \\
\hline 154 & 16585 & 16607 & 12920 & 10977 & 11949 & 14267 \\
\hline
\end{tabular}

Table 4.3 Various pressure parameters of the selected shots 
To explore the effects of various pressure parameters on casting volume, the plots of casting volume versus final pressure, the casting volume versus maximum metal pressure from hydraulic pressure, the casting volume versus maximum Kistler pressure, , the casting volume versus average Kistler pressure, and the casting volume versus mean pressure are shown in Figure 4.2, Figure 4.3, Figure 4.4, and Figure 4.5 and Figure 4.6, respectively.

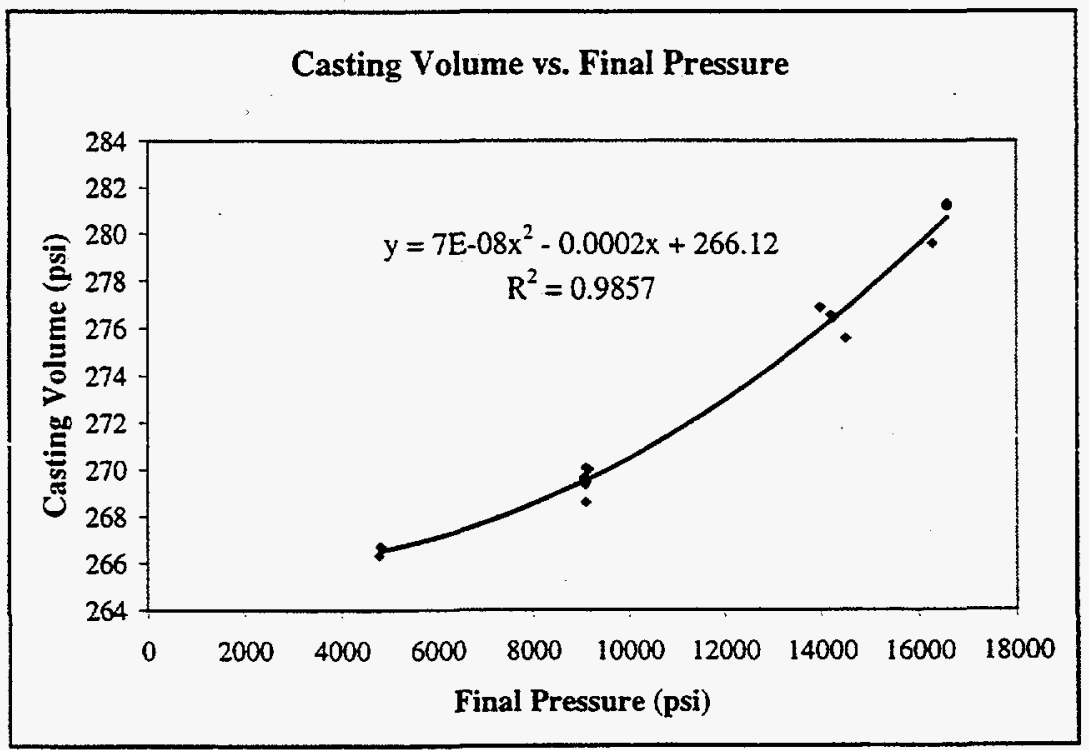

Figure 4.2 The effect of final pressure on the casting volume

The casting volume increases with increasing final pressure. However, more than one value of casting volume will correspond to a given value of final pressure. 


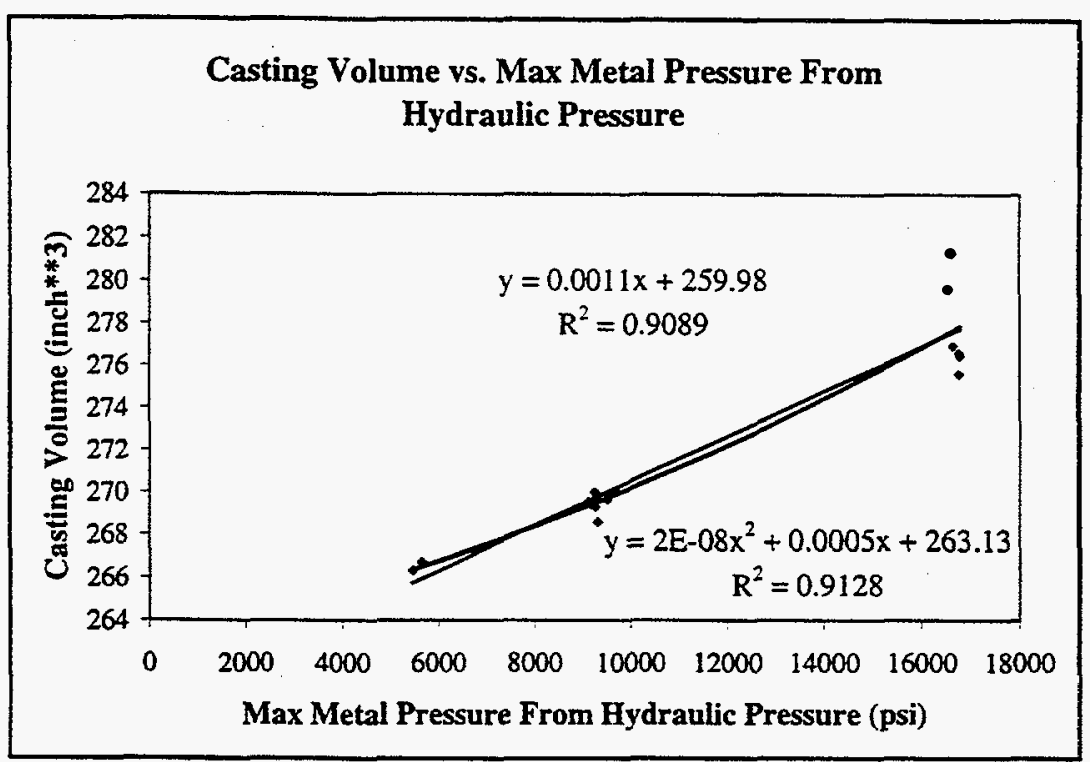

Figure 4.3 The effect of max metal pressure from hydraulic pressure on the casting volume

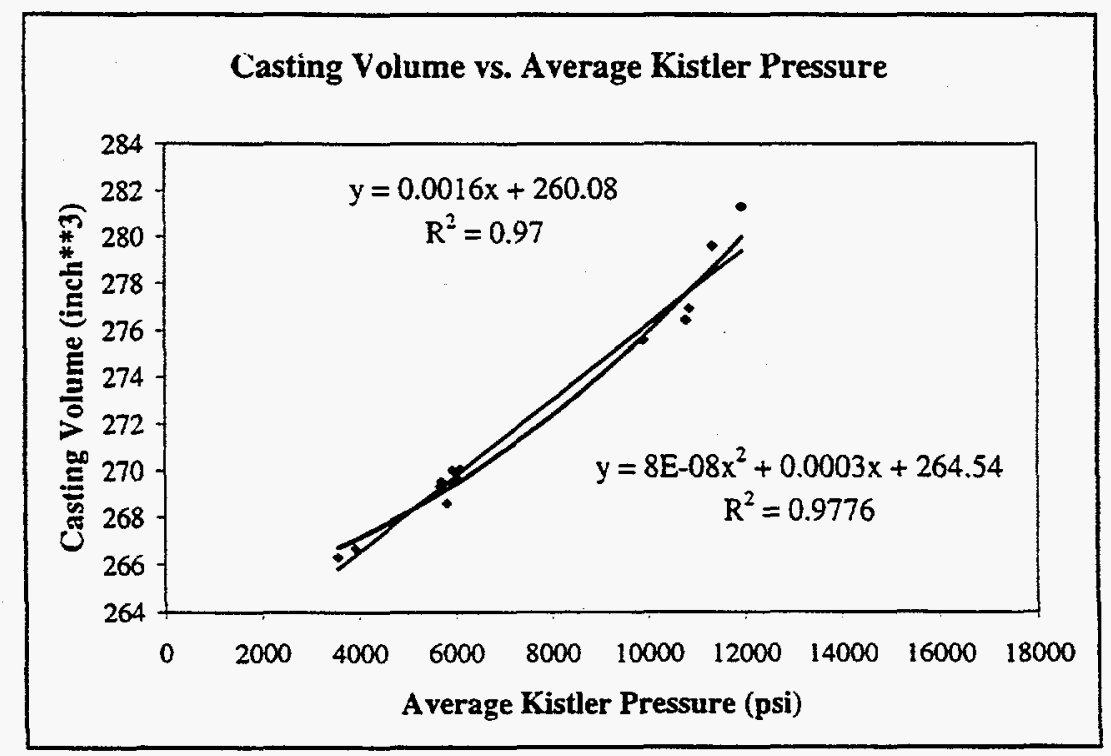

Figure 4.4 The effect of average Kistler pressure on the casting volume 


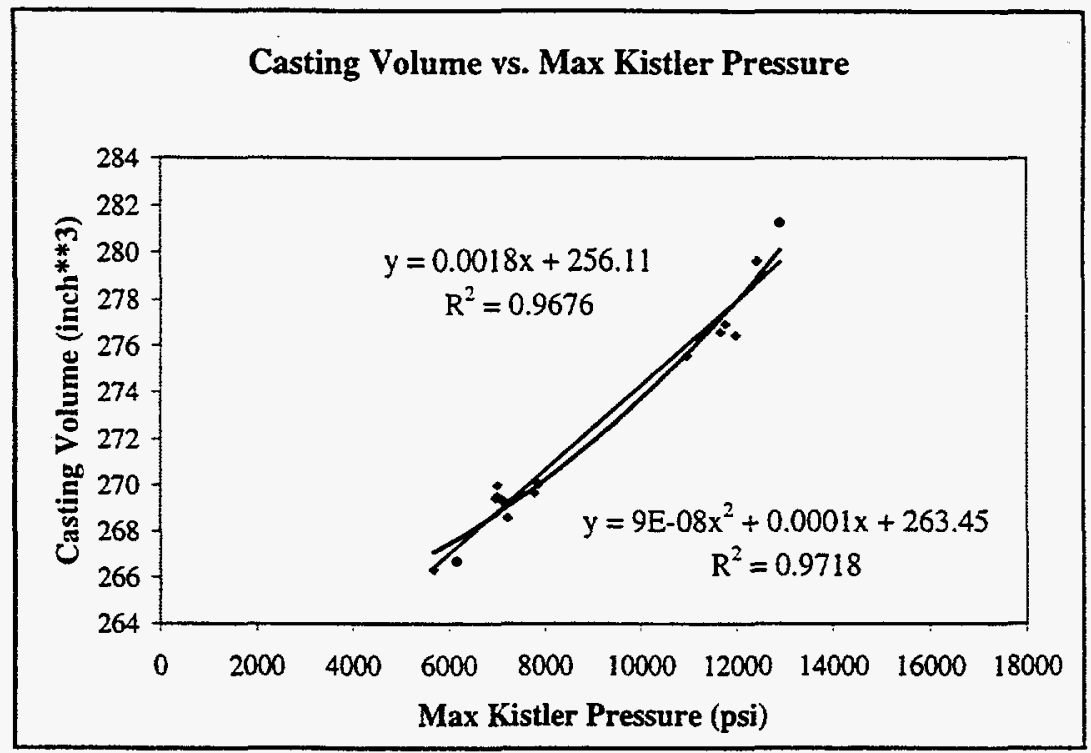

Figure 4.5 The effect of max Kistler pressure on the casting volume

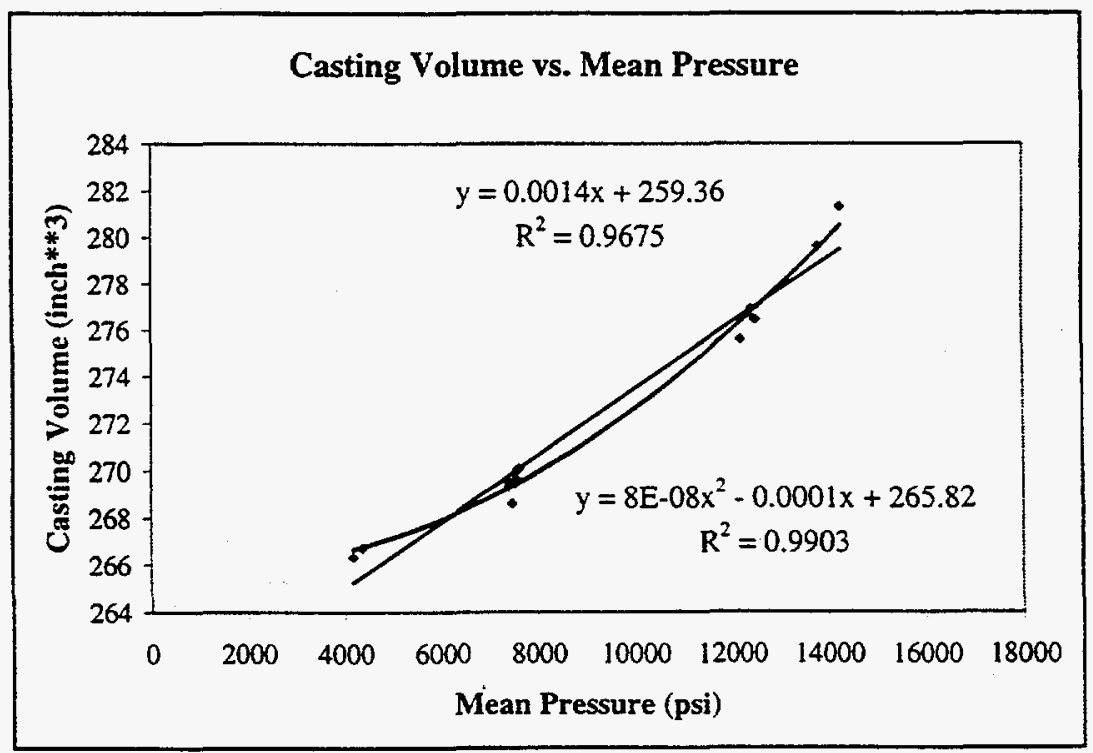

Figure 4.6 Effect of mean pressure on the casting volume 
In terms of the $\mathrm{R}^{2}$ value (correlation coefficient), the mean pressure is the appropriate pressure parameter to establish the actual correlation with casting volume. The $R^{2}$ values for trendlines of casting volume vs. final pressure $y=7 E-8 x^{2}-0.0002 x+$ 266.12, maximum metal pressure from hydraulic pressure $y=2 E-8 x^{2}+0.0005 x+$ 263.13, average Kistler pressure $y=8 E-8 x^{2}+0.0003 x+264.54$, maximum Kistler pressure $y=9 E-8 x^{2}+0.0001 x+263.45$, and mean pressure $y=8 E-8 x^{2}-0.0001 x+$ 265.82 are $0.9857,0.9128,0.9776,0.9718$, and 0.9903 , respectively. 


\subsection{THE EFFECTS OF APPLIED PRESSURE ON THE CASTING DENSITY}

To explore the effects of various pressure parameters on casting density, the plots of casting density versus the reciprocal of final pressure, maximum metal pressure from hydraulic pressure, average Kistler pressure, maximum Kistler pressure, and mean pressure are shown in Figure 4.7, Figure 4.8, Figure 4.9, Figure 4.10, and Figure 4.11.

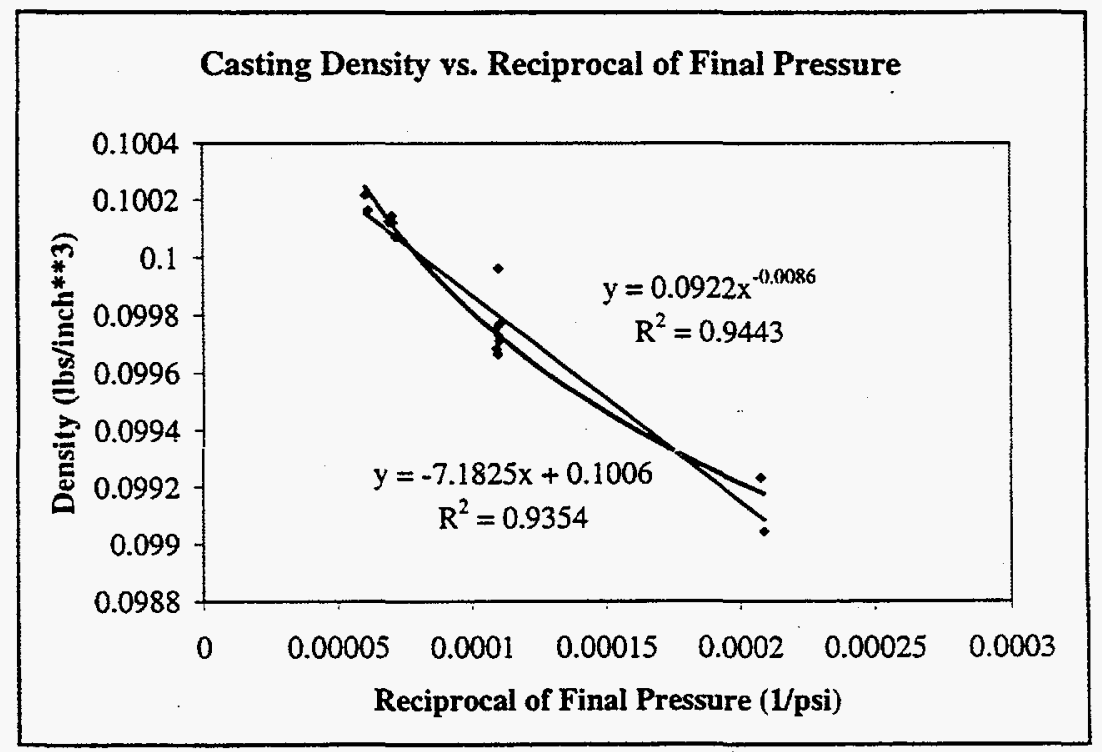

Figure 4.7 The effect of final pressure on casting density 


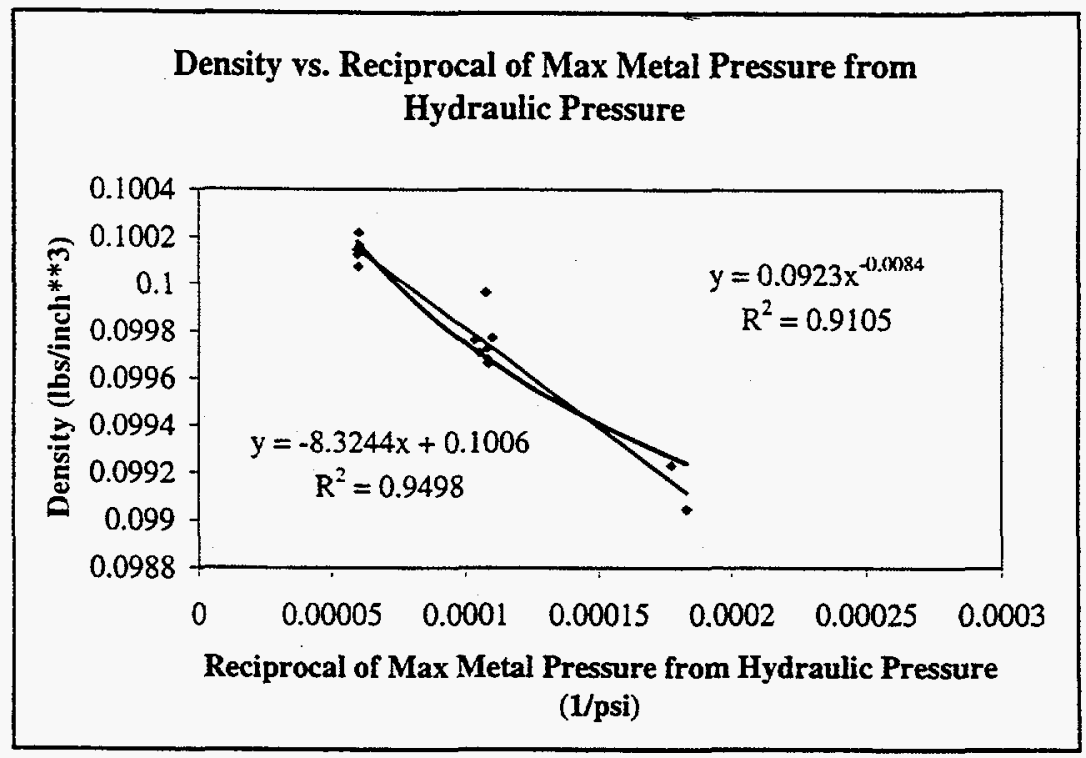

Figure 4.8 The effect of max metal pressure from hydraulic pressure on the casting density

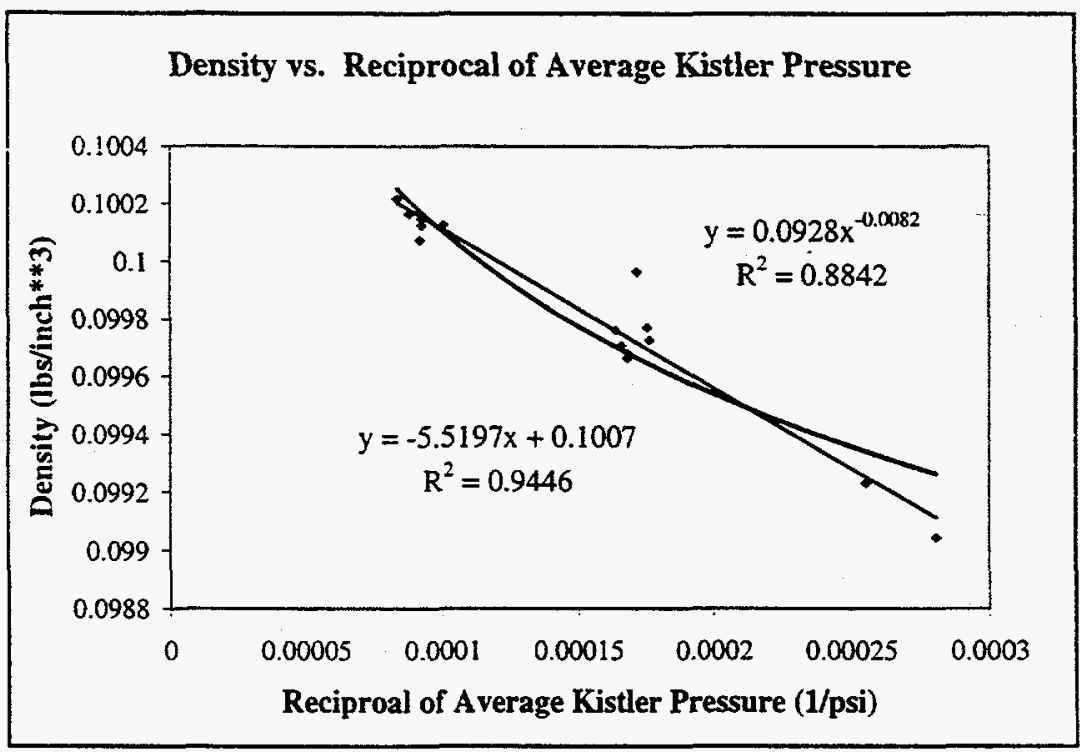

Figure 4.9 The effect of average Kistler pressure on the casting density 
Density vs. Reciprocal of Max Kistler Pressure

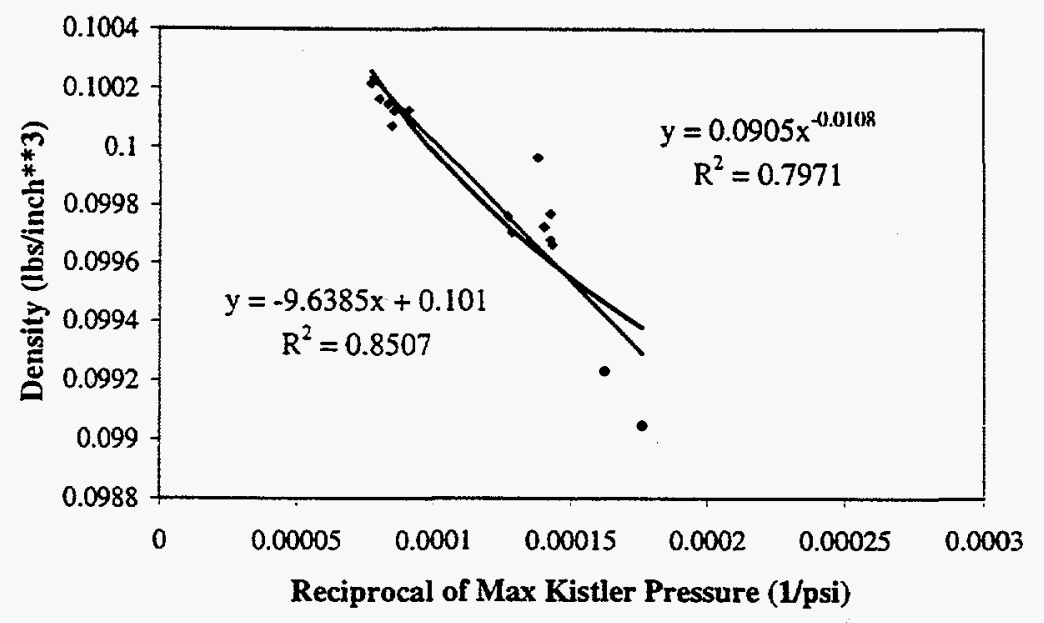

Figure 4.10 The effect of max Kistler pressure on the casting density

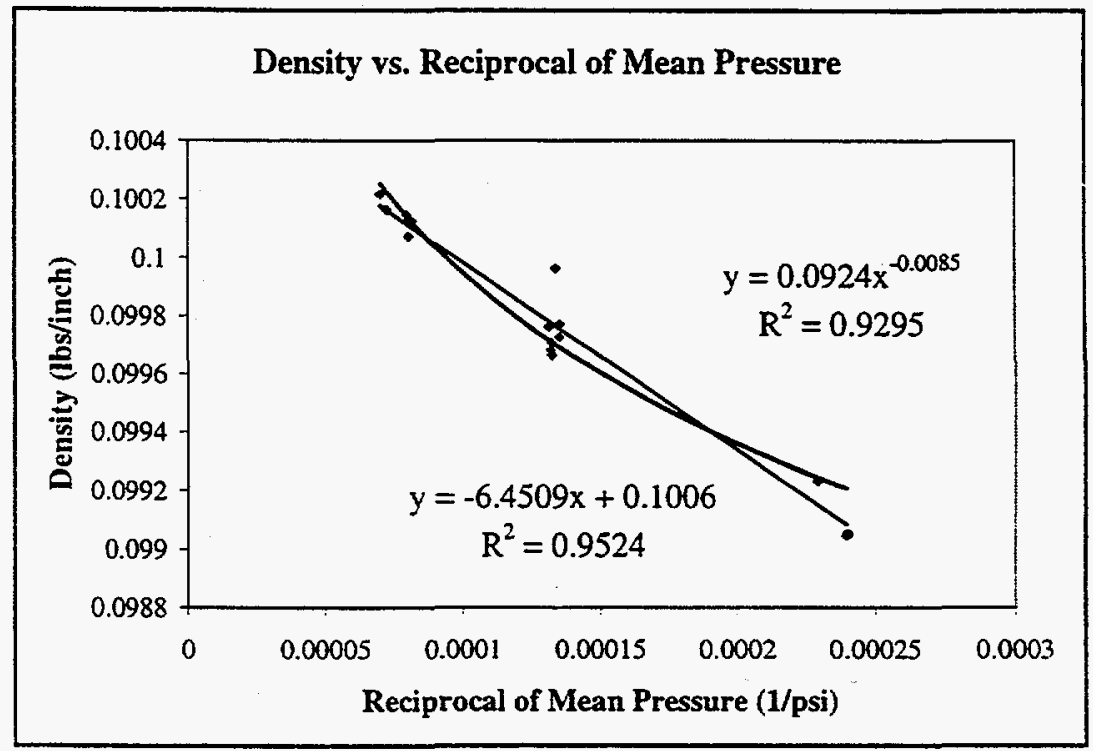

Figure 4.11 The effect of mean pressure on the casting density 
From the above figures, it can be concluded that the casting density increases with increasing pressure. For a given value of reciprocal of pressure, there always exist more than one density value that correspond to it. The significant difference exists in these figure is the variation of the data points. Part of the difference in $\mathrm{R}^{2}$ values can be attributed to the gradient of the trendline. The trendline of the Figure 4.10 has the minimum gradient and has the lowest $R^{2}$ value among these figures.

In terms of the $\mathrm{R}^{2}$ value (correlation coefficient), the mean pressure better correlates with casting density than other pressure parameters. The $\mathrm{R}^{2}$ values for trendline casting density vs. reciprocal of final pressure $\mathrm{y}=0.0922 \mathrm{x}^{-0.0086}$, maximum metal pressure from hydraulic pressure $y=-8.3244 x+0.1006$, average Kistler pressure $y=-5.5197 x+0.1007$, maximum Kistler pressure $y=-9.6385 x+0.101$, and mean pressure $y=-6.4509 x+0.1006$ are $0.9443,0.9498,0.9446,0.8507,0.9524$, respectively.

\subsection{THE EFFECTS OF APPLIED PRESSURE ON THE CASTING WEIGHT}

Weight equals the product of volume and density. To explore the effects of various pressure parameters on casting weight, the calculated casting weight value is acquired by multiplying the calculated density gathered from the equation of the trendline of the density versus various pressure parameters and the calculated volume gotten from the equation of the trendline of the volume versus various pressure parameters. These equation can be polynomial or power as long as it has the higher $R^{2}$ value. The calculated 
casting weight values are compared to the actual casting weight values by using the average relative error. The actual casting weight values, $\mathrm{Wt}_{\mathrm{act}}$ calculated casting weight

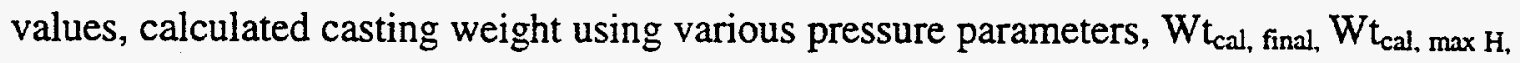
$\mathrm{Wt}_{\text {cal, aver }} \mathrm{K}, \mathrm{Wt} \mathrm{t}_{\mathrm{cal}}, \max \mathrm{k}, \mathrm{Wt} \mathrm{t}_{\mathrm{cal}}$, mean, and average absolute relative error of various pressure parameters, $\mathrm{E}_{\text {aveerage, abs }}$ are listed in Table 4.4.

Table 4.4 Actual casting weight, calculated casting weight, and average absolute relative error

\begin{tabular}{|c|c|c|c|c|c|c|}
\hline Shot & $\begin{array}{c}\mathrm{Wt}_{\mathrm{t}_{\text {act }}} \\
(\mathrm{lbs})\end{array}$ & $\begin{array}{c}\mathrm{Wt}_{\text {cal, final }} \\
(\mathrm{lbs})\end{array}$ & $\begin{array}{c}W \mathrm{t}_{\text {cal, max }} \mathrm{H} \\
(\mathrm{lbs})\end{array}$ & $\begin{array}{c}\mathrm{Wt}_{\text {cal, aveg } \mathrm{K}} \\
(\mathrm{lbs})\end{array}$ & $\begin{array}{c}\mathrm{Wt}_{\text {cal, max }} \mathrm{K} \\
(\mathrm{lbs})\end{array}$ & $\begin{array}{c}W t_{\text {cal, mean }} \\
(\mathrm{lbs})\end{array}$ \\
\hline 20 & 26.9149 & 26.9428 & 26.8659 & 26.8516 & 26.7582 & 26.8948 \\
\hline 50 & 26.8553 & 26.9365 & 26.8642 & 26.8516 & 26.7527 & 26.8914 \\
\hline 60 & 26.4673 & 26.4575 & 26.4244 & 26.5026 & 26.5974 & 26.4562 \\
\hline 90 & 26.3789 & 26.4551 & 26.3987 & 26.4334 & 26.5069 & 26.4272 \\
\hline 91 & 27.5936 & 27.8284 & 27.7423 & 27.5789 & 27.5726 & 27.6743 \\
\hline 120 & 27.7135 & 27.7274 & 27.7263 & 27.7777 & 27.7606 & 27.7170 \\
\hline 121 & 27.6856 & 27.7771 & 27.7442 & 27.7653 & 27.8137 & 27.7369 \\
\hline 123 & 26.8595 & 26.9340 & 26.8679 & 26.8057 & 26.7800 & 26.8708 \\
\hline 126 & 26.8494 & 26.9345 & 26.8737 & 26.8299 & 26.7993 & 26.8813 \\
\hline 131 & 26.8883 & 26.9311 & 26.8963 & 26.8649 & 26.9043 & 26.8942 \\
\hline 136 & 26.9427 & 26.9350 & 26.9148 & 26.8783 & 26.9211 & 26.9019 \\
\hline 151 & 26.8934 & 26.9287 & 26.8511 & 26.8105 & 26.7582 & 26.8701 \\
\hline 152 & 27.6933 & 27.7692 & 27.7414 & 27.7590 & 27.7363 & 27.7299 \\
\hline 153 & 28.0081 & 28.2055 & 27.7145 & 27.8801 & 27.9252 & 28.0077 \\
\hline 154 & 28.1923 & 28.2720 & 27.7223 & 28.0191 & 28.0476 & 28.1091 \\
\hline$E_{\text {average, abs }}(\%)$ & 0.28 & 0.30 & 0.23 & 0.32 & 0.12 \\
\hline
\end{tabular}

In terms of the average absolute relative error $0.12 \%$, the mean pressure is the best pressure parameter to establish the correlation with casting density, volume and density. 
The plots of actual casting weight versus final pressure, maximum metal pressure from hydraulic pressure, average Kistler pressure, maximum Kistler pressure, and mean pressure are shown in Figure 4.12, Figure 4.13, Figure 4.14, Figure 4.15, and Figure 4.16.

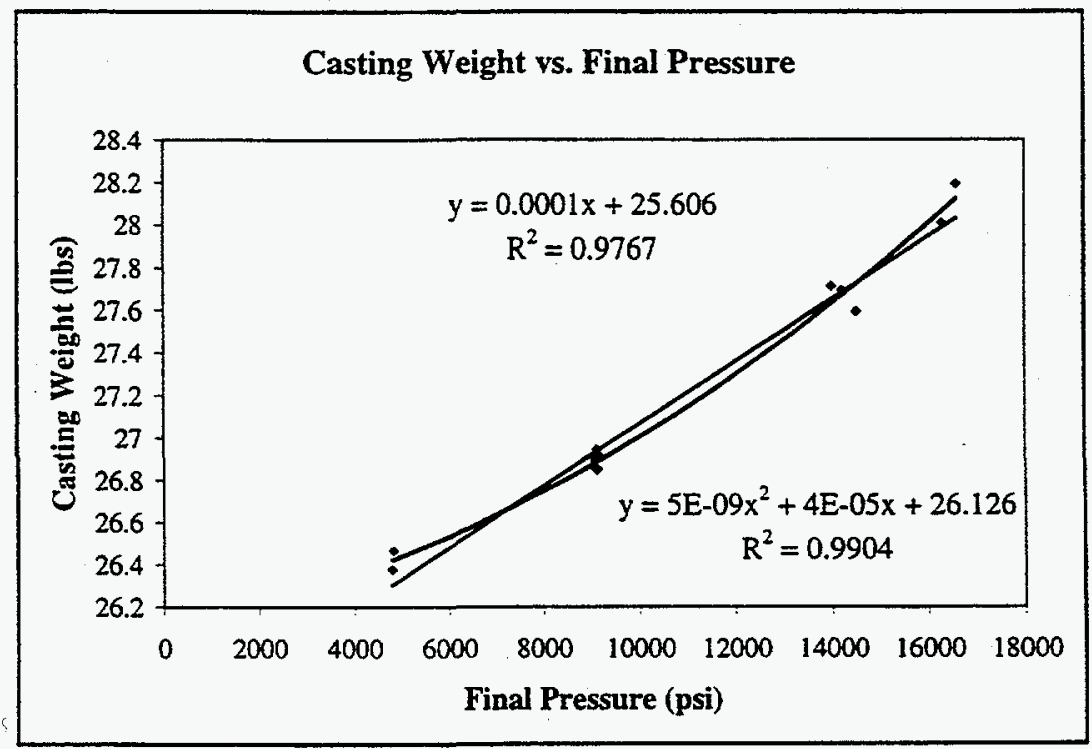

Figure 4.12 The effect of final pressure on the casting weight

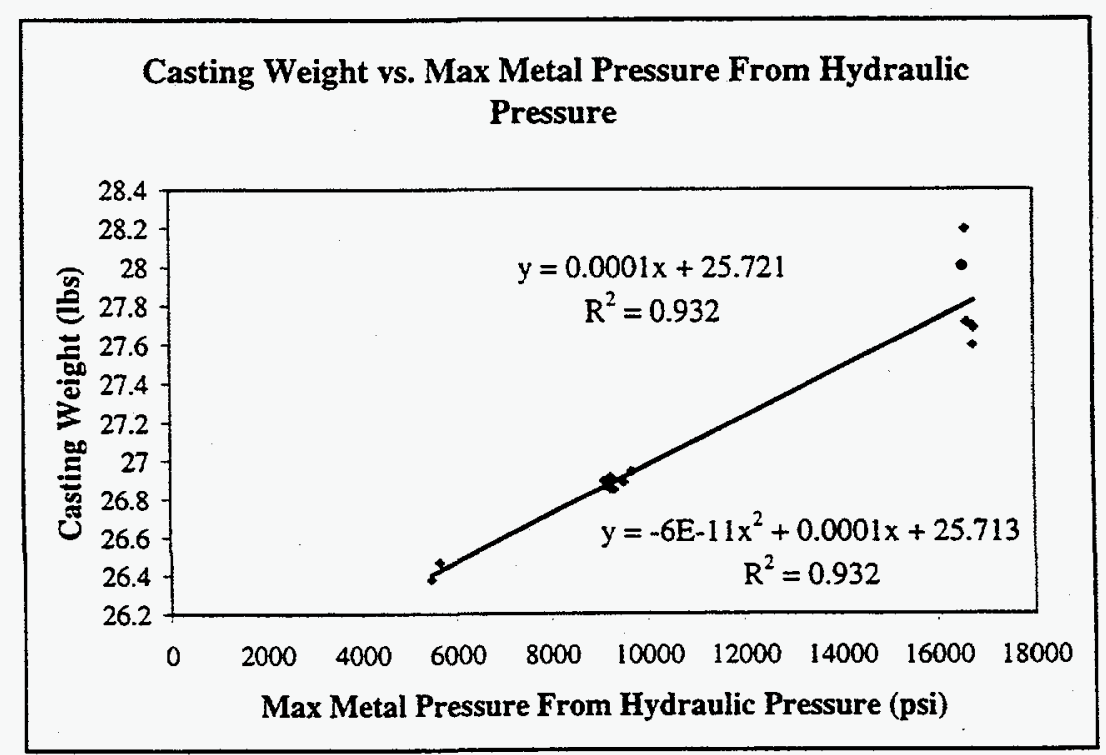

Figure 4.13 The effect of maximum metal pressure from hydraulic pressure on the casting weight 


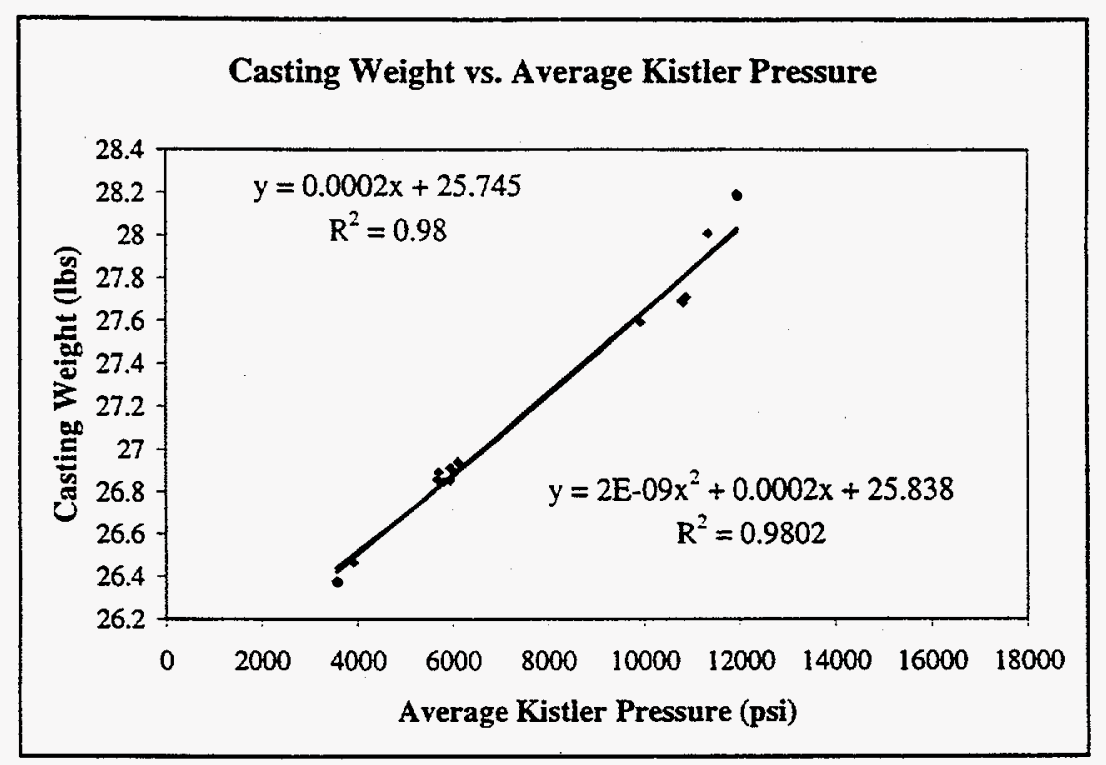

Figure 4.14 The effect of average Kistler pressure on the casting weight

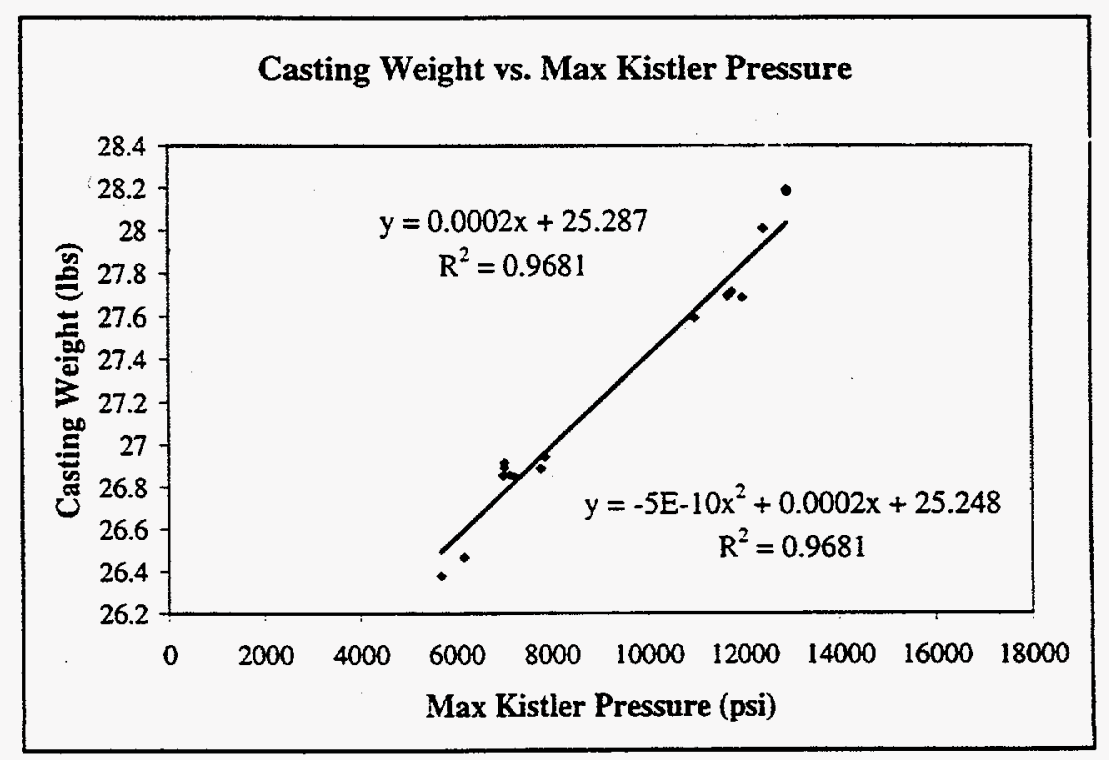

Figure 4.15 The effect of maximum Kistler pressure on the casting weight 


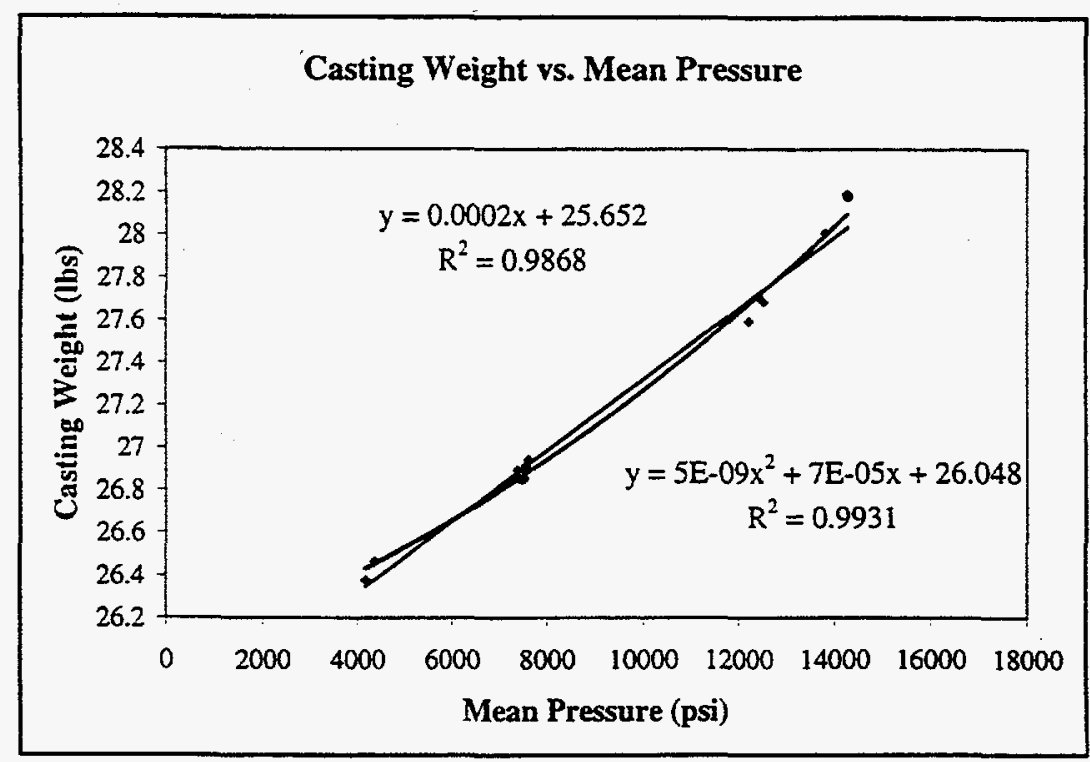

Figure 4.16 The effect of mean pressure on the casting weight

From the above figures, it can be concluded that the casting weight increases with increasing pressure. The distribution of data points in the Figure 4.16 is less ambiguous than Figure 4.12. Although the $\mathrm{R}^{2}$ value in Figure 4.12 are the second highest, there are more than one data points will correspond to a given final pressure. The distribution of data points in Figure 4.14 are no worse than Figure 4.16, but the range in which the data points fall are narrower than Figure 4.16. The range is even narrower in Figure 4.15 and the $\mathrm{R}^{2}$ value is lower than Figure 4.14. In Figure 4.13, the ambiguity is worsen around 17000 psi as compared to Figure 4.12 . The $\mathrm{R}^{2}$ values for the trendlines of casting weight vs. final pressure $y=5 E-9 x^{2}+4 E-5 x+26.126$, maximum metal pressure from hydraulic pressure $y=0.0001 x+25.721$, average Kistler pressure $y=0.0002 x+25.745$, maximum Kistler pressure $y=0.0002 x+25.287$, and mean pressure $y=5 E-9 x^{2}+7 E-5 x+26.048$ are $0.9904,0.932,0.98,0.9681,0.9931$, respectively. So that the mean pressure is the appropriate pressure parameter to correlate with the casting volume, density, and weight. 
The runner and biscuit of shots $20,50,60,90,91,120$ and overflows of 50,60 , $90,91,120$ were collected. The volume, $\mathrm{Vol}_{\mathrm{o}}, \mathrm{Vol}_{\mathrm{r}+\mathrm{b}}$, weight, $\mathrm{Wt}_{\mathrm{o}}, \mathrm{Wt}_{\mathrm{r}+\mathrm{b}}$, and density, $\rho_{\mathrm{o}}$, $\rho_{\mathrm{r}+\mathrm{b}}$, of the overflows, runner and biscuit were measured using Archimedes' density measurement method. The data are listed in Table 4.5. The casting density $\rho_{c}$ and final pressure $P_{\text {final }}$ data are also added.

\begin{tabular}{|c|c|c|c|c|c|c|c|c|}
\hline shot & $\begin{array}{c}P_{\text {final }} \\
(\mathrm{psi})\end{array}$ & $\begin{array}{c}\rho_{\mathrm{c}} \\
\left(\mathrm{lbs} / \mathrm{in}^{3}\right)\end{array}$ & $\begin{array}{c}\rho_{\mathrm{o}} \\
\left(\mathrm{lbs} / \mathrm{in}^{3}\right)\end{array}$ & $\begin{array}{c}\rho_{\mathrm{r}+\mathrm{b}} \\
\left(\mathrm{lbs} / \mathrm{in}^{3}\right)\end{array}$ & $\begin{array}{c}V_{\mathrm{O}_{\mathrm{o}}} \\
\left(\mathrm{in}^{3}\right)\end{array}$ & $\begin{array}{c}V_{0 l_{\mathrm{r}+b}} \\
\left(\mathrm{in}^{3}\right)\end{array}$ & $\begin{array}{c}\mathrm{Wt}_{\mathrm{o}} \\
(\mathrm{lbs})\end{array}$ & $\begin{array}{c}\mathrm{Wt}_{\mathrm{r}+\mathrm{b}} \\
(\mathrm{lbs})\end{array}$ \\
\hline 20 & 9167 & 0.09968 & - & 0.10043 & - & 94.8 & - & 9.5209 \\
\hline 50 & 9120 & 0.09966 & 0.09368 & 0.10040 & 16.70 & 101.60 & 1.5645 & 10.2011 \\
\hline 60 & 4811 & 0.09923 & 0.09573 & 0.10027 & 16.50 & 108.90 & 1.5795 & 10.9199 \\
\hline 90 & 4786 & 0.09905 & 0.09347 & 0.10011 & 16.50 & 100.50 & 1.5423 & 10.0613 \\
\hline 91 & 14507 & 0.10013 & 0.09766 & 0.10063 & 16.60 & 86.10 & 1.6211 & 8.6639 \\
\hline 120 & 13993 & 0.10007 & 0.09697 & 0.10047 & 16.70 & 92.40 & 1.6194 & 9.2831 \\
\hline
\end{tabular}

Table 4.5 Casting Weight, final pressure, weight, volume, and density of overflow, runner and biscuit of shot $20,50,60,90,91$, and 120 
By plotting the density of biscuit and runner, casting, and overflows versus reciprocal of final pressure, it is found that the density of runner and biscuit and density of casting increase with increasing final pressure; for a given final pressure the density of runner and biscuit is higher than the density of casting and the density of casting is higher than the density of overflows. The second finding can be attributed to the different pressures and gas content over pressure ratios in runner and biscuit, casting, and overflows during solidification.. Figure 4.17 shows the density of these three location versus the reciprocal of final pressure. Series 1 are the data points for runner and biscuit; series 2 are the data points for casting; and series 3 are the data points for overflows.

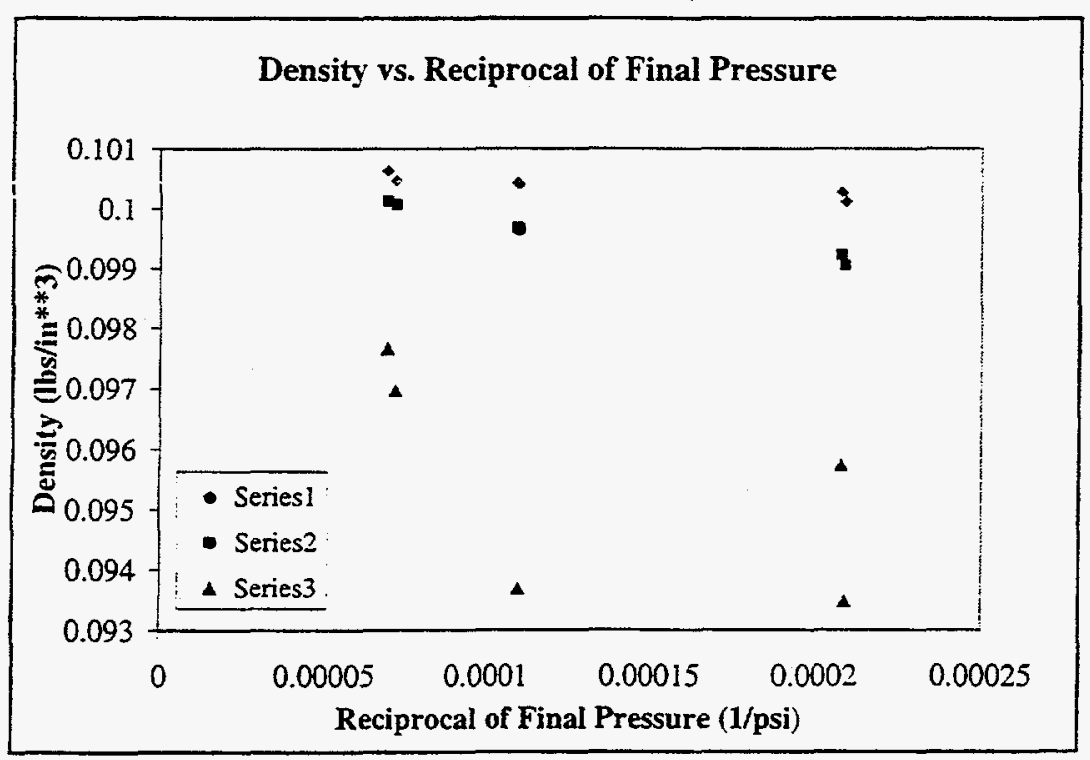

Figure 4.17 Density of runner and biscuit, casting, and overflows vs. reciprocal of final pressure 
Since the final pressure is the appropriate pressure parameter to represent the overall effects of pressure applied during solidification in runner and biscuit, the mean pressures are used instead of the final pressure to represent the overall effects of pressure applied in the die cavity for the casting. By plotting the density of runner and biscuit versus the reciprocal value of the final pressure and the density of casting versus the reciprocal value of the mean pressure multiplied by 3.2 in one plot and adding one trendline for both data point sets, a straight line with $R^{2}$ value 0.9774 is acquired. The density $\rho_{c}$ is a function of $v / P[13]$ as following:

$$
\begin{aligned}
& \rho_{\mathrm{c}}=\rho_{\mathrm{t}}(1-\Phi(v / \mathrm{P})) \\
& \Phi=\text { Constant } \\
& \nu=\text { Gas content in that part } \\
& P=\text { Representative pressure parameter in that part }
\end{aligned}
$$

The $v / P$ ratio in the casting is about three to four times that of the runner and biscuit. A common trendline for both data point sets can be achieved by simply multiplying the $1 / \mathrm{P}$ of the casting with the ratio of gas contents in these two parts. The plot is shown in Figure 4.18. 


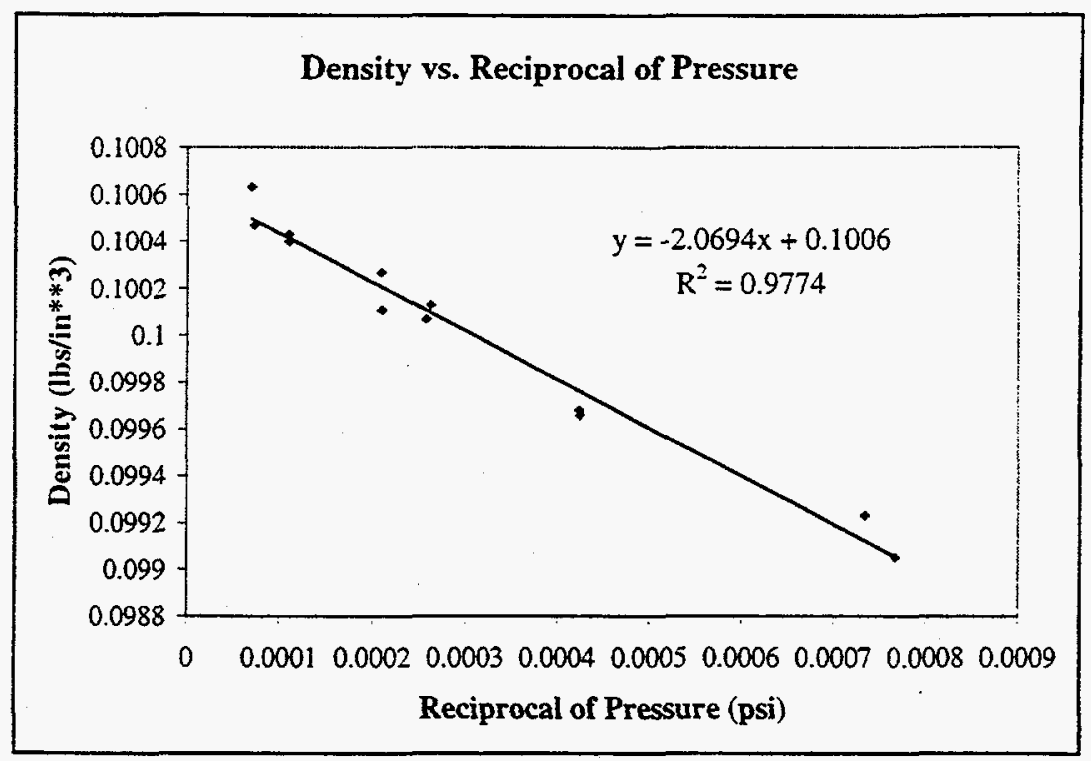

Figure 4.18 Density of runner and biscuit, casting versus reciprocal of final pressure for runner and biscuit and reciprocal of mean pressure

By comparing the equation of the trendline in Figure 4.18 to the Figure 4.11 , it can be found that the constants or theretical density values in both equations are the same; the slope of the trendline in Figure 4.18 is about 3.12 times the slope of the trendline in Figure 4.11. The number 3.12 is very close to the multiplier 3.2. This agreement confirms the assumption that the $v / P$ in casting is about 3.2 times the $v / P$ in runner and biscuit. It also suggests that the mean pressure is the appropriate pressure parameter for correlation with casting density. 
CHARPTER 5

CONCLUSIONS AND RECOMMANDATIONS

Based on the data acquired from the OSU (ERC/NSM) campaign and GM CADC campaign, it can be concluded that:

1. the Kistler in cavity pressure is reliable and durable. The Kistler pressure sensor was able to sustain the one hundred and fifty-six shot campaign without degradation.

2. Pressure records from the Kistler direct pressure sensor can provide insight into the die casting process and serve as necessary complementary data to the hydraulic pressure record. The pressure records from the Kistler direct pressure sensor together with hydraulic pressure records can not only provide the information on the metal pressure range in a die cavity but also detect impact, flashing, intensification start time, gate freezing time. 
3. The mean pressure between the average hydraulic pressure and the average Kistler pressure is the preferrable pressure parameter to correlate with casting volume, density, and weight. So that the Kister direct pressure records serve as necessary complementary to the hydraulic pressure record.

4. The difference in density values of runner and biscuit, casting, and overflows is mainly due to the difference in pressure applied during solidification and gas content at different locations

Recommendations:

1. Vacuum fusion measurement should be conducted on the runner and biscuit, and casting to determine the gas content.

2. The volume and density of the remainder of the DoE/GM castings should be measured to improve the stastical significance for each pressure condition. 


\section{BIBLIOGRAPHY}

1. ASM Handbook Volume 15 Casting, Ninth Edition, Metal Handbook ASM International (1992), pp. 286-295

2. Inorganic Chemicals Department, Dow Chemical U.S.A., Product Design and Development for Magnesium Die Castings, Form No. 141-523-84, pp. 109-124

3. A. Kaye and A. Street, Die Casting Metallurgy, Butterworth Scientific (1982), page 205

4. J. Mickowski, "System for Control Critical Parameters", NADCA Transactions, (1981), Paper No. G-T81-141, pp. 1-7

5. C. Mobley and J. Brevick, "Annual Report on Die Cavity Instrumentation OSURF Project 729390", Annual Report Number 2 (1996), Ohio State University Center for Die Casting

6. Y. Mochiku, Dr. Y. Hatamura, and K. Shirahige, "Intelligent Die Casting and Seven Sensors", NADCA Transactions, (1989), Paper No. G-T89-024, pp. 1-7

7. J. Papai and C. Mobley, "Die Thermal Field And Heat Fluxes During Die Casting of 380 Aluminum Alloy in H-13 Steel Dies", NADCA Transactions, (1991) DetroitT91-OC1, pp. 377-384

8. S. Booth and D.Allsop, "Thermal Control and Design of Dies", NADCA Transactions, (1981), Paper No. G-T81-056, pp. 1-7

9. Babington and Klepinger, "Aluminum Die Casting-The Effect of Process Variables on Their Properties", Proceedings ASTM, vol. 51, (1951) pp. 169-197

10. M. Phlipot, W. Willis, and O. Beckendorf, "The Evaluation of Selected Die Casting Process Parameters Using a Micro Processor-Based Process Monitoring System", NADCA Transactions, (1983), Paper No. G-T83-051, pp. 1-6 
11. M. Tokui, A. Morita, T. Masaoka, A. Ohta, I. Sužuki, and F. Kawano, "Development and Application of Vertical Pressure Die Casting Process", NADCA Transactions, (1983), Paper No. G-T83-061, pp. 1-6

12. Y. Sugiyama, H. Iwahori, K. Yonekura, and Y. Ookouchi, "Transferred pressure and casting qualities of aluminum die casting", Transactions of AFS, Vol. 45, (1996), pp. 121-124

13. A. Gordon, G. Meszaros, J. Naizer, and C. Mobley, "Equations for Predicting the Percent Porosity in Die Castings", NADCA Transactions, (1993), Cleveland T93-024, pp. 55-62

14. Y. Yamamoto, Y. Iwata, Dr. M. Nakamira, and Y. Oukouchi, "Molten Metal Velocities and Gas Pressure in Die Cavity and Defects in Commercial Aluminum Pressure Die Castings", NADCA Transactions, (1989), Paper No. G-T89-081, pp.1-8

15. V. Venkatasamy, "Analysis of In-Cavity Thermal and Pressure Characteristics in Aluminum Alloy Die Casting", Master Thesis, Department of Industrial System and Welding Engineering, The Ohio State University, (1997)

16. V. Venkatasamy, J. Brevick, G. Pribyl and C. Mobley, "Die Cavity Sensors for Monitoring Die Casting Processes", A Manuscript to NADCA for $19^{\text {th }}$ International Die Casting Congress and Exposition, (1997)

17. J. Mickowski and C. Teufert, "The control of Impact Pressure in the High Pressure in the High Pressure Die Casting Process", NADCA Transactions, (1993), Cleveland T93-122, pp. 349-354

18. N. Tsumagari, "Microstructural Features as a Measure of Process and Part Reproducibility in 390 Hypereutectic Aluminum-Silicon Alloy Die Castings", Doctoral Dissertation, Department of Materials Science and Engineering, The Ohio State University, (1995)

19. A. Kay, "Does Intensification Pressure Influence The Porosity Distribution In Aluminum Die Castings ?", Master Thesis, Department of Materials Science and Engineering, The Ohio State University, (1996)

20. A.W. Gordon, G.A. Meszaros, J.P. Naizer, P.R. Gangasani, and C. E. Mobley, "Comparison of Methods for Characterization Porosity in Die Castings", Report No. ERC/NSM-C-91-51, Engineering Research Center for Net Shape Manufascturing, The Ohio State University, Auguest, 1991

21. Prince Machine Corporation, One Prince Center, Holland, MI 49423, Pro-Manager Version 3 User's Manual, pp. 1-30 


\section{APPENDIX A}

\section{VADCA SURVEY OF DIE CAVTTY TNSTRUMENTATION}
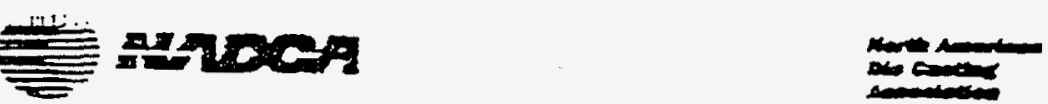

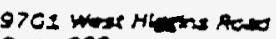
Sures 800

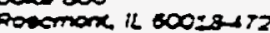
$7 C 2792,3000$ Treation $708.292 .3620 \mathrm{fur}$

\section{NADCA-SURVEY ON DIE CAVTY INSTRUMENTATION}

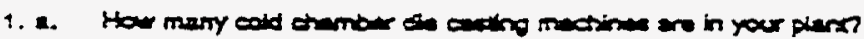

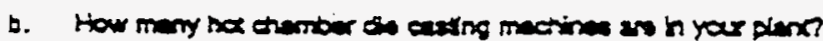

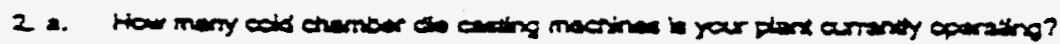

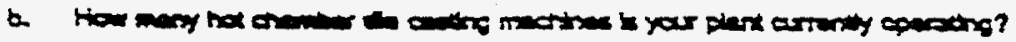

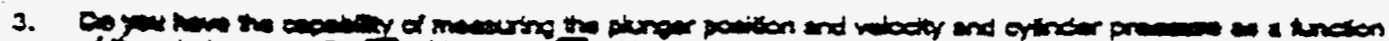

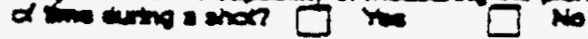

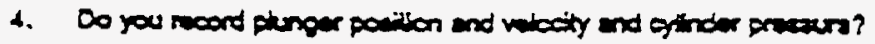
Enary $\sin$
Exry trat

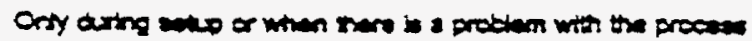

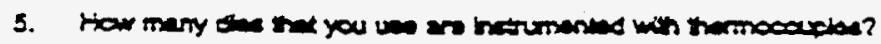

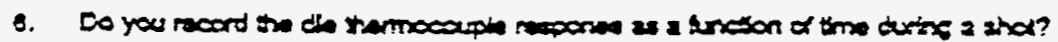

$\square$ Every and $\square$ Erery__ and

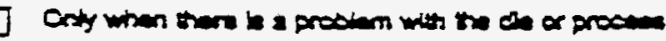

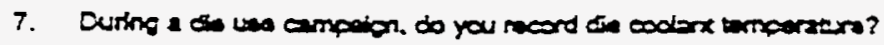
$\square$ Construousy
inturmibunty
Nener

8. Durng a dis ue empaken, do you noort dis codart how rate?
7 Cosinuruaty
incinitaraty
Nomer

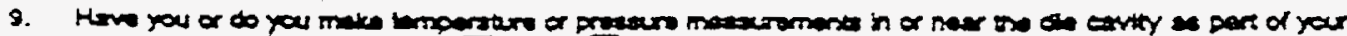
procose moritorixg or cortion $\square$ Vew is

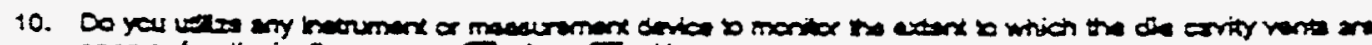
conen or hustioning $\square$ tow $\square$

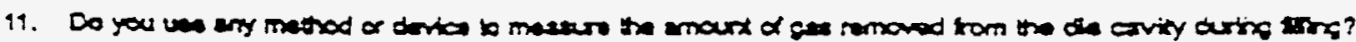
ras No

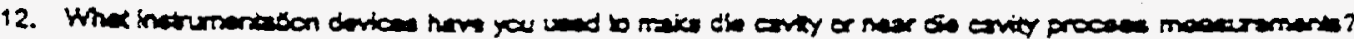

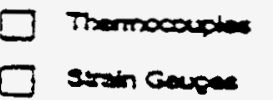

$$
\begin{aligned}
& \text { Traneducers } \\
& \text { Orer (Fuav expins: }
\end{aligned}
$$

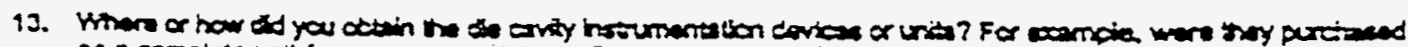

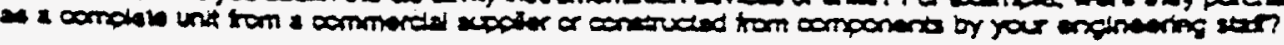




\section{NADCA' SURVEY ON DIE CAVTYY INSTRUMENTATION (cOntInUEd)}

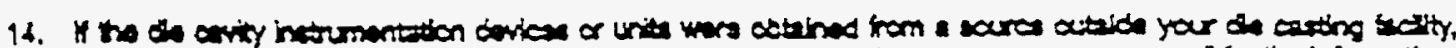

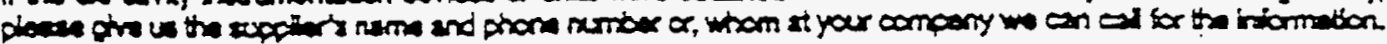

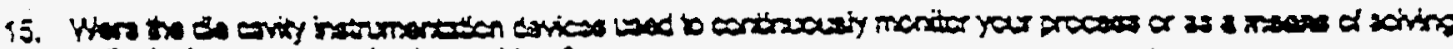
ain decion ex pert producter prodem?

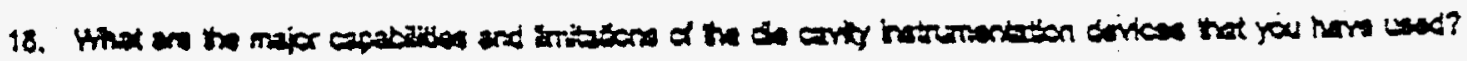

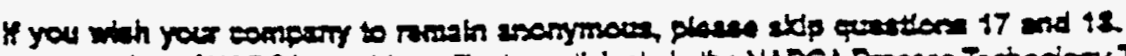

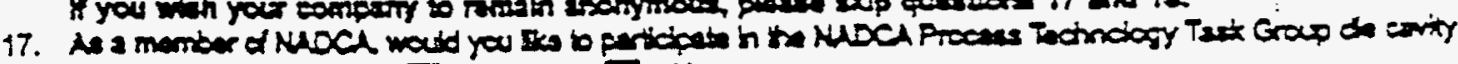
irasumartition projed?

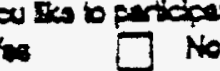

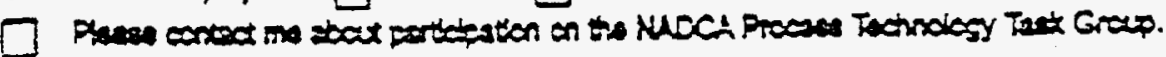

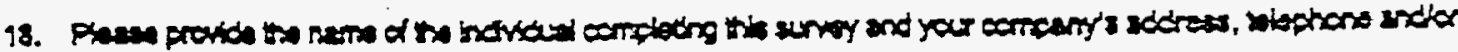
tex number.

incasduar's Mames.

Company Nars:

Company Addres:

Corrangy Ptan:

Compeny Fax

Platse rond your conpleted survy to:

Atuntion: Protwerer Curral Labloy

co Chio sin Utivarity

Dep. use

Fontern

118 Hex 19 m sirme

Coimbur Oris 43210

Fax (814) $202-1537$ 


\section{TECHNICAL SPECIFICATIONS OF BUHLER H-250SC}

TECHNICAL DATA (sUbjECE to moelfiestion wilhout notiee)

BUHLER

Hortzonga! Cold-Chmbar Ofa Caseing Macnine H-2SOSC

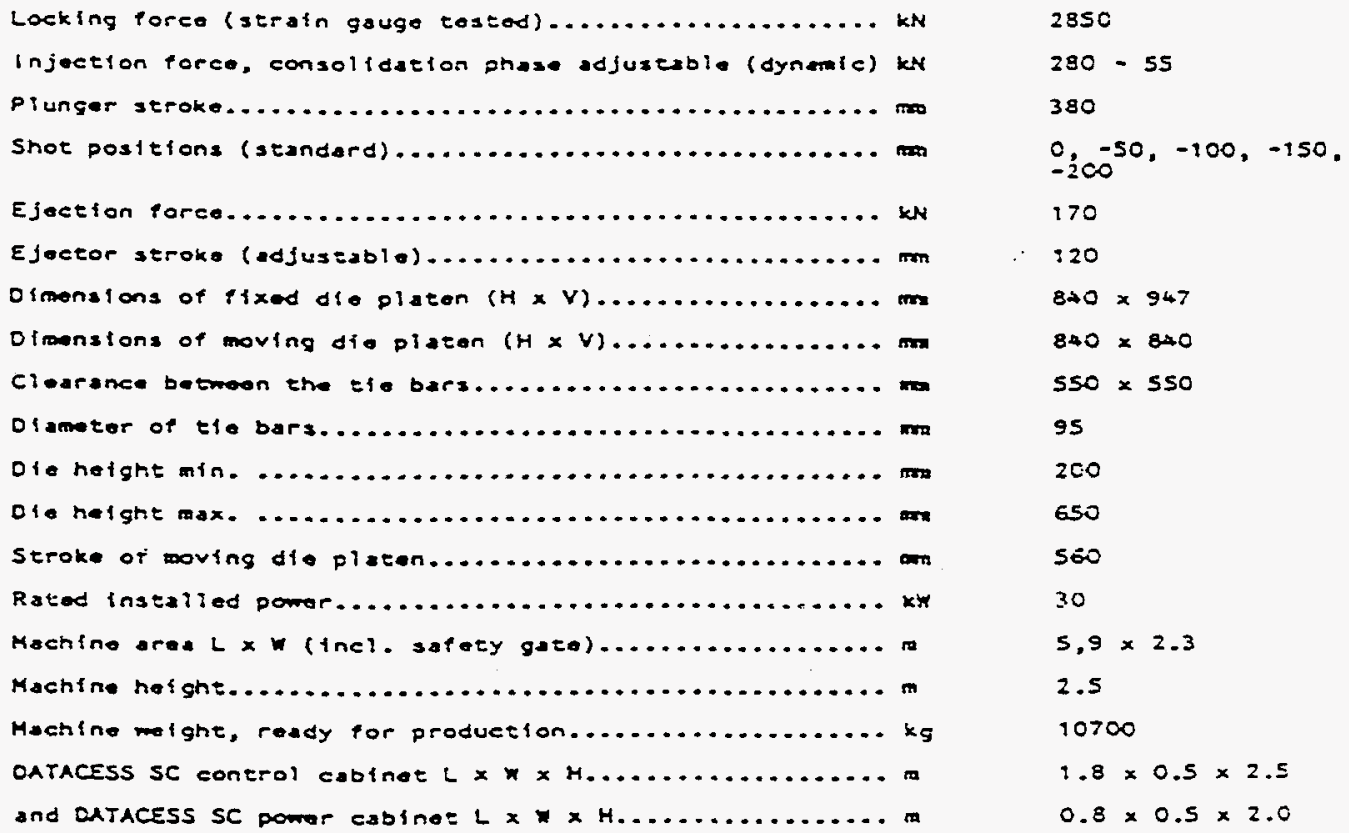

Production data

\begin{tabular}{|c|c|c|c|c|c|c|c|c|c|}
\hline Plunger el moeer & $\min$ & 40 & 45 & so & 55 & 60 & .70 & 80 & 90 \\
\hline $\begin{array}{l}\text { Theoreticel shot volictho } \\
\text { (DiN } 24480)\end{array}$ & $\mathrm{cm} 3$ & 378 & 402 & 497 & 601 & 716 & 975 & 1273 & $16: 9$ \\
\hline $\begin{array}{l}\text { Max. shot lght for } \\
\text { Al }\end{array}$ & kg & 0.9 & $\therefore$ & 1.4 & 1.7 & 2.0 & 2.75 & 3.6 & 4.5 \\
\hline $\begin{array}{l}\text { Mox. spectetc injoetion } \\
\text { prosisure }\end{array}$ & bar & 2230 & 1760 & 1430 & 1180 & 990 & .30 & 560 & 440 \\
\hline Max. projoctod aroam & $\ln 2$ & 128 & 162 & 200 & 241 & 288 & 390 & 509 & $6 \div 8$ \\
\hline
\end{tabular}
- The max. shot wight is caiculated as followa:
plunger strokex plunger aroa $x 0.75 \times$ denilisy
Oonsiky o:
2.5 S. $6.25 \quad 1.63 \quad 8.0$

- Max. Eneoreficai projected aroa dt max. spoctiti injection pressure, mithout consideration of coro locking and dynarie pert of injection procoss. 


\section{APPENDIX C}

\section{MLACHMNE SET-UP ANALYSIS}

\begin{tabular}{|c|c|c|c|c|}
\hline Measured Plunger Diameter & $=$ & $49.2 \mathrm{~mm}$ & $=$ & 1.937 inch \\
\hline $\begin{array}{l}\text { Hydraulic Cylinder Diameter } \\
\text { (Page 2/33, Buhler Manual 1) }\end{array}$ & $=$ & $145 \mathrm{~mm}$ & $=$ & 5.709 inches \\
\hline Hydraulic Cylinder Diameter / & Measured Pl & lunger Diameter & & 2.947 \\
\hline $\begin{array}{l}\text { Recommended Gate Velocity } \\
\text { (NADCA Guidelines) }\end{array}$ & & & $=$ & 1400 inches $/ \mathrm{sec}$ \\
\hline Measured Gate Area & & & $=$ & 0.32 inch $^{2}$ \\
\hline Volumetric Flow Rate $=$ & Gate Velocit & $y *$ Gate Area & $=$ & $504 \mathrm{inch}^{3} / \mathrm{sec}$ \\
\hline Measured Cavity (i.e. casting & $\div$ overflow) & Volume & $=$ & 6.1 inch $^{3}$ \\
\hline $\begin{aligned} \text { Cavity Fill Time } & = \\
& =\end{aligned}$ & $\begin{array}{l}\text { Cavity Volur } \\
12.1 \mathrm{~ms}\end{array}$ & me / Volumetric & Flow $R$ & Rate \\
\hline Measured Total Casting (i.e. b & $\begin{aligned} \text { biscuit } & \div \text { runn } \\
& =\end{aligned}$ & $\begin{array}{c}\text { ler } \div \text { gate } \div \text { casti } \\
11.05 \text { incin }^{3}\end{array}$ & $n g \div 0$ & erflow) Volume \\
\hline Measured Shot Sleeve Length & $=$ & 14.055 inches & & \\
\hline Calculated Shot Sleeve Volum & $\begin{array}{l}= \\
=\end{array}$ & $\begin{array}{l}\pi / 4 *(\text { Plunger } \\
41.44 \text { inch }^{3}\end{array}$ & Diame & ter) $)^{2 *}$ Shot Sleeve Length \\
\hline Percent Shot Sleeve Fill & $\begin{array}{l}100 \\
26.6\end{array}$ & $\begin{array}{l}\text { * Total Casting } \\
7 \%\end{array}$ & & I Shot Sleeve Volume \\
\hline
\end{tabular}




$$
\begin{aligned}
\text { Calculated Injection Pressure } & =(d / D)^{2} * p^{*} V_{g}{ }^{2 / 2} * g * C_{D}{ }^{2} \\
& =70.64 \mathrm{psi}
\end{aligned}
$$

where

$$
\begin{aligned}
& \mathrm{d}=\text { Plunger Diameter, inch } \\
& \text { D = Hydraulic Cy;inder Diameter, inch } \\
& \rho=\text { Alloy Density, lb/inch }{ }^{3}=0.087{\mathrm{lb} / \text { inch }^{3}} \\
& \mathrm{~V}_{\mathrm{g}}=\text { Gate Velocity, inch/sec } \\
& \mathrm{g}=\text { Gravitational Acceleration. inch } / \mathrm{sec}^{2}=386 \mathrm{inch} / \mathrm{sec}^{2} \\
& C_{D}=\text { Gate Coefficieny of Discharge }=0.6
\end{aligned}
$$

$\begin{array}{lll}\text { Intensification Pressure } & =20 * \text { Injection Pressure }=1412.8 \text { psi } \\ \text { Projected Area of Casting } & =44.95 \text { inch }^{2} \\ \text { Locking Force } & =\text { Projected Area of Casting * Intensification Pressure } \\ & =63505.36 \text { psi } \\ \text { Plunger Cross Sectional Area } & =\quad \text { Plunger Diameter }{ }^{2} \pi / 4 \\ & =2.948 \text { inch }{ }^{2} \\ \text { Fast Shot Velocity } & =\quad \text { Volumetric Flow Rate / Plunger Cross Sectional Area } \\ & =170.96 \text { inch/sec }\end{array}$

Slow Shot Profile (Thome Model : Straight Line Acceleration)

\begin{tabular}{|l|l|}
\hline Plunger Position, inch (m) & Plunger Velocity, inch/sec (m/sec) \\
\hline $0(0)$ & \\
$9.07(0.23)$ & $0(0)$ \\
$10.31(0.26)$ & $24.98(0.63)$ \\
$11.19(0.28)$ & $24.98(0.63)$ \\
$13.26(0.34)$ & $170.96(4.34)$ \\
\hline
\end{tabular}




\section{APPENDIX D}

$P^{2}$ ANALYSIS

BUHLER

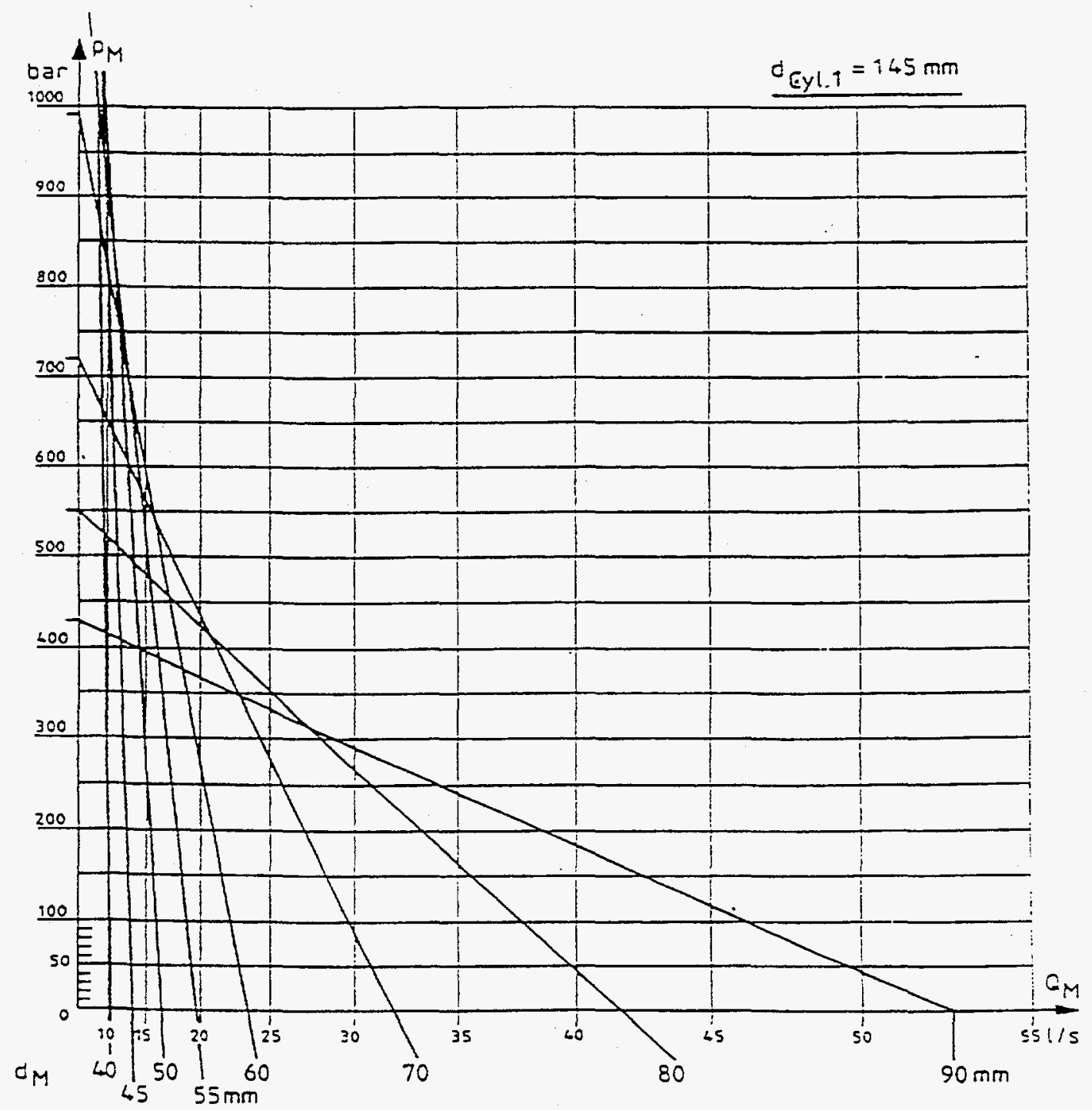




\section{APPENDIX E}

\section{DoE/ GM Data Summary}

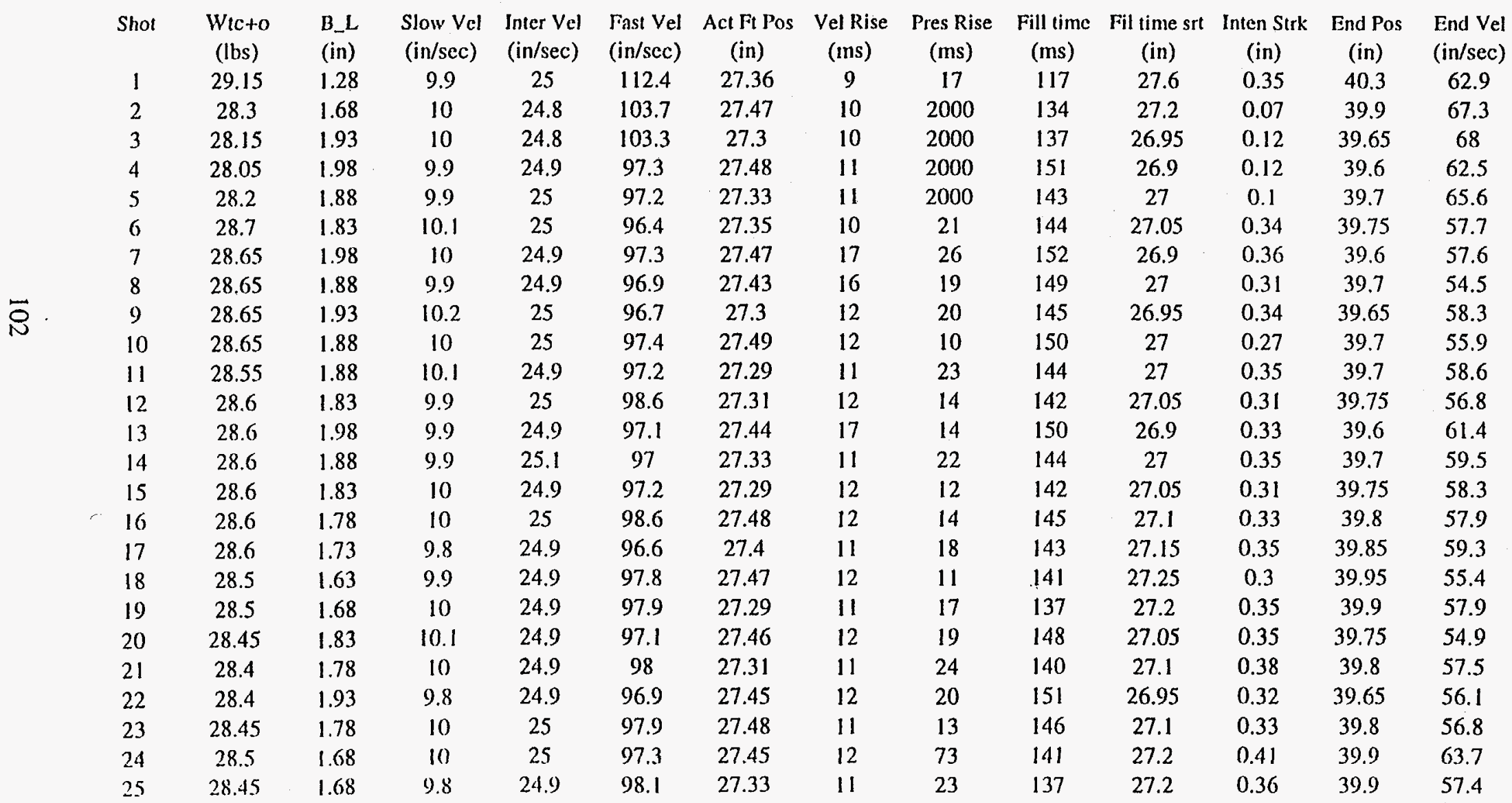




\begin{tabular}{|c|c|c|c|c|c|c|c|c|c|c|c|c|c|}
\hline Shot & $\begin{array}{c}\text { Wicto } \\
\text { (lbs) }\end{array}$ & $\begin{array}{l}\text { B_L } \\
\text { (in) }\end{array}$ & $\begin{array}{c}\text { Slow Vel } \\
\text { (in/sec) }\end{array}$ & $\begin{array}{l}\text { Inter Vel } \\
(\mathrm{in} / \mathrm{sec})\end{array}$ & $\begin{array}{l}\text { Fast Vel } \\
(\mathrm{in} / \mathrm{sec})\end{array}$ & $\begin{array}{l}\text { Act Fi Pos } \\
\quad \text { (in) }\end{array}$ & $\begin{array}{l}\text { Vel Rise } \\
\text { (ms) }\end{array}$ & $\begin{array}{l}\text { Pres Rise } \\
\text { (ms) }\end{array}$ & $\begin{array}{l}\text { Fill time } \\
\text { (ms) }\end{array}$ & $\begin{array}{l}\text { Fil time srt } \\
\text { (in) }\end{array}$ & $\begin{array}{l}\text { Inten Strk } \\
\text { (in) }\end{array}$ & $\begin{array}{l}\text { End Pos } \\
\text { (in) }\end{array}$ & $\begin{array}{l}\text { End Vel } \\
(\mathrm{in} / \mathrm{sec})\end{array}$ \\
\hline 26 & 28.4 & 1.63 & 10 & 24.8 & 97.8 & 27.48 & 11 & 12 & 142 & 27.25 & 0.33 & 39.95 & 55.1 \\
\hline 27 & 28.35 & 1.68 & 10 & 24.9 & 95.7 & 27.47 & 11 & 17 & 144 & 27.2 & 0.34 & 39.9 & 57.8 \\
\hline 28 & 28.45 & 1.78 & 10.4 & 24.9 & 98.2 & 27.29 & 12 & 15 & 139 & 27.1 & 0.33 & 39.8 & 58.1 \\
\hline 29 & 28.45 & 1.53 & 10 & 25 & 98.2 & 27.34 & 11 & 24 & 134 & 27.35 & 0.4 & 40.05 & 58.6 \\
\hline 30 & 28.4 & 2.33 & 9.9 & 25 & 96.9 & 27.46 & 17 & 28 & 162 & 26.55 & 0.4 & 39.25 & 60.3 \\
\hline 31 & 28.4 & 2.33 & 10.1 & 24.9 & 97.7 & 27.31 & 16 & 31 & 157 & 26.55 & 0.39 & 39.25 & 60 \\
\hline 32 & 28.35 & 2.38 & 9.9 & 24.9 & 96.8 & 27.29 & 16 & 12 & 160 & 26.5 & 0.31 & 39.2 & 58 \\
\hline 33 & 28.45 & 2.48 & 9.9 & 25 & 97.2 & 27.48 & 16 & 24 & 168 & 26.4 & 0.39 & 39.1 & 58.8 \\
\hline 34 & 28.5 & 2.33 & 10 & 24.8 & 98.5 & 27.47 & 17 & 11 & 163 & 26.55 & 0.35 & 39.25 & 56.5 \\
\hline 35 & 28.45 & 2.38 & 9.9 & 24.9 & 98.4 & 27.43 & 16 & 21 & 162 & 26.5 & 0.39 & 39.2 & 58.8 \\
\hline 36 & 28.45 & 2.33 & 10.3 & 25 & 97.5 & 27.38 & 16 & 16 & 160 & 26.55 & 0.34 & 39.25 & 56.9 \\
\hline 37 & 28.45 & 2.23 & 10.1 & 24.8 & 97.8 & 27.29 & 16 & 12 & 154 & 26.65 & 0.33 & 39.35 & 58.4 \\
\hline 38 & 28.4 & 2.23 & 10 & 25 & 97.1 & 27.29 & 16 & 17 & 154 & 26.65 & 0.34 & 39.35 & 59.3 \\
\hline 39 & 28.4 & 2.28 & 10.3 & 25 & 98.5 & 27.37 & 17 & 19 & 157 & 26.6 & 0.39 & 39.3 & 57.3 \\
\hline 40 & 28.4 & 2.23 & 10 & 25 & 98.4 & 27.44 & 16 & 19 & 158 & 26.65 & 0.34 & 39.35 & 59.1 \\
\hline 41 & 28.4 & 2.28 & 10 & 24.7 & 98.3 & 27.48 & 18 & 20 & 163 & 26.6 & 0.38 & 39.3 & 53.9 \\
\hline 42 & 28.45 & 2.28 & 10 & 25 & 99.2 & 27.32 & 17 & 27 & 155 & 26.6 & 0.41 & 39.3 & 58.6 \\
\hline 43 & 28.45 & 2.23 & 9.8 & 24.9 & 98.3 & 27.32 & 16 & 27 & 154 & 26.65 & 0.41 & 39.35 & 59.2 \\
\hline 44 & 28.4 & 2.23 & 10.5 & 24.9 & 98.6 & 27.39 & 16 & 21 & 156 & 26.65 & 0.38 & 39.35 & 59.4 \\
\hline 45 & 28.4 & 2.18 & 10 & 24.9 & 98.9 & 27.46 & 18 & 19 & 158 & 26.7 & 0.38 & 39.4 & 58.7 \\
\hline 46 & 28.4 & 2.13 & 10 & 24.9 & 98.5 & 27.48 & 12 & 10 & 157 & 26.75 & 0.31 & 39.45 & 56.2 \\
\hline 47 & 28.4 & 2.23 & 10 & 24.8 & 97.9 & 27.46 & 18 & 26 & 160 & 26.65 & 0.4 & 39.35 & 55.4 \\
\hline 48 & 28.45 & 2.28 & 10.1 & 24.9 & 99.7 & 27.42 & 17 & 21 & 158 & 26.6 & 0.38 & 39.3 & 58.1 \\
\hline 49 & 28.5 & 2.18 & 9.9 & 24.9 & 99.2 & 27.33 & 16 & 31 & 152 & 26.7 & 0.42 & 39.4 & 61.4 \\
\hline 50 & 28.4 & 2.18 & 9.9 & 24.9 & 98.5 & 27.45 & 17 & 24 & 157 & 26.7 & 0.38 & 39.4 & 59.4 \\
\hline 51 & 27.9 & 2.13 & 10 & 25 & 98 & 27.49 & 16 & 2000 & 156 & 26.75 & 0.1 & 39.45 & 65.2 \\
\hline 52 & 27.8 & 2.23 & 10.4 & 25 & 98.2 & 27.42 & 16 & 2000 & 156 & 26.65 & 0.09 & 39.35 & 64.6 \\
\hline 53 & 27.85 & 2.18 & 10.3 & 24.9 & 97.9 & 27.36 & 17 & 2000 & 153 & 26.7 & 0.11 & 39.4 & 64.9 \\
\hline 54 & 27.85 & 2.28 & 9.9 & 24.9 & 97.4 & 27.46 & 16 & 2000 & 159 & 26.6 & 0.11 & 39.3 & 67.8 \\
\hline 55 & 27.85 & 2.13 & 9.9 & 24.9 & 98 & 27.5 & 16 & 2000 & 156 & 26.75 & 0.1 & 39.45 & 65 \\
\hline 56 & 27.95 & 2.13 & 10 & 24.9 & 99 & 27.35 & 16 & 2000 & 150 & 26.75 & 0.14 & 39.45 & 67.2 \\
\hline
\end{tabular}




\begin{tabular}{|c|c|c|c|c|c|c|c|c|c|c|c|c|c|}
\hline Shot & $\begin{array}{c}\text { Wicto } \\
(\mathrm{lbs})\end{array}$ & $\begin{array}{l}\text { B_L } \\
\text { (in) }\end{array}$ & $\begin{array}{l}\text { Slow Vel } \\
\text { (in/sec) }\end{array}$ & $\begin{array}{l}\text { Inter Vel } \\
\text { (in/sec) }\end{array}$ & $\begin{array}{l}\text { Fast Vel } \\
(\mathrm{in} / \mathrm{sec})\end{array}$ & $\begin{array}{l}\text { Act Ft Pos } \\
\text { (in) }\end{array}$ & $\begin{array}{c}\text { Vel Rise } \\
\text { (ms) }\end{array}$ & $\begin{array}{c}\text { Pres Rise } \\
(\mathrm{ms})\end{array}$ & $\begin{array}{l}\text { Fill time } \\
(\mathrm{ms})\end{array}$ & $\begin{array}{l}\text { Fil time srt } \\
\text { (in) }\end{array}$ & $\begin{array}{l}\text { Inten Strk } \\
\text { (in) }\end{array}$ & $\begin{array}{l}\text { End Pos } \\
\text { (in) }\end{array}$ & $\begin{array}{l}\text { End Vel } \\
\text { (in/sec) }\end{array}$ \\
\hline 57 & 27.9 & 2.08 & 10 & 25 & 98.2 & 27.32 & 12 & 2000 & 149 & 26.8 & 0.12 & 39.5 & 65.1 \\
\hline 58 & 27.85 & 2.43 & 9.9 & 24.9 & 98.7 & 27.46 & 18 & 2000 & 165 & 26.45 & 0.11 & 39.15 & 65.3 \\
\hline 59 & 27.85 & 2.43 & 9.9 & 24.8 & 98.2 & 27.48 & 17 & 2000 & 165 & 26.45 & 0.14 & 39.15 & 65.8 \\
\hline 60 & 28.1 & 2.38 & 10 & 25 & 99.3 & 27.47 & 16 & 2000 & 162 & 26.5 & 0.19 & 39.2 & 68.6 \\
\hline 61 & 28 & 2.23 & 9.9 & 24.8 & 98.1 & 27.46 & 17 & 2000 & 158 & 26.65 & 0.11 & 39.35 & 64.4 \\
\hline 62 & 28.05 & 2.23 & 10.3 & 24.9 & 99.9 & 27.38 & 17 & 2000 & 154 & 26.65 & 0.19 & 39.35 & 66.3 \\
\hline 63 & 28 & 2.33 & 9.9 & 25 & 99.1 & 27.46 & 17 & 2000 & 160 & 26.55 & 0.15 & 39.25 & 66.6 \\
\hline 64 & 28.05 & 2.28 & 10.1 & 24.9 & 99.3 & 27.31 & 16 & 2000 & 153 & 26.6 & 0.23 & 39.3 & 67 \\
\hline 65 & 27.9 & 2.33 & 10 & 24.9 & 97.7 & 27.46 & 16 & 2000 & 161 & 26.55 & 0.1 & 39.25 & 64.9 \\
\hline 66 & 27.95 & 2.28 & 10.2 & 24.8 & 98.8 & 27.4 & 17 & 2000 & 158 & 26.6 & 0.15 & 39.3 & 64 \\
\hline 67 & 27.85 & 2.43 & 10.3 & 24.9 & 98.8 & 27.38 & 17 & 2000 & 162 & 26.45 & 0.15 & 39.15 & 66.9 \\
\hline 68 & 27.95 & 2.23 & 10.4 & 24.9 & 99.1 & 27.4 & 16 & 2000 & 155 & 26.65 & 0.14 & 39.35 & 64.2 \\
\hline $\begin{array}{l}69 \\
70\end{array}$ & 28 & 2.28 & 10.2 & 25.1 & 99 & 27.35 & 16 & 2000 & 155 & 26.6 & 0.19 & 39.3 & 64.6 \\
\hline 70 & 28.2 & 2.18 & 10.3 & 24.9 & 99 & 27.39 & 18 & 2000 & 154 & 26.7 & 0.17 & 39.4 & 64.4 \\
\hline 71 & 28.05 & 2.13 & 10 & 24.8 & 97.9 & 27.48 & 18 & 2000 & 155 & 26.75 & 0.22 & 39.45 & 68.2 \\
\hline 72 & 27.95 & 2.13 & 9.9 & 24.9 & 98 & 27.33 & 16 & 2000 & 151 & 26.75 & 0.14 & 39.45 & 61.4 \\
\hline 73 & 28.05 & 2.23 & 10 & 24.8 & 98.4 & 27.49 & 17 & 2000 & 158 & 26.65 & 0.21 & 39.35 & 68.5 \\
\hline 74 & 28 & 2.18 & 10.2 & 24.8 & 98.7 & 27.46 & 18 & 2000 & 157 & 26.7 & 0.21 & 39.4 & 65.8 \\
\hline 75 & 28 & 2.13 & 9.9 & 24.9 & 98.1 & 27.3 & 16 & 2000 & 149 & 26.75 & 0.17 & 39.45 & 67.6 \\
\hline 76 & 28.05 & 2.13 & 9.9 & 24.9 & 97.1 & 27.3 & 16 & 2000 & 151 & 26.75 & 0.15 & 39.45 & 63.7 \\
\hline 77 & 27.9 & 2.18 & 10 & 24.8 & 99.3 & 27.3 & 17 & 2000 & 152 & 26.7 & 0.1 & 39.4 & 62.6 \\
\hline 78 & 27.8 & 2.13 & 10 & 24.9 & 98.1 & 27.5 & 15 & 2000 & 156 & 26.75 & 0.15 & 39.45 & 63.2 \\
\hline 79 & 28.1 & 2.08 & 9.9 & 25 & 100 & 27.36 & 16 & 2000 & 148 & 26.8 & 0.25 & 39.5 & 68.3 \\
\hline 80 & 27.85 & 2.13 & 9.8 & 24.8 & 99 & 27.45 & 17 & 2000 & .154 & 26.75 & 0.12 & 39.45 & 63 \\
\hline 81 & 28 & 1.98 & 9.9 & 25 & 98 & 27.33 & 11 & 2000 & 146 & 26.9 & 0.14 & 39.6 & 64.9 \\
\hline 82 & 27.85 & 2.13 & 10.1 & 24.9 & 98.3 & 27.51 & 16 & 2000 & 156 & 26.75 & 0.11 & 39.45 & 64.1 \\
\hline 83 & 28 & 2.08 & 9.9 & 25 & 97.7 & 27.49 & 17 & 2000 & 155 & 26.8 & 0.11 & 39.5 & 64.5 \\
\hline 84 & 28 & 1.93 & 9.8 & 24.9 & 97.6 & 27.33 & 16 & 2000 & 144 & 26.95 & 0.21 & 39.65 & 66.4 \\
\hline 85 & 28.05 & 1.98 & 10 & 24.9 & 97.9 & 27.48 & 16 & 2000 & 151 & 26.9 & 0.2 & 39.6 & 63.8 \\
\hline 86 & 27.95 & 1.98 & I0) & 25.1 & 96.8 & 27.5 & 16 & 2000 & 154 & 26.9 & 0.15 & 39.6 & 62.5 \\
\hline 87 & 28 & 2.03 & 10 & 24.9 & 97.9 & 27.31 & 16 & 2000 & 147 & 26.85 & 0.12 & 39.55 & 64.6 \\
\hline
\end{tabular}




\begin{tabular}{|c|c|c|c|c|c|c|c|c|c|c|c|c|c|}
\hline Shot & $\begin{array}{c}\text { Wtc+o } \\
\text { (lbs) }\end{array}$ & $\begin{array}{l}\text { B_L } \\
\text { (in) }\end{array}$ & $\begin{array}{c}\text { Slow Vel } \\
\text { (in/sec) }\end{array}$ & $\begin{array}{c}\text { Inter Vel } \\
\text { (in/sec) }\end{array}$ & $\begin{array}{l}\text { Fast Vel } \\
\text { (in/sec) }\end{array}$ & $\begin{array}{l}\text { Act Ft Pos } \\
\text { (ii) }\end{array}$ & $\begin{array}{c}\text { Vel Rise } \\
\text { (ms) }\end{array}$ & $\begin{array}{c}\text { Pres Rise } \\
\text { (ms) }\end{array}$ & $\begin{array}{l}\text { Fill time } \\
\text { (ms) }\end{array}$ & $\begin{array}{l}\text { Fil time srt } \\
\text { (in) }\end{array}$ & $\begin{array}{l}\text { Inten Strk } \\
\text { (in) }\end{array}$ & $\begin{array}{l}\text { End Pos } \\
\text { (ii) }\end{array}$ & $\begin{array}{l}\text { End Vel } \\
\text { (in/sec) }\end{array}$ \\
\hline 88 & 27.95 & 1.88 & 9.8 & 25 & 97.3 & 27.47 & 17 & 2000 & 148 & 27 & 0.1 & 39.7 & 63.9 \\
\hline 89 & 27.95 & 1.98 & 10 & 24.9 & 97.8 & 27.44 & 16 & 2000 & 149 & 26.9 & 0.11 & 39.6 & 66.5 \\
\hline 90 & 27.9 & 1.93 & 10.4 & 24.9 & 96.6 & 27.39 & 16 & 2000 & 149 & 26.95 & 0.15 & 39.65 & 63.4 \\
\hline 91 & 29.3 & 1.83 & 10 & 24.9 & 98.6 & 27.48 & 11 & 118 & 146 & 27.05 & 0.79 & 39.75 & 65.7 \\
\hline 92 & 29.4 & 1.83 & 9.9 & 24.9 & 98.2 & 27.5 & 11 & 120 & 147 & 27.05 & 0,88 & 39.75 & 65.4 \\
\hline 93 & 29.55 & 2.28 & 10 & 24.8 & 99.4 & 27.41 & 16 & 138 & 157 & 26.6 & 0.89 & 39.3 & 67.1 \\
\hline 94 & 29.5 & 2.18 & 10.4 & 24.9 & 98.8 & 27.35 & 11 & 135 & 151 & 26.7 & 0.9 & 39.4 & 62.7 \\
\hline 95 & 29.55 & 2.23 & 9.9 & 24.8 & 99.9 & 27.5 & 16 & 143 & 157 & 26.65 & 0.91 & 39.35 & 68 \\
\hline 96 & 29.45 & 2.23 & 10 & 24.8 & 96.6 & 27.51 & 14 & 124 & 160 & 26.65 & 0.91 & 39.35 & 65.5 \\
\hline 97 & 29.4 & 2.33 & 10 & 25 & 98.9 & 27.51 & 14 & 133 & 161 & 26.55 & 0.8 & 39.25 & 61.9 \\
\hline 98 & 29.45 & 2.28 & 10.4 & 24.8 & 98.1 & 27.48 & 16 & 126 & 161 & 26.6 & 0.83 & 39.3 & 62.4 \\
\hline 99 & 29.5 & 2.13 & 10 & 24.9 & 98 & 27.33 & 16 & 74 & 151 & 26.75 & 0.86 & 39.45 & 58.5 \\
\hline 100 & 29.45 & 2.23 & 10 & 24.9 & 98.8 & 27.5 & 15 & 128 & 159 & 26.65 & 0.85 & 39.35 & 62 \\
\hline 101 & 29.45 & 2.13 & 9.8 & 24.9 & 98 & 27.5 & 14 & 71 & 156 & 26.75 & 0.89 & 39.45 & 57.2 \\
\hline 102 & 29.5 & 2.13 & 9.9 & 24.8 & 98.2 & 27.48 & 18 & 122 & 157 & 26.75 & 0.84 & 39.45 & 55.6 \\
\hline 103 & 29.5 & 2.13 & 10 & 24.9 & 97.5 & 27.31 & 14 & 136 & 150 & 26.75 & 0.88 & 39.45 & 63.7 \\
\hline 104 & 29.4 & 2.13 & 9.9 & 24.9 & 99.1 & 27.48 & 11 & 123 & 153 & 26.75 & 0.85 & 39.45 & 64.6 \\
\hline 105 & 29.45 & 2.13 & 10.4 & 24.8 . & 99 & 27.4 & 15 & 115 & 153 & 26.75 & 0.88 & 39.45 & 62.8 \\
\hline 106 & 29.6 & 2.18 & 10 & 24.8 & 98.5 & 27.32 & 17 & 127 & 152 & 26.7 & 0.89 & 39.4 & 62.4 \\
\hline 107 & 29.45 & 2.13 & 9.9 & 24.9 & 97.5 & 27.44 & 14 & 134 & 156 & 26.75 & 0.83 & 39.45 & 61 \\
\hline 108 & 29.55 & 2.23 & 10 & 24.9 & 98.8 & 27.45 & 17 & 126 & 157 & 26.65 & 0.93 & 39.35 & 64.7 \\
\hline 109 & 29.5 & 2.33 & 9.9 & 24.8 & 98 & 27.45 & 16 & 126 & 161 & 26.55 & 0.89 & 39.25 & 61.2 \\
\hline 110 & 29.4 & 2.23 & 10.1 & 25 & 97.3 & 27.38 & 14 & 130 & 155 & 26.65 & 0.86 & 39.35 & 63.2 \\
\hline 111 & 29.5 & 2.28 & 9.9 & 24.9 & 98.2 & 27.47 & 16 & 128 & .160 & 26.6 & 0,89 & 39.3 & 65.8 \\
\hline 112 & 29.5 & 2.18 & 10 & 24.9 & 98.3 & 27.32 & 17 & 71 & 153 & 26.7 & 0.88 & 39.4 & 57.5 \\
\hline 113 & 29.5 & 2.23 & 10 & 25 & 98.3 & 27.38 & 16 & 136 & 155 & 26.65 & 0.88 & 39.35 & 65.5 \\
\hline 114 & 29.5 & 2.28 & 9.9 & 25 & 98.8 & 27.49 & 16 & 125 & 160 & 26.6 & 0.91 & 39.3 & 63.8 \\
\hline 115 & 29.45 & 2.33 & 10 & 25 & 97 & 27.33 & 14 & 129 & 157 & 26.55 & 0.89 & 39.25 & 62.9 \\
\hline 116 & 29.55 & 2.33 & 9.9 & 24.9 & 99 & 27.33 & 16 & 137 & 156 & 26.55 & 0.86 & 39.25 & 64.8 \\
\hline 117 & 29.45 & 2.28 & 10 & 24.9 & 98.3 & 27.51 & 16 & 45 & 163 & 26.6 & 0.88 & 39.3 & 55.5 \\
\hline 118 & 29.5 & 2.28 & 9.9 & 24.9 & 97.7 & 27.48 & 15 & 122 & 161 & 26.6 & 0.88 & 39.3 & 62.2 \\
\hline
\end{tabular}




\begin{tabular}{|c|c|c|c|c|c|c|c|c|c|c|c|c|c|}
\hline Shot & $\begin{array}{c}\text { Wtc+o } \\
\text { (lbs) }\end{array}$ & $\begin{array}{l}\text { B_L } \\
\text { (in) }\end{array}$ & $\begin{array}{c}\text { Slow Vel } \\
\text { (in/sec) }\end{array}$ & $\begin{array}{c}\text { Inter Vel } \\
\text { (in/sec) }\end{array}$ & $\begin{array}{l}\text { Fast Vel } \\
\text { (in/sec) }\end{array}$ & $\begin{array}{l}\text { Act Ft Pos } \\
\text { (in) }\end{array}$ & $\begin{array}{c}\text { Vel Rise } \\
\text { (ms) }\end{array}$ & $\begin{array}{c}\text { Pres Rise } \\
\quad(\mathrm{ms})\end{array}$ & $\begin{array}{l}\text { Fill time } \\
\text { (ms) }\end{array}$ & $\begin{array}{l}\text { Fil time srt } \\
\text { (in) }\end{array}$ & $\begin{array}{l}\text { Inten Strk } \\
\text { (in) }\end{array}$ & $\begin{array}{l}\text { End Pos } \\
\text { (in) }\end{array}$ & $\begin{array}{l}\text { End Vel } \\
\text { (in/sec) }\end{array}$ \\
\hline 119 & 29.45 & 2.18 & 10 & 24.9 & 97.9 & 27.33 & 16 & 49 & 153 & 26.7 & 0.88 & 39.4 & 56.7 \\
\hline 120 & 29.45 & 2.23 & 10.5 & 24.8 & 98.1 & 27.45 & 11 & 130 & 157 & 26.65 & 0.93 & 39.35 & 65.7 \\
\hline 121 & 29.4 & 2.18 & 10 & 24.9 & 97.8 & 27.48 & 16 & 121 & 157 & 26.7 & 0.85 & 39.4 & 64.4 \\
\hline 122 & 28.35 & 2.23 & 9.7 & 24.8 & 96.9 & 27.48 & 19 & 60 & 161 & 26.65 & 0.4 & 39.35 & 63.5 \\
\hline 123 & 28.45 & 2.13 & 10 & 24.9 & 97.3 & 27.44 & 14 & 23 & 155 & 26.75 & 0.44 & 39.45 & 59.5 \\
\hline 124 & 28.45 & 2.13 & 10.1 & 24.8 & 98.3 & 27.31 & 18 & 15 & 151 & 26.75 & 0.42 & 39.45 & 57.4 \\
\hline 125 & 28.5 & 2.08 & 9.9 & 24.8 & 97.5 & 27.34 & 15 & 14 & 150 & 26.8 & 0.39 & 39.5 & 59.4 \\
\hline 126 & 28.55 & 2.23 & 10 & 24.9 & 97.2 & 27.37 & 16 & 11 & 157 & 26.65 & 0.36 & 39.35 & 57.3 \\
\hline 127 & 28.6 & 2.13 & 10 & 24.9 & 97.5 & 27.34 & 11 & 7 & 153 & 26.75 & 0.33 & 39.45 & 55.4 \\
\hline 128 & 28.6 & 1.88 & 10 & 25 & 97.6 & 27.33 & 17 & 9 & 147 & 27 & 0.36 & 39.7 & 54.2 \\
\hline 129 & 28.55 & 2.03 & 10.1 & 24.8 & 98.1 & 27.5 & 17 & 9 & 155 & 26.85 & 0.4 & 39.55 & 57.7 \\
\hline 130 & 28.5 & 2.13 & 10.4 & 24.9 & 98.3 & 27.35 & 15 & 9 & 152 & 26.75 & 0.39 & 39.45 & 56.6 \\
\hline 131 & 28.6 & 1.98 & 10.2 & 24.9 & 98.8 & 27.37 & 15 & 10 & 148 & 26.9 & 0.38 & 39.6 & 58.8 \\
\hline 132 & 28.5 & 1.88 & 10.3 & 25 & 97.7 & 27.41 & 15 & 6 & 150 & 27 & 0.31 & 39.7 & 52.3 \\
\hline 133 & 28.5 & 1.88 & 10.1 & 25 & 96.3 & 27.46 & 16 & 8 & 151 & 27 & 0.35 & 39.7 & 57 \\
\hline 134 & 28.5 & 2.08 & 9.8 & 25 & 97.4 & 27.47 & 20 & 10 & 156 & 26.8 & 0.44 & 39.5 & 55.7 \\
\hline 1.35 & 28.4 & 2.03 & 10 & 24.9 & 97.6 & 27.35 & 15 & 8 & 149 & 26.85 & 0.35 & 39.55 & 59.9 \\
\hline 136 & 28.55 & 1.83 & 9.9 & 25 & 98.2 & 27.49 & 17 & 8 & 147 & 27.05 & 0.4 & 39.75 & 57.4 \\
\hline 137 & 28.45 & 2.28 & 9.9 & 24.7 & 97.3 & 27.37 & 18 & 6 & 161 & 26.6 & 0.36 & 39.3 & 54.1 \\
\hline 138 & 28.7 & 2.23 & 10.1 & 24.9 & 96.6 & 27.48 & 16 & 6 & 166 & 26.65 & 0.34 & 39.35 & 48.4 \\
\hline 139 & 28.6 & 2.18 & 9.9 & 24.9 & 98 & 27.46 & 16 & 8 & 158 & 26.7 & 0.42 & 39.4 & 56.5 \\
\hline 140 & 28.55 & 2.13 & 10.1 & 25 & 98.7 & 27.34 & 16 & 5 & 155 & 26.75 & 0.35 & 39.45 & 49.6 \\
\hline 141 & 28.5 & 2.33 & 10 & 24.8 & 98.6 & 27.41 & 17 & 84 & 160 & 26.55 & 0.42 & 39.25 & 63.8 \\
\hline 142 & 28.45 & 2.28 & 10 & 24.9 & 97.5 & 27.49 & 17 & 31 & 162 & 26.6 & 0.4 & 39.3 & 60.3 \\
\hline 143 & 28.55 & 2.18 & 10 & 25 & 99.6 & 27.36 & 16 & 28 & 152 & 26.7 & 0.39 & 39.4 & 60.8 \\
\hline 144 & 28.5 & 2.18 & 10 & 24.9 & 99.3 & 27.44 & 16 & 22 & 155 & 26.7 & 0.38 & 39.4 & 61.3 \\
\hline 145 & 28.45 & 2.28 & 10.1 & 24.9 & 97.6 & 27.49 & 16 & 78 & 161 & 26.6 & 0.42 & 39.3 & 67 \\
\hline 146 & 28.45 & 2.13 & 9.9 & 24.8 & 97.7 & 27.5 & 16 & 77 & 156 & 26.75 & 0.44 & 39.45 & 67.1 \\
\hline 147 & 28.45 & 2.18 & 10 & 24.8 & 98.2 & 27.33 & 17 & 16 & 153 & 26.7 & 0.34 & 39.4 & 59.2 \\
\hline 148 & 28.45 & 2.18 & 10 & 24.8 & 98 & 27.47 & 17 & 21 & 159 & 26.7 & 0.38 & 39.4 & 57.3 \\
\hline 149 & 28.5 & 2.23 & 9.8 & 24.8 & 99.4 & 27.47 & 11 & 14 & 157 & 26.65 & 0.34 & 39.35 & 58.1 \\
\hline
\end{tabular}




$\begin{array}{cccccccccccccc}\text { Shot } & \begin{array}{c}\text { Wicto } \\ \text { (Ibs) }\end{array} & \text { B_L } & \begin{array}{c}\text { Slow Vel } \\ \text { (in/sec) }\end{array} & \begin{array}{c}\text { Inter Vel } \\ \text { (in/sec) }\end{array} & \begin{array}{c}\text { Fast Vel } \\ \text { (in/sec) }\end{array} & \begin{array}{c}\text { Act Ft Pos } \\ \text { (in) }\end{array} & \begin{array}{c}\text { Vel Rise } \\ \text { (ms) }\end{array} & \begin{array}{c}\text { Pres Rise } \\ \text { (ms) }\end{array} & \begin{array}{c}\text { Fill time } \\ \text { (ms) }\end{array} & \begin{array}{c}\text { Fil time srt } \\ \text { (in) }\end{array} & \begin{array}{c}\text { Inten Strk } \\ \text { (in) }\end{array} & \begin{array}{c}\text { End Pos } \\ \text { (in) }\end{array} & \begin{array}{c}\text { End Vel } \\ \text { (in/sec) }\end{array} \\ 150 & 28.65 & 2.18 & 10 & 24.8 & 99.2 & 27.48 & 17 & 20 & 158 & 26.7 & 0.36 & 39.4 & 56.3 \\ 151 & 28.5 & 2.18 & 9.9 & 24.8 & 99.4 & 27.5 & 17 & 12 & 158 & 26.7 & 0.32 & 39.4 & 57.1 \\ 152 & 29.4 & 2.23 & 10.4 & 24.9 & 98.9 & 27.41 & 16 & 125 & 155 & 26.65 & 0.84 & 39.35 & 65.7 \\ 153 & 29.75 & 2.13 & 10 & 24.9 & 99.6 & 27.49 & 16 & 26 & 155 & 26.75 & 1 & 39.45 & 57.7 \\ 154 & 29.95 & 2.13 & 9.9 & 24.9 & 97.5 & 27.31 & 15 & 35 & 151 & 26.75 & 1.19 & 39.45 & 58.7 \\ 155 & 30.3 & 2.08 & 10.4 & 24.8 & 100 & 27.4 & 16 & 11 & 150 & 26.8 & 1.14 & 39.5 & 57.6 \\ 156 & 30.35 & 2.03 & 10 & 24.8 & 100.3 & 27.31 & 16 & 16 & 145 & 26.85 & 1.84 & 39.55 & 61.9\end{array}$




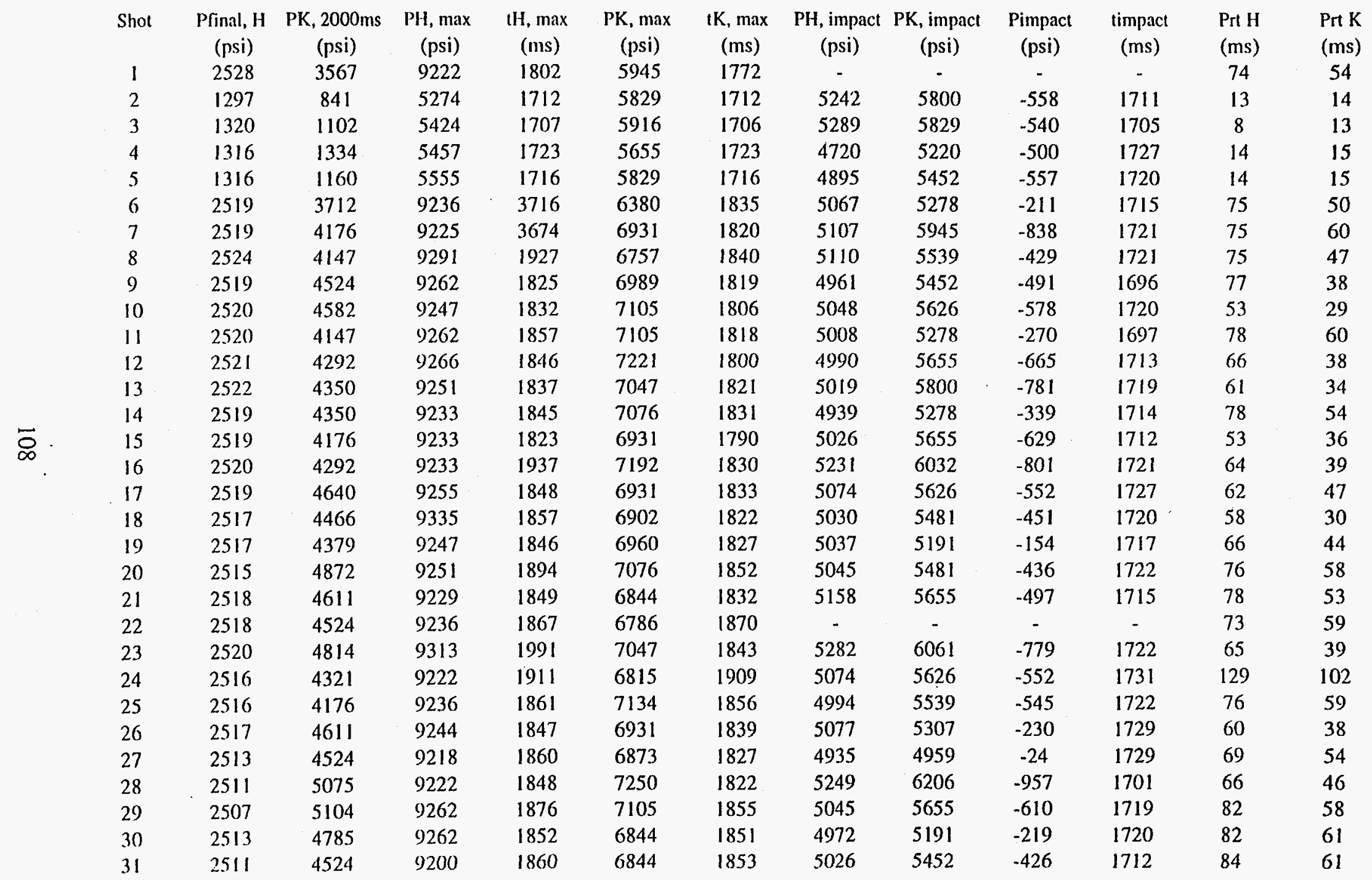




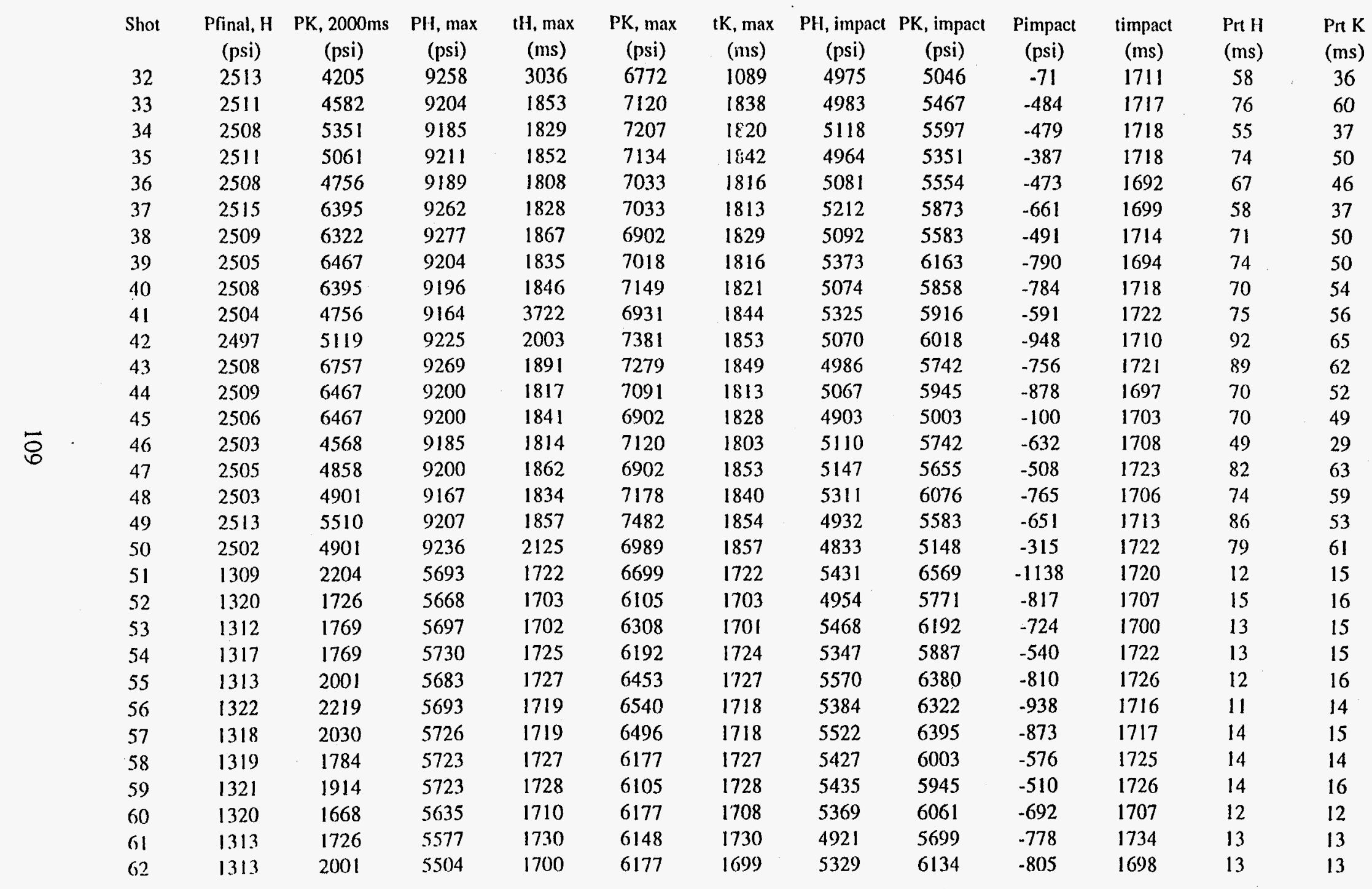




\begin{tabular}{|c|c|c|c|c|c|c|c|c|c|c|c|c|}
\hline Shot & $\begin{array}{l}\text { Pfinal, H } \\
(\mathrm{psi})\end{array}$ & $\begin{array}{l}\mathrm{PK}, 2000 \mathrm{~ms} \\
\text { (psi) }\end{array}$ & $\begin{array}{c}\text { PH, max } \\
\text { (psi) }\end{array}$ & $\begin{array}{l}\text { IH, max } \\
\text { (Ims) }\end{array}$ & $\begin{array}{l}\text { PK, max } \\
(\mathrm{psi})\end{array}$ & $\begin{array}{l}\mathrm{IK}, \max \\
(\mathrm{ms})\end{array}$ & $\begin{array}{l}\text { PH, impact } \\
\text { (psi) }\end{array}$ & $\begin{array}{l}\text { PK, impact } \\
\text { (psi) }\end{array}$ & $\begin{array}{l}\text { Pimpact } \\
\text { (psi) }\end{array}$ & $\begin{array}{l}\text { timpact } \\
(\mathrm{ms})\end{array}$ & $\begin{array}{l}\text { Prt H } \\
(\mathrm{ms})\end{array}$ & $\begin{array}{l}\text { Prt K } \\
\text { (ms) }\end{array}$ \\
\hline 63 & 1320 & 2074 & 5730 & 1724 & 6685 & 1723 & 5548 & 6612 & -1064 & 1722 & 13 & 13 \\
\hline 64 & 1320 & 1885 & 5653 & 1700 & 6177 & 1699 & 5355 & 6061 & .706 & 1697 & 11 & 12 \\
\hline 65 & 1320 & 1987 & 5715 & 1709 & 6293 & 1709 & 5460 & 6163 & -703 & 1707 & 14 & 16 \\
\hline 66 & 1329 & 1972 & 5624 & 1704 & 6148 & 1704 & 5242 & 5931 & -689 & 1707 & 13 & 14 \\
\hline 67 & 1316 & 1943 & 5693 & 1704 & 6192 & 1703 & 4950 & 5757 & -807 & 1708 & 13 & 16 \\
\hline 68 & 1320 & 2016 & 5610 & 1704 & 6308 & 1703 & 5158 & 5902 & -744 & 1707 & 15 & 14 \\
\hline 69 & 1314 & 1711 & 5617 & 1702 & 5989 & 1701 & 4735 & 5452 & -717 & 1707 & 12 & 13 \\
\hline 70 & 1318 & 1929 & 5628 & 1707 & 6250 & 1706 & 4913 & 5757 & -844 & 1711 & 13 & 14 \\
\hline 71 & 1318 & 2030 & 5653 & 1727 & 6293 & 1725 & 4928 & 5626 & -698 & 1731 & 11 & 12 \\
\hline 72 & 1322 & 1929 & 5580 & 1720 & 6134 & 1720 & 4913 & 5699 & -786 & 1724 & 9 & 14 \\
\hline 73 & 1319 & 1972 & 5602 & 1727 & 6308 & 1727 & 5085 & 5844 & .759 & 1731 & 12 & 12 \\
\hline 74 & 1318 & 1987 & 5683 & 1714 & 6163 & 1714 & 4855 & 5699 & -844 & 1719 & 13 & 13 \\
\hline 75 & 1313 & 1813 & 5650 & 1719 & 6235 & 1521 & 4771 & 5481 & -710 & 1724 & 12 & 12 \\
\hline 76 & 1321 & 1929 & 5642 & 1723 & 6148 & 1723 & 4961 & 5844 & -883 & 1727 & 13 & 14 \\
\hline 77 & 1318 & 1856 & 5580 & 1710 & 6105 & 1710 & 4830 & 5815 & -985 & 1714 & 13 & 14 \\
\hline 78 & 1312 & 1798 & 5464 & 1710 & 6090 & 1710 & 4903 & 5786 & -883 & 1713 & 12 & 15 \\
\hline 79 & 1318 & 2161 & 5653 & 1724 & 6612 & 1723 & 5595 & 6612 & -1017 & 1723 & 12 & 12 \\
\hline 80 & 1318 & 2030 & 5573 & 1729 & 6264 & 1729 & 5129 & 5960 & -831 & 1732 & 15 & 16 \\
\hline 81 & 1314 & 1842 & 5537 & 1726 & 6061 & 1725 & 5016 & 5713 & -697 & 1729 & 13 & 14 \\
\hline 82 & 1319 & 1929 & 5683 & 1713 & 6250 & 1713 & 4881 & 5757 & -876 & 1718 & 13 & 15 \\
\hline 83 & 1317 & 1711 & 5679 & 1729 & 6134 & 1729 & 4819 & 5757 & -938 & 1734 & 14 & 14 \\
\hline 84 & 1316 & 1639 & 5617 & 1729 & 6032 & 1728 & 4684 & 5438 & -754 & 1734 & 12 & 12 \\
\hline 85 & 1319 & 1552 & 5493 & 1712 & 5742 & 1713 & 4709 & 5409 & -700 & 1717 & 12 & 13 \\
\hline 86 & 1313 & 1668 & 5555 & 1717 & 6090 & 1717 & 4844 & 5670 & -826 & 1721 & 14 & 14 \\
\hline 87 & 1314 & 1624 & 5522 & 1720 & 5873 & 1720 & 4841 & 5525 & -684 & 1724 & 12 & 15 \\
\hline 88 & 1315 & 1407 & 5566 & 1733 & 5568 & 1733 & 4695 & 5177 & -482 & 1738 & 13 & 13 \\
\hline 89 & 1311 & 1494 & 5555 & 1716 & 5684 & 1715 & 4782 & 5220 & -438 & 1720 & 12 & 13 \\
\hline 90 & 1313 & 1436 & 5457 & 1708 & 5699 & 1708 & 4819 & 5394 & -575 & 1712 & 12 & 15 \\
\hline 91 & 3980 & 8889 & 16749 & 2596 & 10991 & 2479 & 5351 & 5757 & -406 & 1715 & 505 & 533 \\
\hline 92 & 3899 & 9715 & 16851 & 2488 & 11832 & 2461 & 4680 & 5625 & -945 & 1738 & 540 & 533 \\
\hline 93 & 3788 & 10716 & 16716 & 2489 & 12499 & 2498 & 5034 & 6250 & -1216 & 1717 & 548 & 564 \\
\hline
\end{tabular}




\begin{tabular}{|c|c|c|c|c|c|c|c|c|c|c|c|c|}
\hline Shot & $\begin{array}{c}\text { Pfinal, H } \\
\text { (psi) }\end{array}$ & $\begin{array}{c}\mathrm{PK}, 2000 \mathrm{~ms} \\
(\mathrm{psi})\end{array}$ & $\begin{array}{l}\text { PH, max } \\
\text { (psi) }\end{array}$ & $\begin{array}{l}\mathrm{tH}, \max \\
(\mathrm{ms})\end{array}$ & $\begin{array}{l}\text { PK, max } \\
\text { (psi) }\end{array}$ & $\begin{array}{l}\mathrm{tK}, \max \\
(\mathrm{ms})\end{array}$ & $\begin{array}{l}\text { PH, impact } \\
\text { (psi) }\end{array}$ & $\begin{array}{l}\mathrm{PK}, \text { impact } \\
\text { (psi) }\end{array}$ & $\begin{array}{l}\text { Pimpact } \\
\text { (psi) }\end{array}$ & $\begin{array}{l}\text { timpact } \\
(\mathrm{ms})\end{array}$ & $\begin{array}{l}\text { Prt H } \\
(\mathrm{ms})\end{array}$ & $\begin{array}{l}\mathrm{PrtK} \\
(\mathrm{ms})\end{array}$ \\
\hline 94 & 3758 & 11165 & 16669 & 2485 & 12383 & 2481 & 4855 & 6003 & -1148 & 1707 & 549 & 561 \\
\hline 95 & 3736 & 10948 & 16720 & 2538 & 12717 & 2519 & 4629 & 4698 & -69 & 1742 & 551 & 561 \\
\hline 96 & 3851 & 10020 & 16811 & 2565 & 12151 & 2502 & 4695 & 5757 & -1062 & 1736 & 554 & 539 \\
\hline 97 & 3878 & 9904 & 16763 & 2496 & 11832 & 2455 & 4972 & 6453 & -1481 & 1712 & 540 & 529 \\
\hline 98 & 3906 & 9773 & 16789 & 2451 & 11644 & 2456 & 4702 & 5641 & -939 & 1709 & 525 & 520 \\
\hline 99 & 4105 & 9628 & 16741 & 2735 & 11760 & 2333 & 5045 & 5648 & -603 & 1707 & 515 & 453 \\
\hline 100 & 3860 & 10121 & 16767 & 2555 & 12093 & 2454 & 4742 & 6250 & -1508 & 1715 & 537 & 533 \\
\hline 101 & 4098 & 9585 & 16825 & 2444 & 11977 & 2433 & 5008 & 5583 & -575 & 1727 & 518 & 474 \\
\hline 102 & 3048 & 11412 & 16741 & 3176 & 11919 & 3123 & 5034 & 5757 & -723 & 1727 & 1014 & 924 \\
\hline 103 & 3852 & 10165 & 16829 & 2514 & 12021 & 2489 & 4815 & 6134 & -1319 & 1729 & 547 & 525 \\
\hline 104 & 3928 & 9672 & 16825 & 2550 & 11499 & 2484 & 5129 & 6032 & -903 & 1729 & 530 & 527 \\
\hline 105 & 3923 & 9585 & 16833 & 2550 & 11629 & 2464 & 4698 & 5278 & -580 & 1710 & 536 & 521 \\
\hline 106 & 3871 & 9918 & 16803 & 2467 & 11905 & 2454 & 4771 & 5844 & -1073 & 1712 & 540 & 530 \\
\hline 107 & 3844 & 9991 & 16756 & 2577 & 11992 & $2<79$ & 4804 & 5844 & -1040 & 1730 & 526 & 529 \\
\hline 108 & 3817 & 10310 & 16720 & 2460 & 12180 & 2475 & 4793 & 5815 & -1022 & 1716 & 559 & 528 \\
\hline 109 & 3867 & 9947 & 16741 & 2583 & 11861 & 2496 & 4760 & 6221 & -1461 & 1730 & 536 & 533 \\
\hline 110 & 3860 & 9831 & 16654 & 2564 & 11876 & 2564 & 4892 & 6076 & -1184 & 1712 & 534 & 535 \\
\hline 111 & 3848 & 9947 & 16814 & 2497 & 12050 & 2461 & 4739 & 6148 & -1409 & 1716 & 541 & 521 \\
\hline 112 & 4070 & 10614 & 16825 & 2472 & 12035 & 2432 & 4917 & 5626 & -709 & 1719 & 527 & 462 \\
\hline 113 & 3840 & 9976 & 16760 & 2530 & 11774 & 2473 & 4903 & 6772 & -1869 & 1713 & 534 & 520 \\
\hline 114 & 3838 & 10092 & 16727 & 2520 & 12050 & 2485 & 4895 & 5365 & -470 & 1729 & 539 & 530 \\
\hline 115 & 3850 & 9730 & 16814 & 2524 & 11847 & 2473 & 4786 & 6148 & -1362 & 1725 & 534 & 528 \\
\hline 116 & 3807 & 10498 & 16698 & 2495 & 12151 & 2473 & 4957 & 6337 & -1380 & 1708 & 547 & 529 \\
\hline 117 & 4151 & 9962 & 16734 & 2457 & 11919 & 2400 & 5150 & 5510 & -360 & 1713 & 499 & 438 \\
\hline 118 & 3876 & 9976 & 16661 & 2526 & 11832 & 2518 & 4822 & 6366 & -1544 & 1734 & 536 & 517 \\
\hline 119 & 4135 & 10049 & 16774 & 2494 & 11992 & 2395 & 5016 & 5380 & -364 & 1720 & 503 & 440 \\
\hline 120 & 3839 & 9976 & 16614 & 2564 & 11615 & 2564 & 4946 & 6540 & -1594 & 1708 & 532 & 492 \\
\hline 121 & 3909 & 9643 & 16782 & 2638 & 11919 & 2423 & 4804 & 5873 & -1069 & 1718 & 535 & 492 \\
\hline 122 & 2504 & 4263 & 9262 & 1873 & 7047 & 1872 & 4604 & 6250 & -1646 & 1747 & 92 & 77 \\
\hline 123 & 2497 & 4205 & 9269 & 1821 & 7134 & 1844 & - & - & - & - & 63 & 49 \\
\hline 124 & 2499 & 4568 & 9309 & 1774 & 7627 & 1772 & 5023 & 5597 & -574 & 1705 & 44 & 36 \\
\hline
\end{tabular}




\begin{tabular}{|c|c|c|c|c|c|c|c|c|c|c|c|c|}
\hline Shot & $\begin{array}{c}\text { Pfinal, H } \\
(\mathrm{psi})\end{array}$ & $\begin{array}{l}\mathrm{PK}, 2000 \mathrm{~ms} \\
\quad(\mathrm{psi})\end{array}$ & $\begin{array}{l}\text { PH, max } \\
\text { (psi) }\end{array}$ & $\begin{array}{l}\mathrm{tH}, \max \\
(\mathrm{ms})\end{array}$ & $\begin{array}{l}\text { PK, max } \\
\text { (psi) }\end{array}$ & $\begin{array}{c}\text { IK, max } \\
\text { (Ins) }\end{array}$ & $\begin{array}{l}\text { PH, impact } \\
\text { (psi) }\end{array}$ & $\begin{array}{l}\text { PK, impact } \\
\text { (psi) }\end{array}$ & $\begin{array}{l}\text { Pimpact } \\
\text { (psi) }\end{array}$ & $\begin{array}{l}\text { timpact } \\
(\mathrm{ms})\end{array}$ & $\begin{array}{l}\operatorname{Prt~H} \\
(\mathrm{ms})\end{array}$ & $\begin{array}{l}\text { Prt K } \\
\text { (ms) }\end{array}$ \\
\hline 125 & 2498 & 4365 & 9324 & 1786 & 7250 & 1762 & 4968 & 5452 & -484 & 1719 & 41 & 33 \\
\hline 126 & 2498 & 4394 & 9320 & 1760 & 7250 & 1762 & 5118 & 6192 & -1074 & 1075 & 33 & 24 \\
\hline 127 & 2495 & 3843 & 9481 & 1742 & 7323 & 1747 & 5110 & 5510 & -400 & 1706 & 24 & 19 \\
\hline 128 & 2495 & 4612 & 9473 & 1773 & 7149 & 1773 & - & - & - & - & 33 & 28 \\
\hline 129 & 2504 & 4278 & 9503 & 1762 & 7105 & 1766 & 5369 & 5771 & -402 & 1715 & 29 & 25 \\
\hline 130 & 2495 & 4118 & 9466 & 1749 & 7468 & 1752 & 5019 & 5394 & -375 & 1703 & 29 & 25 \\
\hline 131 & 2491 & 4263 & 9521 & 1754 & 7772 & 1752 & 5125 & 5452 & -327 & 1707 & 30 & 25 \\
\hline 132 & 2497 & 4452 & 9718 & 1746 & 7323 & 1751 & 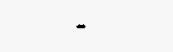 & - & - & - & 23 & 25 \\
\hline 133 & 2496 & 4249 & 9714 & 1773 & 7598 & 1773 & 4997 & 5612 & -615 & 1735 & 25 & 22 \\
\hline 134 & 2490 & 4133 & 9732 & 1769 & 7453 & 1766 & 5365 & 5612 & -247 & 1728 & 27 & 27 \\
\hline 135 & 2501 & 4640 & 9772 & 1759 & 7671 & 1761 & 5023 & 6032 & -1009 & 1723 & 30 & 34 \\
\hline 136 & 2499 & 4336 & 9685 & 1768 & 7888 & 1765 & 5016 & 5713 & -697 & 1730 & 22 & 26 \\
\hline 137 & 2498 & 4452 & 9925 & 1751 & 7845 & 1752 & 5016 & 5293 & -277 & 1714 & 23 & 25 \\
\hline 138 & 2496 & 4466 & 9885 & 1748 & 8483 & 1749 & 5205 & 6003 & -798 & 1711 & 27 & 25 \\
\hline 139 & 2490 & 4437 & 9900 & 1752 & 8149 & 1750 & 5008 & 5771 & -763 & 1713 & 27 & 25 \\
\hline 140 & 2488 & 4858 & 9852 & 1759 & 8425 & 1756 & 5037 & 6003 & -966 & 1723 & 23 & 22 \\
\hline 141 & 2497 & 4713 & 9149 & 1897 & 6888 & 1857 & 4841 & 6148 & -1307 & 1713 & 130 & 99 \\
\hline 142 & 2493 & 4626 & 9138 & 1856 & 6757 & 1854 & 5118 & 5409 & -291 & 1712 & 79 & 61 \\
\hline 143 & 2489 & 4553 & 9131 & 1843 & 7163 & 1802 & 4928 & 5873 & .945 & 1703 & 77 & 42 \\
\hline 144 & 2484 & 4452 & 9077 & 3714 & 7192 & 1803 & 5030 & 5351 & -321 & 1713 & 70 & 39 \\
\hline 145 & 2494 & 4031 & 9149 & 1897 & 7047 & 1904 & 4841 & 5757 & -916 & 1720 & 127 & 104 \\
\hline 146 & 2498 & 3959 & 9174 & 1920 & 6801 & 1895 & 5325 & 6511 & -1186 & 1732 & 130 & 91 \\
\hline 147 & 2489 & 4785 & 9156 & 1866 & 6714 & 1820 & 4910 & 5612 & -702 & 1706 & 61 & 31 \\
\hline 148 & 2497 & 4234 & 9196 & 2230 & 6728 & 1802 & 4975 & 5539 & -564 & 1712 & 73 & 39 \\
\hline 149 & 2487 & 4858 & 9167 & 1850 & 7482 & 1845 & 5205 & 6003 & -798 & 1729 & 60 & 38 \\
\hline 150 & 2490 & 4843 & 9215 & 2052 & 6975 & 1830 & 5045 & 5829 & -784 & 1711 & 78 & 38 \\
\hline 151 & 2486 & 4379 & 9076 & 1991 & 6902 & 1796 & 5023 & 5815 & -792 & 1725 & 51 & 16 \\
\hline 152 & 3898 & 9904 & 16738 & 2460 & 11673 & 2480 & 4986 & 6279 & -1293 & 1709 & 536 & 522 \\
\hline 153 & 4469 & 10237 & 16541 & 2270 & 12456 & 2280 & 5125 & 6482 & -1357 & 1725 & 367 & 318 \\
\hline 154 & 4550 & 10977 & 16603 & 2200 & 12876 & 2175 & 4968 & 5539 & -571 & 1721 & 330 & 287 \\
\hline 155 & 4497 & 5655 & 16505 & 2065 & 6685 & 2055 & - & - & - & - & 247 & 173 \\
\hline 156 & 4331 & 9904 & 15998 & 2080 & 6467 & 2060 & - & - & - & - & 289 & 136 \\
\hline
\end{tabular}


Wtcto Slow Vel Inter Vel Fast Vel Act Ft Pos Vel Rise Pres Rise Fill time Fil time sit B_L Inten Strk End Pos End Vel

$\begin{array}{cccccccccccccc}\text { Set II } & \text { (lbs) } & \text { (in/sec) } & \text { (in/sec) } & \text { (in/sec) } & \text { (in) } & \text { (ms) } & \text { (ms) } & \text { (ms) } & \text { (in) } & \text { (in) } & \text { (in) } & \text { (in) } & \text { (in/sec) } \\ \text { MEAN } & 28.43 & 10 & 24.9 & 98 & 27.4 & 15 & 22 & 153 & 26.77 & 2.11 & 0.37 & 39.47 & 58.2 \\ \text { MEDIAN } & 28.4 & 10 & 24.9 & 98.2 & 27.43 & 16 & 21 & 157 & 26.65 & 2.23 & 0.38 & 39.35 & 58.3 \\ \text { MODE } & 28.4 & 10 & 24.9 & 98.5 & 27.48 & 16 & 24 & 157 & 26.65 & 2.23 & 0.38 & 39.35 & 58.1 \\ \text { STDEV } & 0.04 & 0.2 & 0.1 & 0.8 & 0.07 & 3 & 11 & 9 & 0.27 & 0.27 & 0.03 & 0.27 & 1.9 \\ \text { MAX } & 28.5 & 10.5 & 25 & 99.7 & 27.48 & 18 & 73 & 168 & 27.35 & 2.48 & 0.42 & 40.05 & 63.7 \\ \text { MIN } & 28.35 & 9.8 & 24.7 & 95.7 & 27.29 & 11 & 10 & 134 & 26.4 & 1.53 & 0.31 & 39.1 & 53.9 \\ \text { RANGE } & 0.15 & 0.7 & 0.3 & 4 & 0.19 & 7 & 63 & 34 & 0.95 & 0.95 & 0.11 & 0.95 & 9.8 \\ \text { COUNT } & 30 & 30 & 30 & 30 & 30 & 30 & 30 & 30 & 30 & 30 & 30 & 30 & 30 \\ \text { CONF LEV(95\%) } & 0.0139 & 0.059 & 0.0278 & 0.2976 & 0.0262 & 0.9243 & 4.0423 & 3.1647 & 0.098 & 0.098 & 0.0119 & 0.098 & 0.6917 \\ \text { STDEV/MEAN } & 0.0014 & 0.0165 & 0.0031 & 0.0085 & 0.0027 & 0.1737 & 0.5158 & 0.0577 & 0.0102 & 0.13 & 0.0907 & 0.0069 & 0.0332\end{array}$

$\vec{\omega}$

\begin{tabular}{|c|c|c|c|c|c|c|c|c|c|c|c|c|c|}
\hline Set III & & & & & & & & & & & & & \\
\hline MEAN & 27.96 & 10 & 24.9 & 98.3 & 27.413 & 16 & 2000 & 154 & 26.72 & 2.16 & 0.15 & 39.42 & 65.2 \\
\hline MEDIAN & 27.95 & 10 & 24.9 & 98.2 & 27.43 & 16 & 2000 & 155 & 26.75 & 2.13 & 0.14 & 39.45 & 64.9 \\
\hline MODE & 28 & 10 & 24.9 & 98 & 27.46 & 16 & 2000 & 156 & 26.75 & 2.13 & 0.11 & 39.45 & 64.6 \\
\hline STDEV & 0.09 & 0.2 & 0.1 & 0.8 & 0.07 & 2 & 0 & 5 & 0.14 & 0.14 & 0.04 & 0.14 & 1.8 \\
\hline $\operatorname{MAX}$ & 28.2 & 10.4 & 25.1 & 100 & 27.51 & 18 & 2000 & 165 & 27 & 2.43 & 0.25 & 39.7 & 68.6 \\
\hline MIN & 27.8 & 9.8 & 24.8 & 96.6 & 27.3 & 11 & 2000 & 144 & 26.45 & 1.88 & 0.09 & 39.15 & 61.4 \\
\hline RANGE & 0.4 & 0.6 & 0.3 & 3.4 & 0.21 & 7 & 0 & 21 & 0.55 & 0.55 & 0.16 & 0.55 & 7.2 \\
\hline COUNT & 40 & 40 & 40 & 40 & 40 & 40 & 40 & 40 & 40 & 40 & 40 & 40 & 40 \\
\hline CONF LEV $(95 \%)$ & 0.0283 & 0.0537 & 0.0245 & 0.2407 & 0.0217 & 0.4077 & - & 1.5629 & 0.0435 & 0.0435 & 0.0132 & 0.0435 & 0.5525 \\
\hline STDEV/MEAN & 0.0033 & 0.0173 & 0.0032 & 0.0079 & 0.0026 & 0.081 & 0 & 0.0327 & 0.0052 & 0.0648 & 0.2878 & 0.0036 & 0.0273 \\
\hline
\end{tabular}




\begin{tabular}{|c|c|c|c|c|c|c|c|c|c|c|c|c|c|}
\hline Set IV & $\begin{array}{c}\text { Wicto } \\
\text { (lbs) }\end{array}$ & $\begin{array}{c}\text { Slow Vel } \\
\text { (in/sec) }\end{array}$ & $\begin{array}{c}\text { Inter Vel } \\
\text { (in/sec) }\end{array}$ & $\begin{array}{l}\text { Fast Vel } \\
(\mathrm{in} / \mathrm{sec})\end{array}$ & $\begin{array}{l}\text { Act Ft Pos } \\
\text { (iin) }\end{array}$ & $\begin{array}{c}\text { Vel Rise } \\
\text { (ms) }\end{array}$ & $\begin{array}{c}\text { Pres Rise } \\
\text { (ms) }\end{array}$ & $\begin{array}{c}\text { Fill time } \\
\text { (ms) }\end{array}$ & $\begin{array}{l}\text { Fil time srt } \\
\text { (in) }\end{array}$ & $\begin{array}{l}\text { B_L } \\
\text { (iin) }\end{array}$ & $\begin{array}{l}\text { Inten Strk } \\
\text { (in) }\end{array}$ & $\begin{array}{l}\text { End Pos } \\
\text { (in) }\end{array}$ & $\begin{array}{l}\text { End Vel } \\
\text { (in/sec) }\end{array}$ \\
\hline MEAN & 29.47 & 10 & 24.9 & 98.3 & 27.43 & 15 & 117 & 156 & 26.68 & 2.2 & 0.87 & 39.38 & 62.6 \\
\hline MEDIAN & 29.45 & 10 & 24.9 & 98.2 & 27.45 & 16 & 126 & 157 & 26.65 & 2.23 & 0.88 & 39.35 & 62.9 \\
\hline MODE & 29.5 & 10 & 24.9 & 98.8 & 27.48 & 16 & 126 & 157 & 26.65 & 2.23 & 0.88 & 39.35 & 65.7 \\
\hline STDEV & 0.06 & 0.2 & 0.1 & 0.7 & 0.07 & 2 & 26 & 4 & 0.12 & 0.12 & 0.03 & 0.12 & 3.3 \\
\hline $\operatorname{MAX}$ & 29.6 & 10.5 & 25 & 99.9 & 27.51 & 18 & 143 & 163 & 27.05 & 2.33 & 0.93 & 39.75 & 68 \\
\hline MIN & 29.3 & 9.8 & 24.8 & 96.6 & 27.31 & 11 & 45 & 146 & 26.55 & 1.83 & 0.79 & 39.25 & 55.5 \\
\hline RANGE & 0.3 & 0.7 & 0.2 & 3.3 & 0.2 & 7 & 98 & 17 & 0.5 & 0.5 & 0.14 & 0.5 & 12.5 \\
\hline COUNT & 31 & 31 & 31 & 31 & 31 & 31 & 31 & 31 & 31 & 31 & 31 & 31 & 31 \\
\hline CONF LEV(95\%) & 0.0212 & 0.0599 & 0.0236 & 0.2479 & 0.025 & 0.7006 & 9.1538 & 1.4845 & 0.0417 & 0.0417 & 0.0116 & 0.0417 & 1.1763 \\
\hline STDEV/MEAN & 0.002 & 0.017 & 0.0027 & 0.0072 & 0.0026 & 0.1344 & 0.2213 & 0.0271 & 0.0044 & 0.054 & 0.0377 & 0.003 & 0.0534 \\
\hline
\end{tabular}

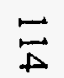

$\begin{array}{cccccccccccccc}\text { Set } V & & & & & & & & & & & & & \\ \text { MEAN } & 28.51 & 10 & 24.9 & 98 & 27.42 & 16 & 21 & 155 & 26.75 & 2.13 & 0.38 & 39.45 & 58 \\ \text { MEDIAN } & 28.5 & 10 & 24.9 & 97.9 & 27.44 & 16 & 12 & 155 & 26.73 & 2.16 & 0.38 & 39.43 & 57.4 \\ \text { MODE } & 28.5 & 10 & 24.8 & 97.5 & 27.48 & 16 & 8 & 155 & 26.7 & 2.18 & 0.4 & 39.4 & 57.4 \\ \text { STDEV } & 0.08 & 0.1 & 0.1 & 0.8 & 0.07 & 2 & 23 & 5 & 0.13 & 0.13 & 0.04 & 0.13 & 4.2 \\ \text { MAX } & 28.7 & 10.4 & 25 & 99.6 & 27.5 & 20 & 84 & 166 & 27.05 & 2.33 & 0.44 & 39.75 & 67.1 \\ \text { MIN } & 28.35 & 9.7 & 24.7 & 96.3 & 27.31 & 11 & 5 & 147 & 26.55 & 1.83 & 0.31 & 39.25 & 48.4 \\ \text { RANGE } & 0.35 & 0.7 & 0.3 & 3.3 & 0.19 & 9 & 79 & 19 & 0.5 & 0.5 & 0.13 & 0.5 & 18.7 \\ \text { COUNT } & 30 & 30 & 30 & 30 & 30 & 30 & 30 & 30 & 30 & 30 & 30 & 30 & 30 \\ \text { CONFLEV(95\%) } & 0.0269 & 0.0505 & 0.0303 & 0.3032 & 0.0235 & 0.6668 & 8.0965 & 1.7286 & 0.0465 & 0.0465 & 0.0132 & 0.0465 & 1.4995 \\ \text { STDEV/MEAN } & 0.0026 & 0.0141 & 0.0034 & 0.0086 & 0.0024 & 0.1157 & 1.0689 & 0.0311 & 0.0049 & 0.0611 & 0.0969 & 0.0033 & 0.0723\end{array}$




\begin{tabular}{|c|c|c|c|c|c|c|c|c|c|c|c|}
\hline $\begin{array}{c}\text { Pfinal, H } \\
\text { (psi) }\end{array}$ & $\begin{array}{c}\text { PK, 2000ms } \\
\text { (psi) }\end{array}$ & $\begin{array}{c}\mathrm{PH}, \max \\
(\mathrm{psi})\end{array}$ & $\begin{array}{c}\text { tH, max } \\
\text { (ms) }\end{array}$ & $\begin{array}{c}\text { PK, max } \\
\text { (psi) }\end{array}$ & $\begin{array}{l}\text { tK, max } \\
\text { (ms) }\end{array}$ & $\begin{array}{c}\mathrm{PH}, \text { impact } \\
(\mathrm{psi})\end{array}$ & $\underset{\text { (psi) }}{\mathrm{PK}, \text { impact }}$ & $\begin{array}{l}\text { Pimpact } \\
\text { (psi) }\end{array}$ & $\begin{array}{l}\text { timpact } \\
\text { (mis) }\end{array}$ & $\begin{array}{c}\text { Prt H } \\
\text { (ms) }\end{array}$ & $\begin{array}{c}\text { Prt K } \\
\text { (ms) }\end{array}$ \\
\hline 2510 & 5164 & 9224 & 1971 & 7037 & 1815 & 4912 & 5432 & -520 & 1714 & 74 & 53 \\
\hline 2510 & 4879.5 & 9220 & 1855 & 7033 & 1840 & 5072 & 5612 & -527 & 1717 & 74 & 54 \\
\hline 2513 & 4524 & 9200 & 1867 & 6844 & 1853 & 5074 & 5655 & - & 1722 & 82 & 59 \\
\hline 6 & 791 & 35 & 398 & 178 & 139 & 937 & 1081 & 265 & 10 & 14 & 13 \\
\hline 2520 & 6757 & 9313 & 3722 & 7482 & 1909 & 5373 & 6206 & 0 & 1731 & 129 & 102 \\
\hline 2497 & 4176 & 9164 & 1808 & 6772 & 1089 & 0 & 0 & -957 & 1692 & 49 & 29 \\
\hline 23 & 2581 & 149 & 1914 & 710 & 820 & 5373 & 6206 & 957 & 39 & 80 & 73 \\
\hline 30 & 30 & 30 & 30 & 30 & 30 & 30 & 30 & 30 & 29 & 30 & 30 \\
\hline 1.9643 & 283.1181 & 12.3533 & 142.527 & 63.834 & 49.6114 & 335.307 & 386.6887 & 94.8256 & 3.7421 & 5.158 & 4.7213 \\
\hline 0.0022 & 0.1532 & 0.0037 & 0.202 & 0.0254 & 0.0764 & 0.1908 & 0.1989 & -0.5095 & 0.0061 & 0.1937 & 0.2475 \\
\hline
\end{tabular}

\begin{tabular}{|c|c|c|c|c|c|c|c|c|c|c|c|c|}
\hline Set III & & & & & & & & & & 1719 & & \\
\hline MEAN & 1317 & $\begin{array}{l}1853 \\
1900\end{array}$ & $\begin{array}{l}5627 \\
5639\end{array}$ & $\begin{array}{l}1717 \\
1719\end{array}$ & $\begin{array}{l}6178 \\
6177\end{array}$ & $\begin{array}{l}1711 \\
1718\end{array}$ & $\begin{array}{l}5089 \\
4958\end{array}$ & $\begin{array}{l}5860 \\
5801\end{array}$ & $\begin{array}{l}-771 \\
-769\end{array}$ & 1719 & $\begin{array}{l}13 \\
13\end{array}$ & 14 \\
\hline MEDIAN & 1318 & $\begin{array}{l}1900 \\
1929\end{array}$ & $\begin{array}{l}5639 \\
5693\end{array}$ & $\begin{array}{l}1719 \\
1727\end{array}$ & 6177 & $\begin{array}{l}1718 \\
1703\end{array}$ & $\begin{array}{l}4958 \\
4913\end{array}$ & $\begin{array}{l}5801 \\
5757\end{array}$ & $\begin{array}{l}-109 \\
-938\end{array}$ & $\begin{array}{l}1720 \\
1707\end{array}$ & $\begin{array}{l}13 \\
13\end{array}$ & $\begin{array}{l}14 \\
14\end{array}$ \\
\hline MODE & 1318 & $\begin{array}{c}1929 \\
197\end{array}$ & 76 & 10 & 246 & 32 & 292 & 356 & $\begin{array}{l}-900 \\
152\end{array}$ & 11 & 1.19802 & $\begin{array}{l}14 \\
2\end{array}$ \\
\hline STDEV & 4 & $\begin{array}{c}197 \\
2219\end{array}$ & 5730 & 1733 & 6699 & 1733 & 5595 & 6612 & .438 & 1738 & $\begin{array}{l}19002 \\
15\end{array}$ & $\begin{array}{c}2 \\
16\end{array}$ \\
\hline $\begin{array}{l}\text { MAX } \\
\text { MIN }\end{array}$ & $\begin{array}{l}1329 \\
1309\end{array}$ & $\begin{array}{l}2219 \\
1407\end{array}$ & 5457 & 1700 & 5568 & 1521 & 4684 & 5177 & -1138 & 1697 & 9 & 12 \\
\hline $\begin{array}{c}\text { MIN } \\
\text { RANGE }\end{array}$ & $\begin{array}{c}1309 \\
20\end{array}$ & $\begin{array}{l}1401 \\
812\end{array}$ & 273 & 33 & 1131 & 212 & 911 & 1435 & 700 & 41 & 6 & 4 \\
\hline $\begin{array}{l}\text { RANGE } \\
\text { COUNT }\end{array}$ & 40 & 40 & 40 & 40 & 40 & 40 & 40 & 40 & 40 & 40 & 40 & 40 \\
\hline CONF LEV $(95 \%)$ & 1.197 & 61.1915 & 23.5134 & 3.0928 & 76.247 & 10.0667 & 90.6168 & 110.4329 & 47.0862 & 3.2789 & 0.3713 & 0.4089 \\
\hline STDEV/MEAN & 0.0029 & 0.1065 & 0.0135 & 0.0058 & 0.0398 & 0.019 & 0.0575 & 0.0608 & -0.1971 & 0.0062 & 0.0941 & 0.0946 \\
\hline
\end{tabular}




\begin{tabular}{|c|c|c|c|c|c|c|c|c|c|c|c|}
\hline $\begin{array}{c}\text { Pfinal, H } \\
\text { (psi) }\end{array}$ & $\begin{array}{c}\text { PK, } 2000 \mathrm{~ms} \\
\text { (psi) }\end{array}$ & $\begin{array}{c}\mathrm{PH}, \max \\
\text { (psi) }\end{array}$ & $\begin{array}{l}\mathrm{tH}, \max \\
\text { (ms) }\end{array}$ & $\begin{array}{c}\text { PK, max } \\
\text { (psi) }\end{array}$ & $\begin{array}{c}\mathrm{tK}, \max \\
\text { (ms) }\end{array}$ & $\begin{array}{c}\mathrm{PH}, \text { impact } \\
\text { (psi) }\end{array}$ & $\begin{array}{c}\text { PK, impact } \\
\text { (psi) }\end{array}$ & $\begin{array}{c}\text { Pimpact } \\
\text { (psi) }\end{array}$ & $\begin{array}{l}\text { timpact } \\
\text { (ms) }\end{array}$ & $\begin{array}{c}\text { Prt H } \\
\text { (ms) }\end{array}$ & $\begin{array}{c}\text { Prt K } \\
\text { (ms) }\end{array}$ \\
\hline 3872 & 10057 & 16758 & 2548 & 11934 & 2490 & 4882 & 5895 & -1012 & 1720 & 549 & 530 \\
\hline 3860 & 9976 & 16760 & 2524 & 11919 & 2473 & 4855 & 5844 & -1062 & 1717 & 536 & 528 \\
\hline 3860 & 9976 & 16741 & 2550 & 11832 & 2473 & 5034 & 5757 & & 1712 & 540 & 533 \\
\hline 187 & 505 & 59 & 131 & 307 & 126 & 162 & 427 & 439 & 10 & 87 & 80 \\
\hline 4151 & 11412 & 16851 & 3176 & 12717 & 3123 & 5351 & 6772 & -69 & 1742 & 1014 & 924 \\
\hline 3048 & 8889 & 16614 & 2444 & 10991 & 2333 & 4629 & 4698 & -1869 & 1707 & 499 & 438 \\
\hline 1103 & 2523 & 237 & 732 & 1726 & 790 & 722 & 2074 & 1800 & 35 & 515 & 486 \\
\hline 31 & 31 & 31 & 31 & 31 & 31 & 31 & 31 & 31 & 31 & 31 & 31 \\
\hline 65.6472 & 177.7388 & 20.8666 & 46.2012 & 108.106 & 44.3038 & 57.1449 & 150.2532 & 154.391 & 3.5545 & 30.7687 & 28.174 \\
\hline 0.0482 & 0.0502 & 0.0035 & 0.0515 & 0.0257 & 0.0505 & 0.0333 & 0.0724 & -0.4332 & 0.0059 & 0.1591 & 0.1511 \\
\hline
\end{tabular}

$\vec{a}$

$\begin{array}{ccccccccccccc}\text { Set V } & & & & & & & & & & & & \\ \text { MEAN } & 2495 & 4412 & 9425 & 1891 & 7354 & 1794 & 4541 & 5183 & -642 & 1694 & 53 & 39 \\ \text { MEDIAN } & 2496 & 4416 & 9322 & 1774 & 7250 & 1773 & 5021 & 5663 & -656 & 1713 & 37 & 30 \\ \text { MODE } & 2497 & 4452 & 9149 & 1773 & 7047 & 1752 & 0 & 0 & 0 & 1713 & 23 & 25 \\ \text { STDEV } & 5 & 264 & 281 & 361 & 473 & 47 & 1547 & 1781 & 395 & 124 & 33 & 24 \\ \text { MAX } & 2504 & 4858 & 9925 & 3714 & 8483 & 1904 & 5369 & 6511 & 0 & 1747 & 130 & 104 \\ \text { MIN } & 2484 & 3843 & 9076 & 1742 & 6714 & 1747 & 0 & 0 & -1646 & 1075 & 22 & 16 \\ \text { RANGE } & 20 & 1015 & 849 & 1972 & 1769 & 157 & 5369 & 6511 & 1646 & 672 & 108 & 88 \\ \text { COUNT } & 30 & 30 & 30 & 30 & 30 & 30 & 30 & \ddots 30 & 30 & 27 & 30 & 30 \\ \text { CONF LEV(95\%) } & 1.8313 & 94.323 & 100.593 & 129.173 & 169.209 & 16.9284 & 553.7079 & 637.3983 & 141.382 & 44.4179 & 11.9209 & 8.468 \\ \text { STDEV/MEAN } & 0.0021 & 0.0597 & 0.0298 & 0.1909 & 0.0643 & 0.0264 & 0.3407 & 0.3436 & -0.6154 & 0.0733 & 0.6321 & 0.6068\end{array}$

